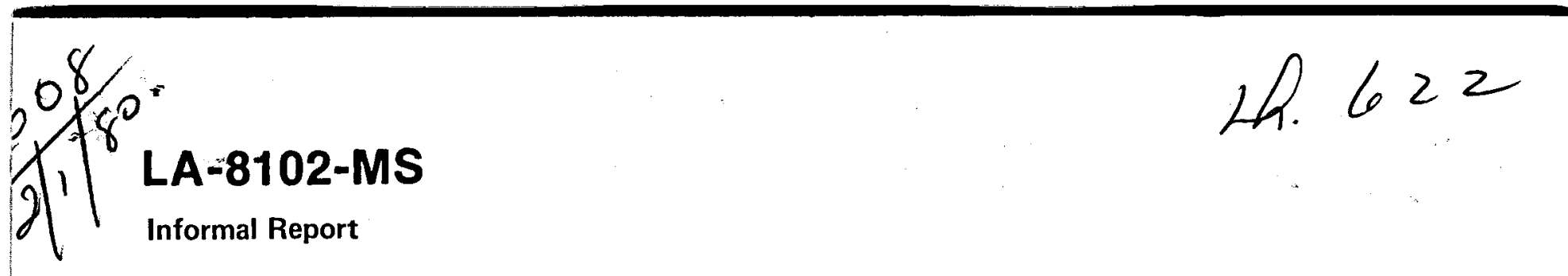

Rock Physics Characterization of Conway Granite From a DOE Borehole, Conway, New Hampshire 


\section{DISCLAIMER}

This report was prepared as an account of work sponsored by an agency of the United States Government. Neither the United States Government nor any agency Thereof, nor any of their employees, makes any warranty, express or implied, or assumes any legal liability or responsibility for the accuracy, completeness, or usefulness of any information, apparatus, product, or process disclosed, or represents that its use would not infringe privately owned rights. Reference herein to any specific commercial product, process, or service by trade name, trademark, manufacturer, or otherwise does not necessarily constitute or imply its endorsement, recommendation, or favoring by the United States Government or any agency thereof. The views and opinions of authors expressed herein do not necessarily state or reflect those of the United States Government or any agency thereof. 


\section{DISCLAIMER}

Portions of this document may be illegible in electronic image products. Images are produced from the best available original document. 
This report was not edited by the Technical Information staff.

Work supported by the US Department of Energy, Grant EY-76-S-03-0034 P. A. 224.

This report was prepured as an secount of work sponsored by the United Stutes Government. Neither the United Stule: nor the Uniled Stules Department of Eneray, nor any of their employees nor any of their contractors. subcontructors. of their employeeth makes any warranty, express or implied, or cenmes any lefal lability or reponsibility for the mecuracy. completenet or unefulness of eny information, appuratus.

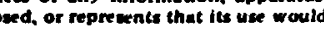
not infintinge privately owned ights. 
LA-8102-MS

Informal Report

UC-66b

Issued: November 1979

\title{
Rock Physics Characterization of Conway Granite From a DOE Borehole, Conway, New Hampshire
}

\author{
Nick Warren*
}

"Consultant. University of California, Institute of Geophysics \& Planetary Science, Los Angeles, CA 90024.

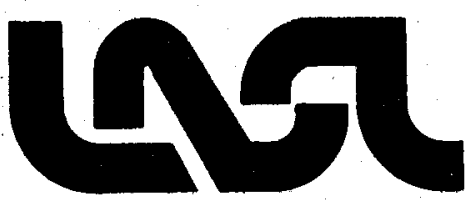

This book was prepared as an account of work sponsored by an agency of the United States Government. This book was prepres the Uates Government nor any agency thersof, nor any of their employees, makes any warranty, express or implied, or assumes any logsl liebility or resoonsibiniy tor the accursey,

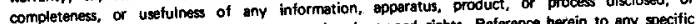

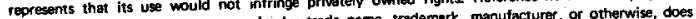
commercial product. process, of senvice by trado name, Ind united

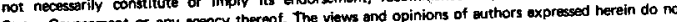
States Government or aty cogency thereo. The views Government or eny agency thereof. 
ROCK PHYSICS CHARACTERIZATION OF CONWAY GRANITE FROM

A DOE BOREHOLE, CONWAY, NEW HAMPSHIRE

by

Nick Warren

\section{ABSTRACT}

The Conway granite of New Hampshire is a highly radioactive intrusive into which a $1-\mathrm{km}-$ deep borehole was drilled and continuously cored by the Department of Energy (formerly ERDA) in 1975. There are two major granitic units, the osceola and the Conway. The Conway is cut by three lamprophyre dikes. We have made elastic moduli and petrographic studies on 14 samples from the core. These data and observations have been used to determine groupings in the rocks by characterizing microstructure. An important result is that carefully. taken physical properties data (for example, velocities and strains) are sensitive indicators of microstructure. Based on velocity and strain data, three distinct groups are found: the lamprophyre dike rocks and two groups each of which contain samples from both the Osceola and Conway formations. These groups are also distinguished by petrographic observations of microcrack patterns. The groups are apparently controlled by grain size and by uniformity of the mixing of the mineral phases in the samples, and not by mineral modes or depth. This last result implies the coring of the Conway samples may have intensified the amount of cracking over that in the rocks in situ, but not the type of cracking. Coring does not apparently induce a distinct population of very thin (low aspect ratio) cracks; that is, such cracks are not needed to explain the low pressure stress and velocity data of these samples.

\section{INTRODUCTION}

In 1975 the Department of Energy (formerly the Energy Research and Development Administration) drilled a 1-km-deep continuously cored borehole in the Conway granite of New Hampshire. The DOE borehole was drilled on the property of the 
Redstone Corporation, CheImsford, Massachusetts, in Conway, New Hampshire. The actual drill site was located about three-tenths of a mile north of the town of Redstone. The drilling was done under a program to study potential geothermal sites east of the Rocky Mountains. Core recovery was almost $100 \%$, providing a uniquely complete suite of samples from this high heat flow member of the White Mountain Plutonic Series.

In our laboratory we have made elastic properties measurements on 14 samples. A primary goal of the study was to determine whether there are regularities in the elastic properties which predict regularities in underlying microstructure, and if so, what it is that controls the microstructure. Two questions are considered here. For the Conway granites, is microstructure related directly to rock type or to depth? Second, does coring generate a set of cracks which is distinguishable from the probable in situ distribution of cracks?

Data for the 14 samples are reported on here, including ultrasonic velocity, dynamic and static elastic moduli, and correlation to mineralogy, depth, and crack pattern. It is shown that for these granitic rocks, the distributions of microstructure are primarily correlated to grain size and the spatial distribution of the minerals within the samples.

\section{THE CONWAY GRANITE}

The Conway formation is the youngest member of the White Mountain Plutonic Series. As discussed by Lyons and Faul (1968), the granites occur as stocks within the intrusive complex of Mt. Ascutney in the Osipee Mountains. They were implanted at about the Triassic-Jurassic boundary (180-185 my), and have exceptionally high heat flow: about 2 to 3 times the average for other New England rocks (Table I). Indeed, a $10 \mathrm{~km}$ thick layer of Conway would supply the total heat flow seen at the surface. The radioactivity of these rocks is not accounted for by fractionation of basalts. The major elements require enrichment of 20-200 times normal, and Birch et al. (1968) propose selective assimilation of preheated crustal rocks to supply this enrichment.

\section{Lithology and Petrology}

The borehole penetrated two formations; first the Conway then the 0sceola, and again, the Conway below the Osceola. The Osceola, or "green phase", occurs in the upper 345 meters. The rock is coarse grained, green to grayish green granite. The major minerals are microperthite, plagioclase; K-feldspar, quartz, biotite, and locally amphibole.

\section{TABLE I}

HEAT FLOW PARAMETERS OF THE CONWAY GRANITES

\begin{tabular}{|c|c|c|c|c|c|c|}
\hline Samples & Th (ppm) & $\underline{U}$ (ppm) & $K(\%)$ & $A\left(\times 10^{-13}\right.$ & $\mathrm{cal} / \mathrm{cm}^{2} \mathrm{sec}$ ) & $Q$ \\
\hline $\begin{array}{l}\text { Conway } \\
\text { (145 samples) }\end{array}$ & 52 & 12.6 & 4.3 & & 17.5 & 1.95 \\
\hline Typical Granit & te 10 & 4 & 2 & & 6 & 1 \\
\hline
\end{tabular}


The "pink phase" of the Conway granite extends from 345 to 731 meters. The rock is light pink to reddish buff and is coarse grained to very coarse grained. The major mineralogy differs from the overlying section mostly in having less amphibole. The pink phase is underlain by a coarse grained porphyritic rock which has considerably less quartz. The color is variable, to a greenish gray cast. There is variability in all the phases (Stewart, 1976).

The upper portion of the borehole contains hydrothermally altered sections. The thickest section occurs from approximately 117 meters to 190 meters. The al tered feldspars range from deep orange-red to pale chalky white. In some places the quartz is almost completely el iminated. In these sections the rock is very soft and permeable.

Three lamprophyre dikes are cut by the borehole. They occur at depths of 498 to 507 meters, 523 to 526 meters, and 605 to 614 meters, and in places are calcite bearing. The formation cross section, sample numbers, and major minerals are given in Figure 1.

Physical properties of fourteen samples from this borehole were measured in this study. Sample numbers correspond to sample depth in meters.

Two sets of four samples each were chosen for detailed analysis, based on the overall quality of their velocity and strain data. Mineralogy and modal analyses of seven of these samples were compiled by Andrea Eddy of Los Alamos Scientific Laboratory. The thin sections that were used in these determinations were cut from core samples adjacent to the samples which we measured. The results are given in Table II. The lamprophyre rock (502.3) that was not analyzed is macroscopically very similar to sample 610.2, the other dike rock.

ERDA CONWAY BOREHOLE, NEW HAMPSHIRE

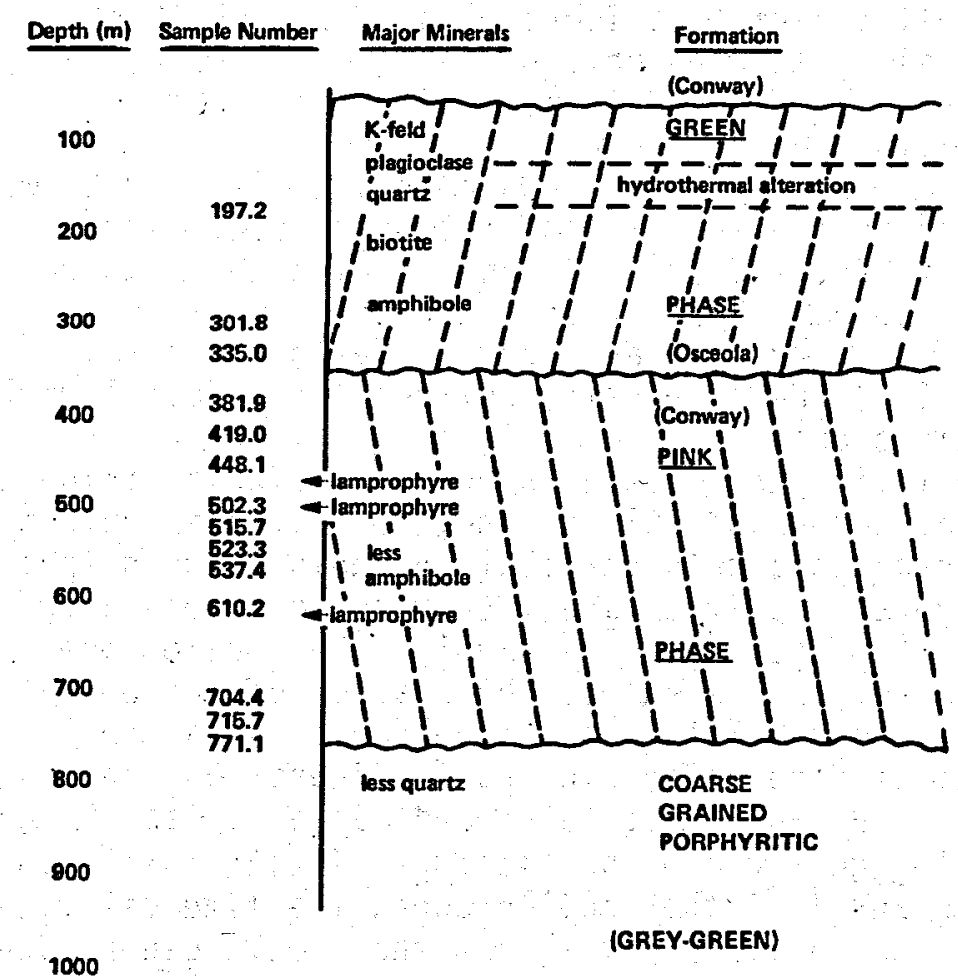

Fig. 1 .

Schematic of Conway borehole section (after Stewart, 1976). Sample numbers are equal to depth in meters. "Major Minerals" indicate general broad trends between the phases, however, the mineralogy within each phase is variable. 
The data in Table II (excluding sample 610.2) show the slight gradations in the major components (plagioclase, K-feldspar, and quartz) which "separate" the members of the green phase from those of the pink phase. The percentage of plagioclase in the two samples from the green phase is $24 \%$ and $47 \%$, but this dips to $6-22 \%$ for the samples from the pink phase. The $K$-feldspar increases from about $10-40 \%$ to $46-55 \%$ respectively. There is no trend in the quartz concentration among the four samples. Therefore, based on major mineralogy alone, only moderate differences are expected in velocities of samples from the two phases. (Indeed, at $3 \mathrm{~Kb}$ the measured velocities for all but one of the granitic samples are $V_{p}=6.3 \pm .2 \mathrm{~km} / \mathrm{sec}$ and $v_{s}=3.5 \pm .1 \mathrm{~km} / \mathrm{sec}$ )

\section{VELOCITY AND STATIC STRAINS MEASUREMENTS: SAMPLES AND DATA}

\section{A. Samples}

A11 of the rock samples were nominally 25 to $30 \mathrm{~mm}$ in length and $16.65 \mathrm{~mm}$ in diameter. The flat ends were ground parallel to a tolerance of better than $\pm .01 \mathrm{~mm}$, more typically better than $\pm .005 \mathrm{~mm}$.

For the velocity measurements, 1 Mhz to 3 Mhz compressional or shear mode PZT transducers were bonded directiy to the rocks. The transducer diameters were $16 \mathrm{~mm}$. Compressional and shear velocity runs were made separately. Transducers were changed for each type of run.

Two different sets of strain measurements were made. For the first set (all of the samples) $120 \Omega$ strain gauges were epoxied directly to the samples, parallel to the axial direction. Strains were measured by balancing a bridge which gave directly the resistance of the gauge. Strains were determined to $\pm 1 \times 10^{-4}$.

For the second set (four samples), strain gauges were mounted in the circumerential direction. A BLH 1200 B strain indicator was used, and strains were determined to $+5 \times 10^{-6}$.

Samples were jacketed with a soft two-part silicone elastomer. By this technique, reliable velocity and strain data were obtained at low pressure. A $7 \mathrm{~Kb}$ hydrostatic pressure vessel was used. The pressure medium was kerosenepetether. Pressures were measured with a Heise gauge.

A new technique was developed for the velocity measurements. Figure 2 shows a schematic of the configuration used in the travel time determination. Three pulse generators (PG), an amplifier (AMP), and an oscilloscope with three independent vertical input channels were used. These pulse generators supply a fiducial mark for the pulse travel time, generate an input pulse to the sample, and provide a moveable marker to measure the time delay between the fiducial mark and the first arrival of the acoustic signal.

PGI supplies two outputs. First, it generates a trigger pulse which triggers both the oscilloscope horizontal sweep and PG2; second, PGI gives an output pulse which is fed into one of the oscilloscope's vertical channels. The output signal from the sample is put through an amplifier and then goes to a second vertical channel on the oscilloscope. Note that with the sample taken out of the configuration, the output pulse from PGl can be set at the positon of the output pulse from PG2 as seen on the oscilloscope. This pulse then serves as a $t=0$ marker because it has calibrated out all the delays in the configuration due to the electronic components and cables. PG3 generates a second marker pulse which is triggered by the variable delay trigger on the oscilloscope. Using this marker on the third vertical input channel of the oscilloscope, the time delay between the $t=0$ marker of $P G 1$ and the acoustic arrival from the sample can be determined. 


\section{TABLE II}

MODES OF CORES FROM ERDA BOREHOLE, CONWAY, NEW HAMPSHIRE

Samples Chosen for Modal 'Analysis

$\begin{array}{lll}\frac{\text { Set } 1}{335.0} & \begin{array}{c}\text { Rock Type } \\ \text { monzonogranite }\end{array} & \frac{\text { Set 2 }}{301.8} \\ 381.9 & \text { syenogranite } & 523.3 \\ 448.1 & \text { syenogranite } & 704.4 \\ 610.2 & \text { lamprophyre } & 502.3^{*}\end{array}$

*No modes measured/very similar to 610.2 in hand specimen.

MODAL ANALYSES

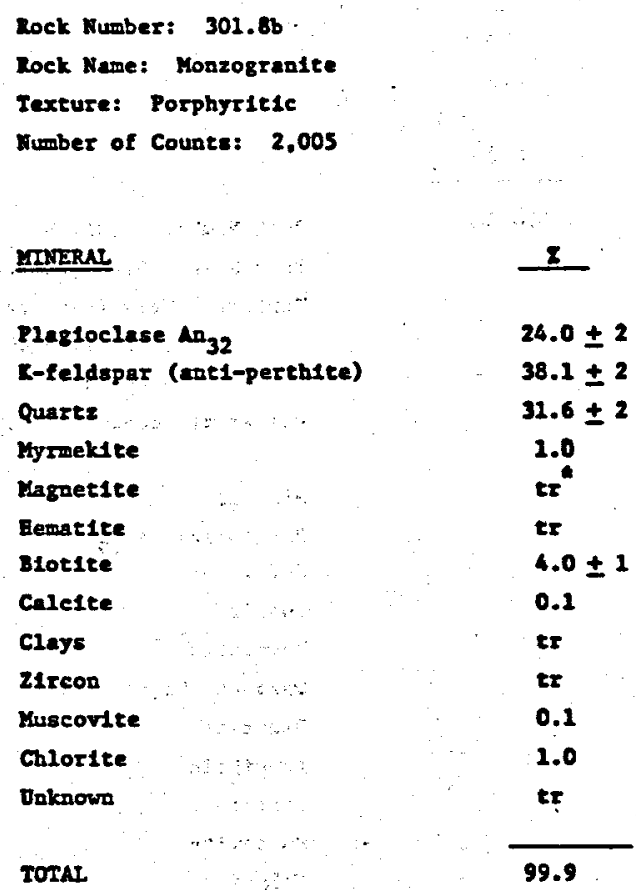

t tr = trace - less than 0.1 
Loek Rumber: $335.0 \mathrm{~b}$

Lock Hame: Blottes-anphtbole granodiorite

Texture: Varlable grals else and texture; locludes elot of dietinct

atoeralogy

Lumber of counts: 1,807 totel wth elot $(1,631$ excluding elot)

YMTIRAL

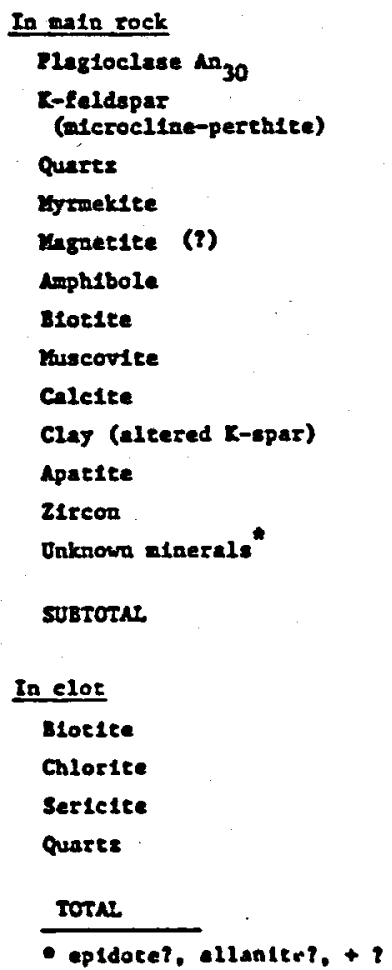

MODE (2) counting clot YODE (7) not counting clot

\begin{tabular}{l}
$42.9 \pm 2$ \\
$12.6 \pm 2$ \\
$9.8 \pm 1$ \\
0.6 \\
0.8 \\
$13.1 \pm 2$ \\
$9.7 \pm 1$ \\
20.1 \\
0.4 \\
0.1 \\
0.3 \\
$6 x$ \\
0.1 \\
90.6 \\
$2.0 \pm 1$ \\
0.9 \\
$6.6 \pm 1$ \\
0.2 \\
\hline 00.3
\end{tabular}

100.3 lock Number: $381.9 b$

Lock Xame: Syenogrante

Texture: Very fine-grained, wth I1neation warked by subparallel blotice, possibly releted to contect vith course-grained srantce

number of Counts: 1,854

\section{Meeral}

Plagtoclase $\operatorname{An}_{29}$

L-feldepar

Quarex

ry rmekt *

Opaques (Xignetite?)

Bemat1te

Amphibole

Bsotite

Yuscovite

chlorite

21rcon

Clinopyroxene, fresh (diopside or

$$
\left\{\begin{array}{l}
\text { augite) } \\
\text { aleered }
\end{array}\right.
$$

Daknown (Garnet ? + ?)

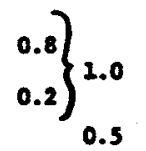

rorat

100.0 
Rock Number: $448.1 \mathrm{~b}$

Rock Name: Syenogranite

Texture: Coarse-grained wich small grains at boundaries between large . grains; shows deformation; filled fractures.

Number of Counts: 1,970

Minerel

Plagloclase

K-Feldepar (microcline-perthite, altered to clay)

Querte

Myrmekte

Magnetite

Benatite

Amphibole (?)

Blotite

Muscovite

Chlorite

Apatite

Calcite

21rcon

Jnknown

TOTAL

- epidote (?) or saussurite +?

$\frac{x}{13.3 \pm 2}$
$55.8 \pm 2$
$26.6 \pm 2$
0.6
0.3
0.2
$t r$
1.2
0.2
$1.7 \pm 1$
$t r$
0.2
$t r$
0.1
100.3

Rock Number: $523.3 \mathrm{~b}$

Sock Nawe: Syenograntee

Textura: At least two senerations of frecturing produced f1lled frectures: one cuch "veln" hav cacaclaste telele gineralo in carbonate.

Number of Counts: 2,053 totel (host, 1,998; re1n, 55)

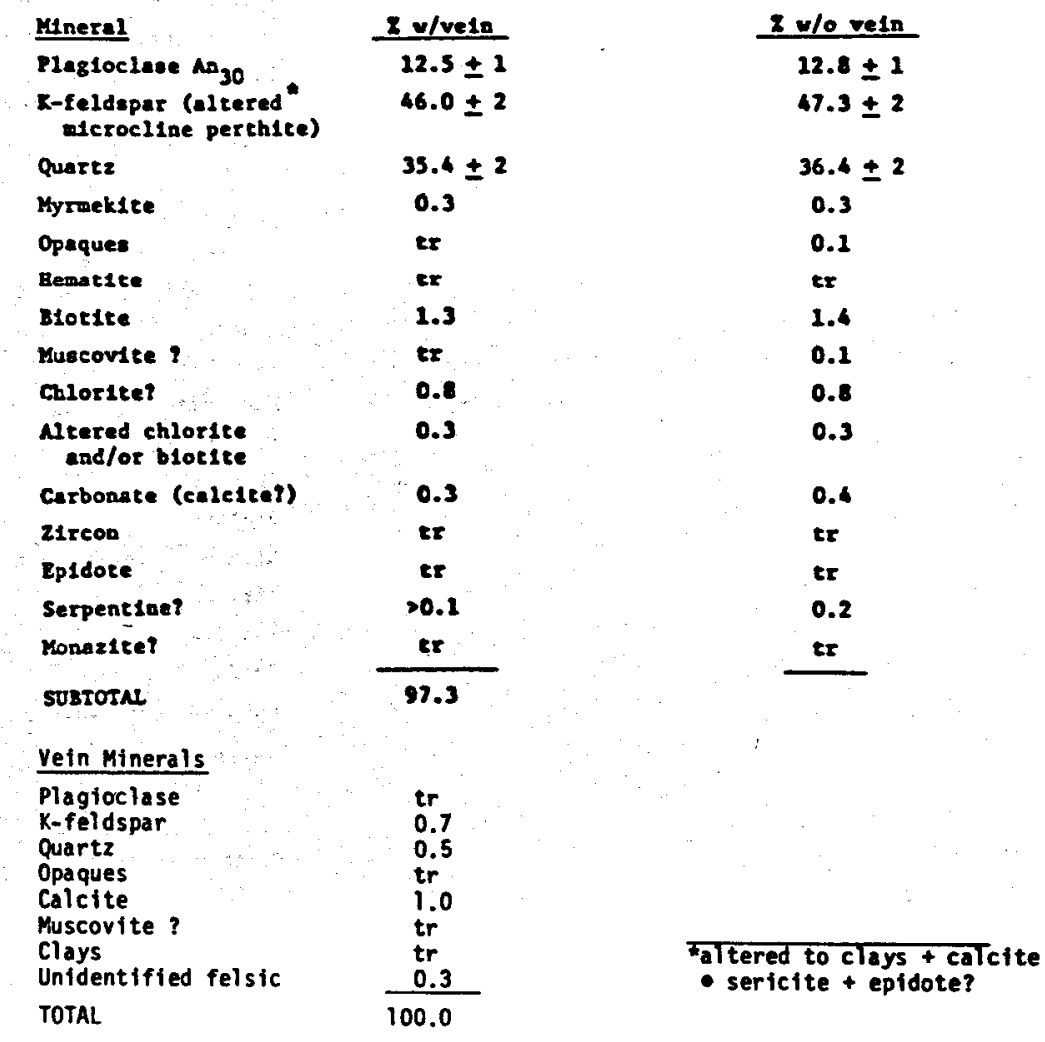


Rock Xumber: 610.26

Rock Hame: Hornblende-pyroxene lamprophyre

Texture: porphyritic uth intersertal groundmase

Number of Counts: 1732 cocal (phenocryse or eegecryate, 212; croundmase, 1520)

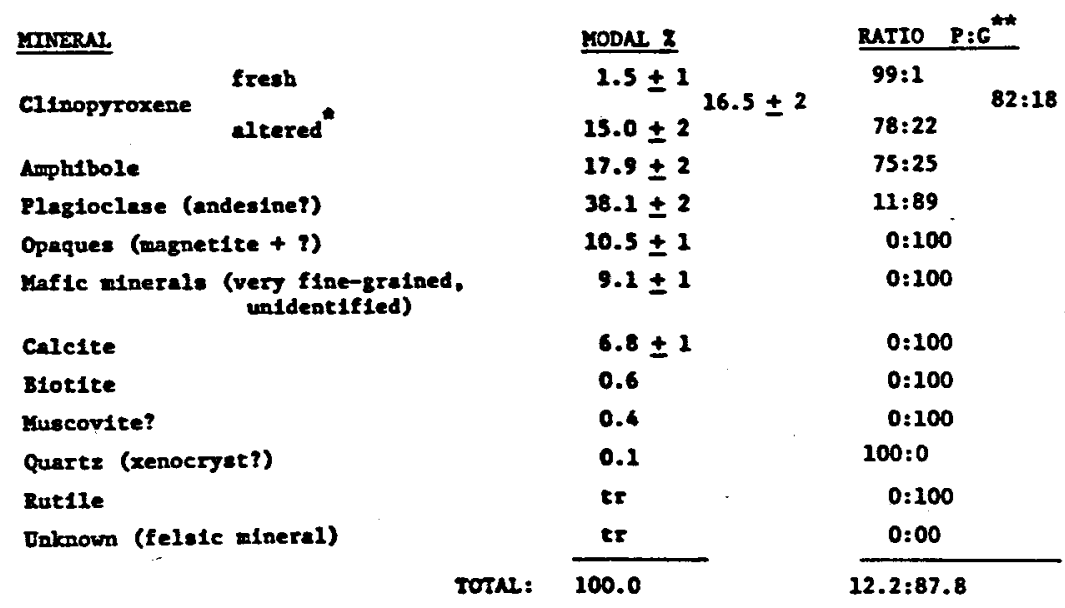

twostly altered to brown (unknown) eineral: al wo alnor chloritic (?), urallete (?), and eaussuritle (?) alceration.

thwere P-counte of phenocryst or segacryat, Gegroundmass counts

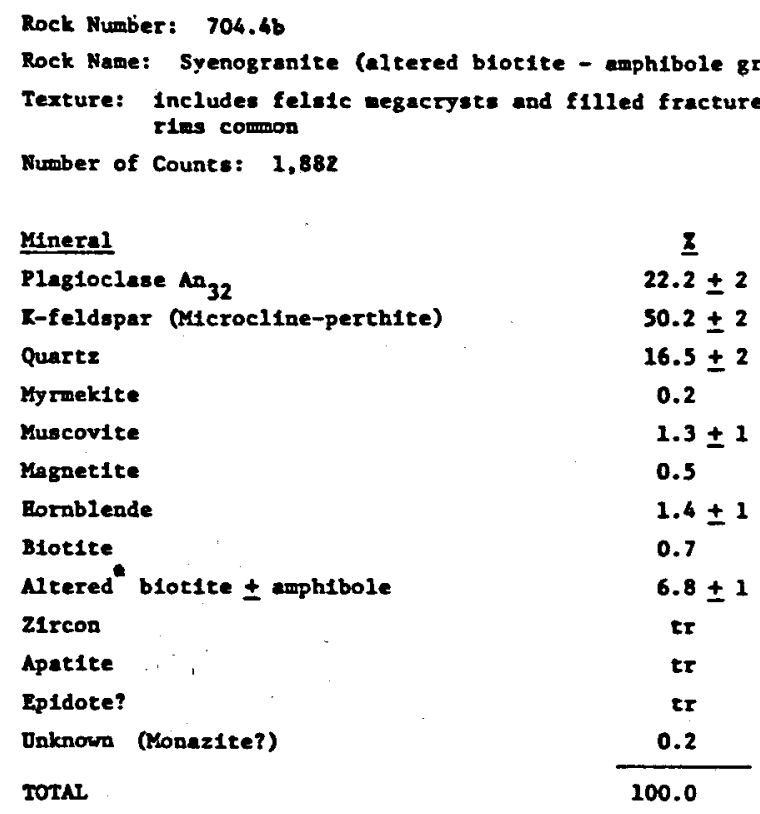

- brown alteration, with Included flne-gralned opaque minerals 


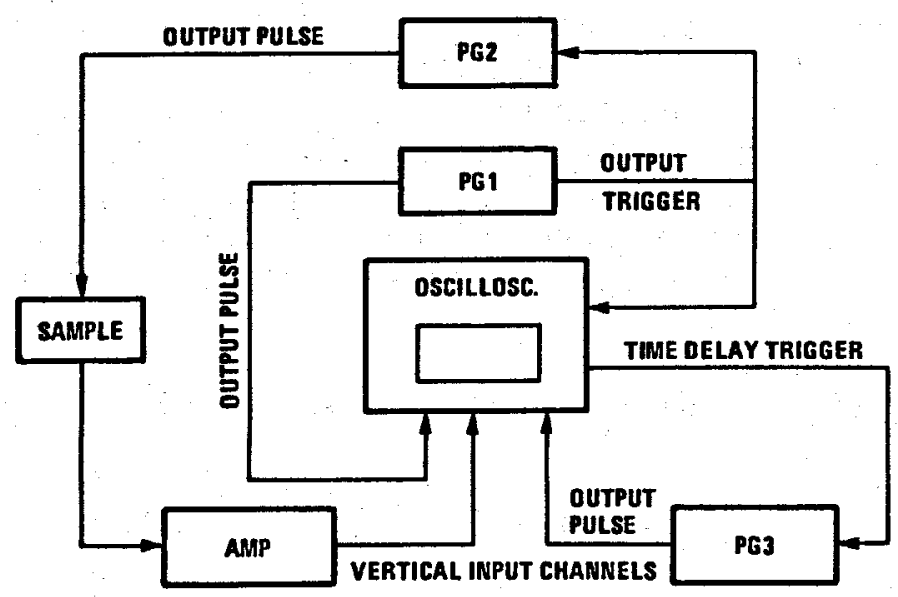

Fig. 2.

Pulse transmission electronic systems. See text for discussion.

This arrangement allows us to eliminate uncertainties on our travel-time measurements due to the electronics, and we achieve reproducibility of a few nanoseconds and an overall absolute uncertainty of about $1 \%$ for our travel-time determinations through any given sample.

B. Velocity and Strain Data

The velocity and pressure data are compiled in Appendix 1. The quality of the data is generally good, but some data show anomalies such as hysteresis and kinks, even at high pressure. However, at the worst the hysteresis at high pressures for such samples is generally still less than $4 \%$. Table A-1 gives the quality of the data.

In the compilation, the columns marked "composite data" contain velocities that are linear extrapolations between raw data points. These extrapolations were made in order to provide a common pressure for both $V_{p}$ and $V_{f}$ curves.

The static bulk moduli data are given in Appendix 2. PThe dynamic moduli calculated from the velocity data are given in Appendix 3.

\section{ANALYSIS}

A. Velocities and Strains/Groupings

The velocity, density, and strain data were searched for systematics which could correlate these physical properties with geological and petrographic variables such as (1) geological formation, (2) mineralogy, (3) depth, (4) grain size, and (5) crack pattern.

Earlier work (Warren, 1977) has established that velocity-pressure data show systematics which allow a number of rocks to be grouped as "similar". The pressure dependence of the elastic moduli of a rock is usually considered to be a function of the microstructure of the rock. Therefore, regularities in velocity systematics are expected to correspond to equivalent regularities in rock microstructure. The microstructure may in turn be expected to correlate with other rock properties which are controlled by grain boundaries and crack physics. 
Primary grouping of the Conway data was made using the compressional velocity data. Two statistical tests were used; first., a chi-squared test was run on the velocity-pressure data of all the samples pairwise; second, a correlation was made of the slopes of a spline curve fit to the data. The details of these techniques are discussed el sewhere. (Tiernan and Warren, in preparation).

Ten of the samples were separated into groups according to the computer tests. The remaining four samples were not tested because of the poor quality or low density of velocity-pressure data; these are 197.2, 515.7, 537.4, and 771.1. The groupings are given in Table III.

The three groups are readily distinguishable. They are separated by chisquare differences of $100 \sigma$ and differences in slope correlation of at least one or two orders of magnitude.

The Lamprophyre samples (group III) are very distinct from the granitic samples (groups I and II). Group I has both the largest number of members and the widest range in values of the similarity criteria. Differences between samples from each group are presented visually in log-log plots in Fig. 3 . In the figure, the dynamic modulus plotted $C$, is defined by $C=V_{p}{ }^{2}$, where $\rho$ is the rock density.

Warren (1977) and Warren and Trice (1975) have pointed out that there are apparent systematic relations between dynamic and static bulk moduli. The dynamic versus static bulk-moduli of group I and group II samples are plotted in Fig. 4. The dynamic bulk moduli are from the "composite data". The static (axial) bulk moduli are the mean of the up and down run data. The static (circum) bulk moduli are up-run data. It is seen that the data within each group are mutualiy consistent and different from those of the other group. The same groupings of samples are suggested using dynamic versus static bulk moduli as by using $v_{p}$ data .

TABLE III

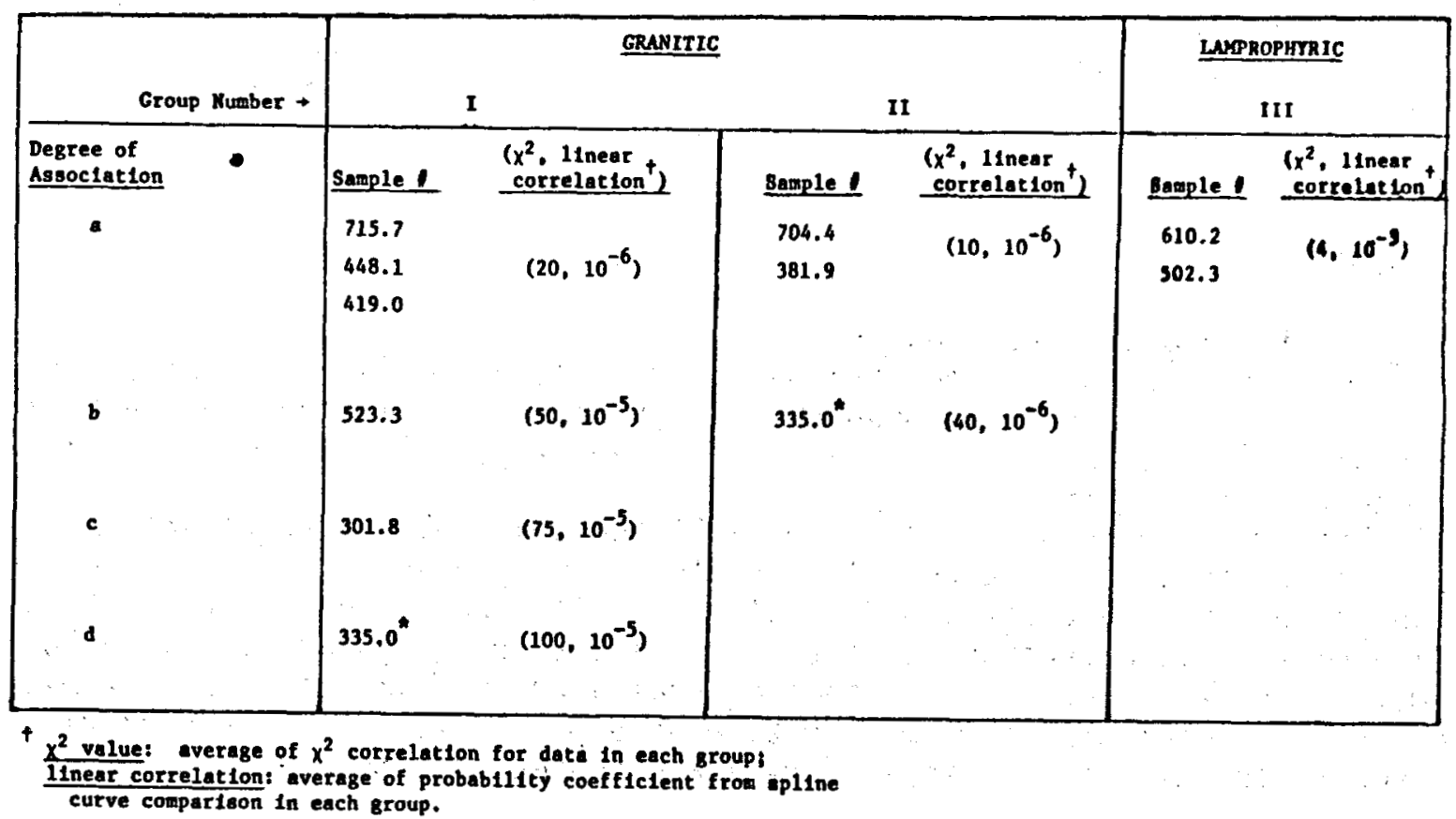




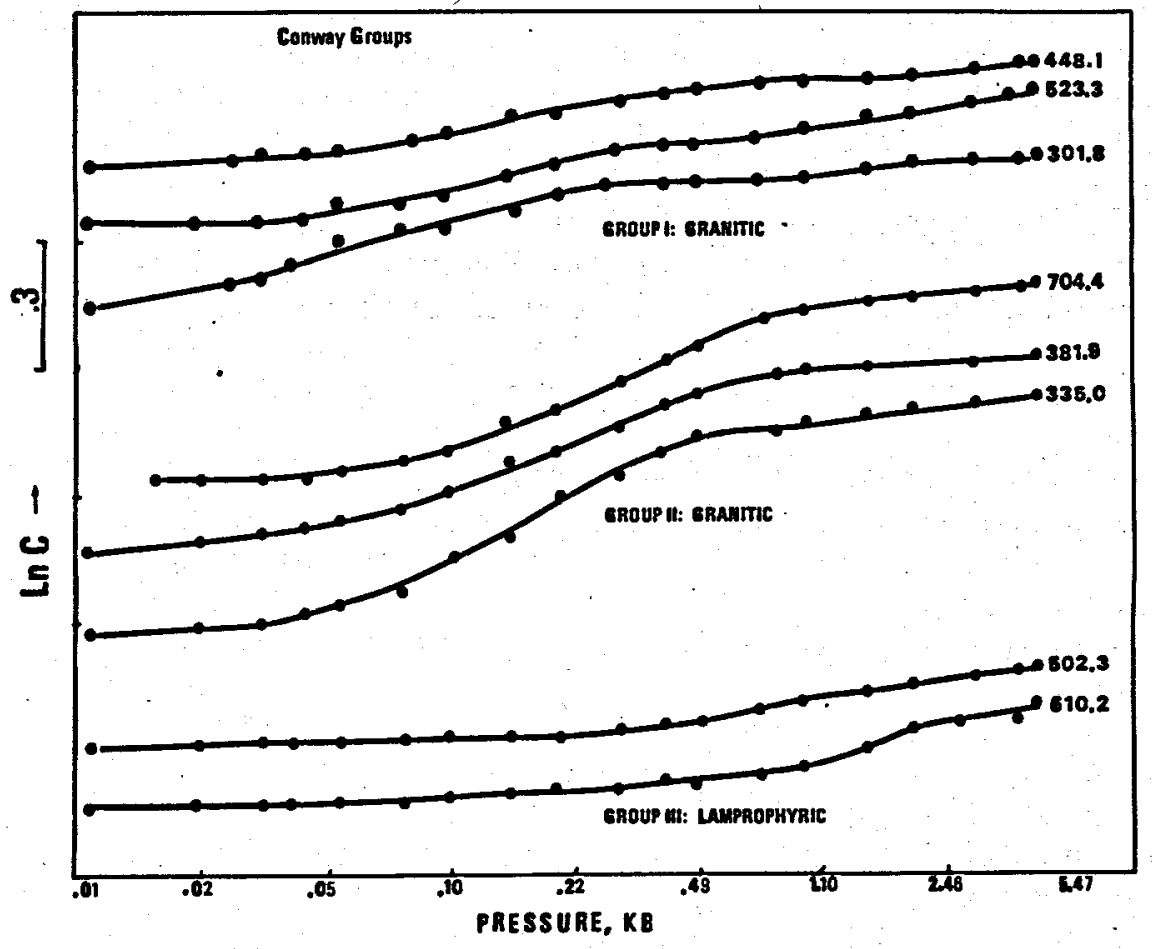

Fig: 3 .

Log-log plot of compressional wave modulus versus pressure for eight Conway samples. The data are stacked to bring out similarities and differences in curve shapes: The top set of curves are for samples from group I. The middle set of curves are for samples from group II, and the bottom set of curves are for samples from group III. The vertical scale unit of 0.3 corresponds to 0.3 in the natural logarithm of the modulus.
Fig. 4. Dynamic versus static bulk moduli for group I and group II samples.

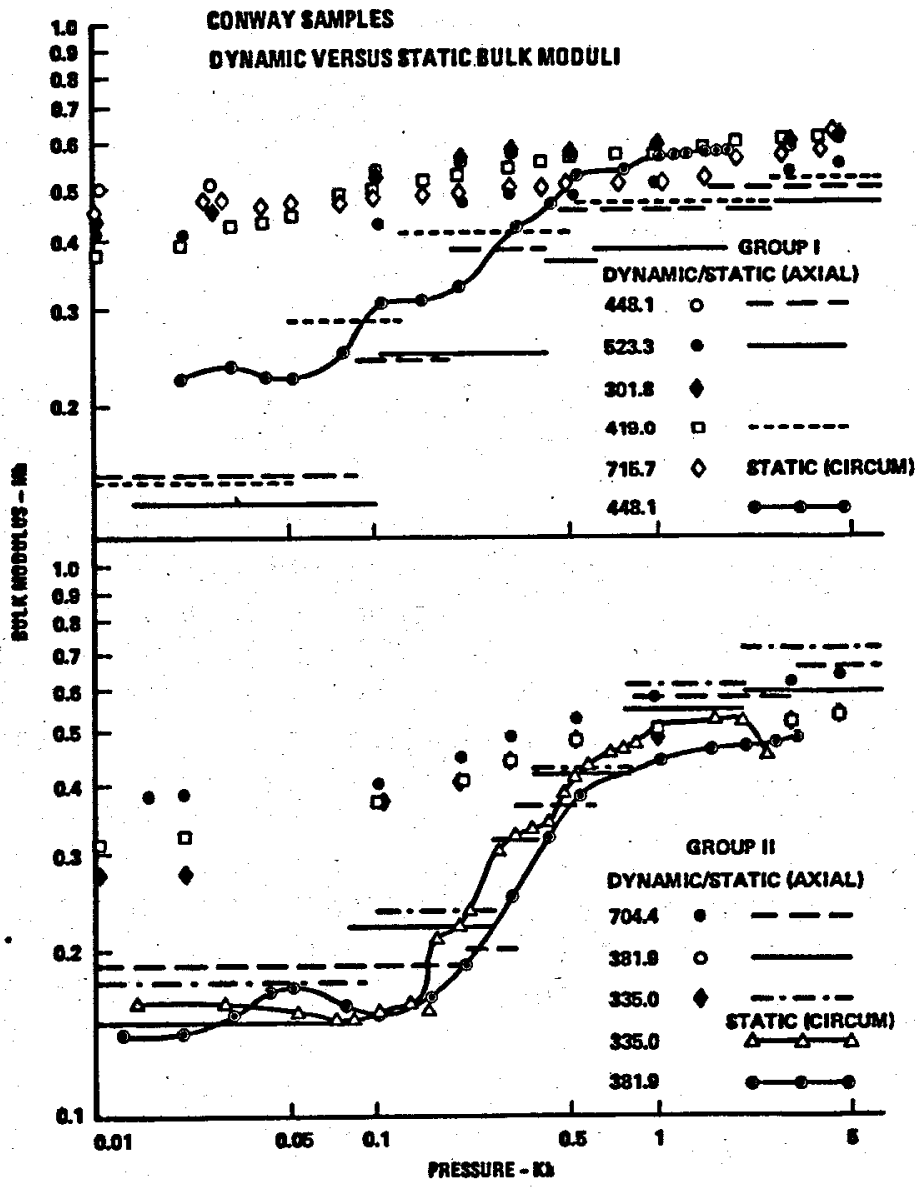


This result strengthens our previous suggestion that dynamic and static moduli are related, and that the differences between them are real and due to different degrees of strain relaxation under the dynamic versus static loading condition. We have proposed that one is essentially looking at a pore-relaxation phenomenon.

The relation between static and dynamic data can further be 91 lustrated by using the bulk modulus data derived from the circumferential strains. As discussed in Appendix 2, for this set of data, the moduli were calculated using a spline-fit computer program, thus allowing for the association of moduli to discrete pressures. Figures 5-8 are plots of the logarithms of these static bulk modulus data and the dynamic moduli data against log pressure. In these figures, the curves are approximately normalized to each other.

In all four figures one sees broad agreement between the pairs of moduli, even though velocities were measured in the axial direction and strains were measured circumferentially. The curve shape for the moduli of 381.9 (Fig. 5) is smooth and S-shaped; concave upward at low pressures, with the top of the inflection region at about 500 bars.

The moduli data for 335.0 show a large, apparent hysteresis. Nevertheless, the general agreement between the dynamic and static moduli is evident. The curves are S-shaped, and similar to those of 381.9 . However, those for 335.0 exhibit more structure within the dominant inflection region, similar to that shown by the data of the group I rocks.

Comparison of the data for sample 610.2 is not as clear cut. The static bulk modulus curves $(\mathrm{Fig}: 7)$ show both considerable structure and inconsistency between the data from the up and down runs. The bulk modulus from the down pressure run, however, shows a Targe stepped increase between about 0.8 and $2 \mathrm{~Kb}$, corresponding to the dominant inflection region in the dynamic data. Both the dynamic and static data (down run) show minor inflection regions at about equal pressures in the range of about 40 bars to 800 bars.

The $\log C / \rho-\log P$ curve for 448.1 (Fig. 8) shows a number of local inflection regions at pressures below 500 bars as well as the apparent start of a fairly dominant inflection above about $11 / 2 \mathrm{~Kb}$. Consistent with this, the static bulk modulus data shows both similar trend and similar inflection regions.

B. Microstructure Patterns/Groupings:

The existence of velocity groups suggests that there are regularities or groupings in microstructure, but this does not determine what the microstructures are.

In an independent study (Warren and Preiser, in preparation), we have been developing a technique to quantitatively compare microstructure of various samples. We applied this technique, still in the development stage, in a general study of the two suites of Conway samples (Table II) and also in a more detailed study of four of the samples. In the general study, the Conway samples were independently grouped by microstructure. In the more detailed study, samples were quantitatively parameterized in order to individually characterize them. The thin sections used for these studies were prepared from our own samples used for the velocity and strain measurements. Here we simply summarize the results to show the differences in the character of the microstructures of samples which belong to groups I, II, and III.

In the more general study, photographs of the eight Conway samples which make up sets 1 and 2 were subjectively matched. Reflection microphotographs were taken between $32 x$ and 600x magnification. Groups were formed based on a strategy in which photographs at different magnifications were compared and 


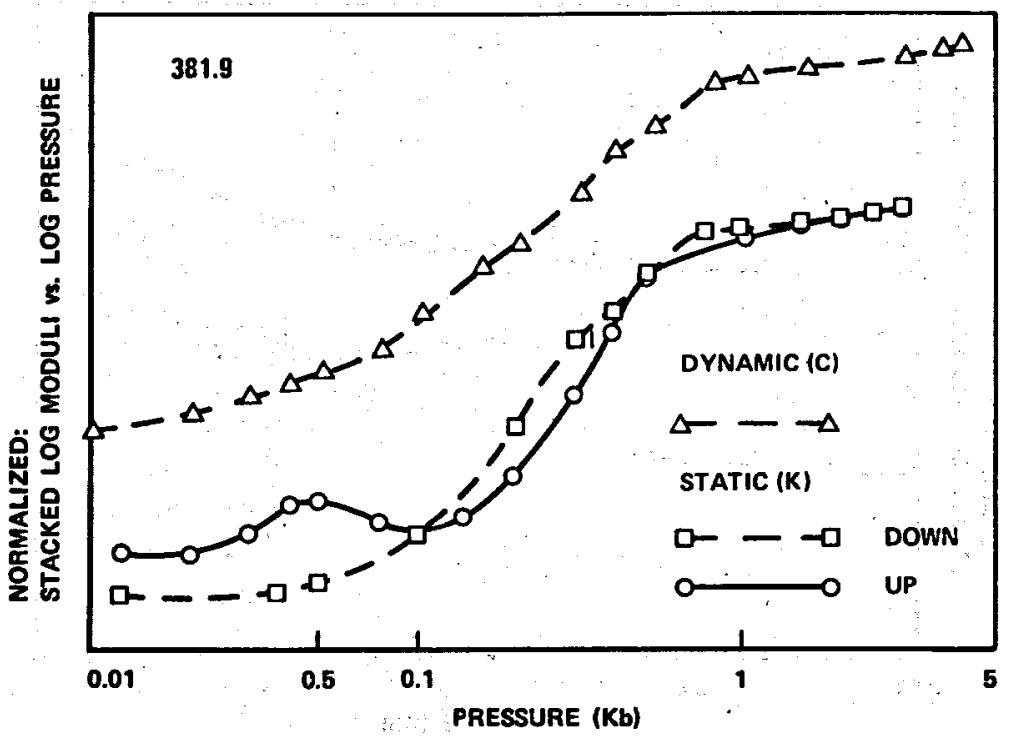

Fig. 5 .

Stacked data, sample 381.9: dynamic compressional modulus ( $\log C)$ and static bulk modulus data $(\log K)$ versus $\log$ pressure. The vertical scales for the static modulus is the same as in Fig. 4. The dynamic data have been approximately normalized to the static data.

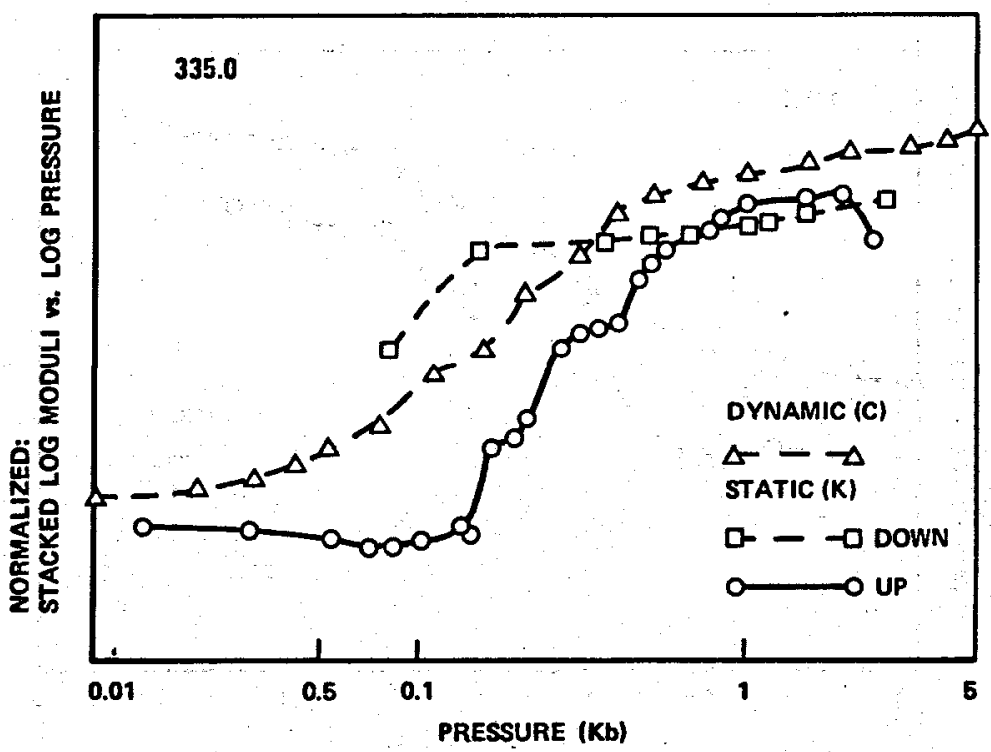

Fig. 6 .

Stacked data, sample 335.0: dynamic compressional modulus $(\log C)$ and static bulk modulus data $(\log K)$ versus $l o g$ pressure. The vertical scales for the static modulus is the same as in Fig. 4. The dynamic data have been approximately normalized to the static data. 


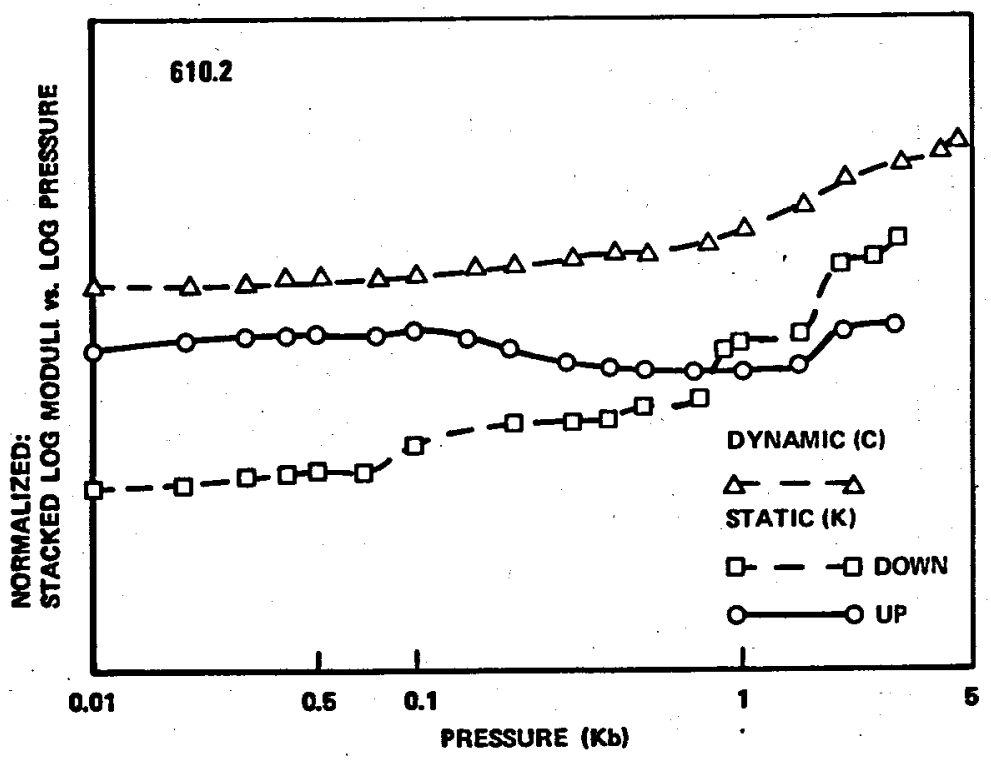

Fig. 7.

Stacked data, sample 610.2: dynamic compressional modulus ( $\log C)$ and static bulk modulus data ( $\log K$ ) versus $\log$ pressure. The vertical scales for the static modulus is the same as in Fig. 4. The dynamic data have been approximately normalized to the static data.

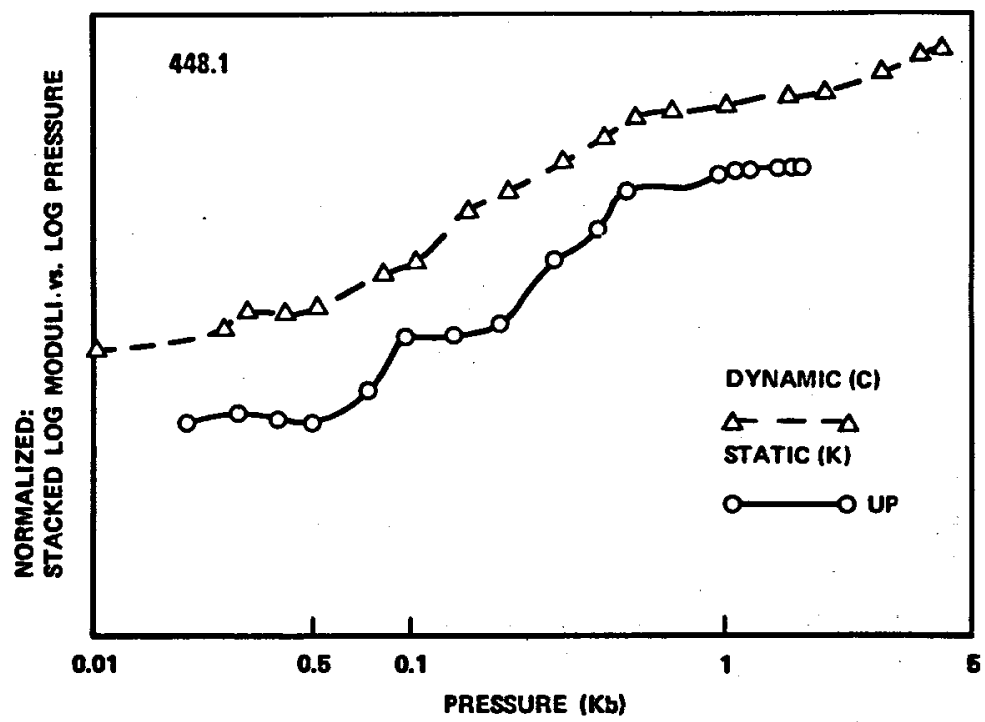

Fig. 8 .

Stacked data, sample 448.1: dynamic compressional modulus $(\log C)$ and static bulk modulus data $(\log K)$ versus $\log$ pressure. The vertical scales for the static modulus is the same as in Fig. 4. The dynamic data have been approximately normalized to the static data. 
considered to be matched if the crack and gra in structures (the "petrostructure") looked equivalent (irrespective of the actual magnification of the photos).

That is, two photography were "matched" if, by eye, they looked like independent photographs from the same thin section. This gave both groupings in terms of crack patterns and scale factors between the structure lengths of the patterns.

Three groupings were suggested by the photographs independently of the results from the velocity data. The first group is dominated by long (dendritic) crack and grain boundary cracks. Little crack structure is seen at high magnification. The second group is characterized by a similar microstructure, except that it has fewer large scale microcracks. The third set, the two samples from the lamprophyre dikes, showed large cracks only in phenocrysts, and very small scale fractures in the groundmass.

Similarities and differences in the patterns of the microstructure of four samples are apparent in plates $1-4$.

Plates 1 and 2 show reflection micro photographs of 704.4 and 381.9 at a $32 x, b 63 x, c 160 x$, and $d 400 x$. These two sets of photos appear as if they could easily be of separate parts of a single section of one rock.

Plate 3 shows one of the differences between two rocks, 448.1 from group I and 335.0 from group II. It illustrates that although 448.1 has a fine structure similar to that of 335.0 , it also has more large scale cracks. Photos (c and $d$ ) in the plate are both at $400 x$ magnification. In general, it is only at this power that the thin sections of both samples looked equivalent. At lower magnifications, photos of the two samples only looked equivalent if the two photos were at different magnifications. Photo $a$ is of 448.1 at $32 x$ and photo $\underline{b}$ is of 335.0 at $63 x$. The crack patterns in the two photos look "equivalent" indicating a scale factor of $\times 2$ between the coarser structures of these two samples.

Photomicrographs of 610.29 (Plate 4) at $32 x$ through $400 x$ indicate the relatively very fine microstructure of these lamprophyre dike rocks compared to any of the granitic samples.

The more detailed study quantified these general results for four samples. A large number of photographs were taken and the crack patterns were parameterized by three factors: a count of the number of cracks intersected by a standard circle placed over the photograph; a count of the number of forks, branchings, or intersections in a unit area of photograph; and a measure of the curvature of a crack (i.e. linear to closed or granular).

Here we restrict our discussion to some results based on counting cracks intersected by standard circles which were placed randomly on the photographs. The number of cracks (N) intersected by a standard circle (of length $L$ ) gives a number density $N / L=\rho^{-}$. This procedure loosely defines hierarchies of crack structures since only the most visually dominant pattern that is on the scale of the photograph is counted. The probability of counting cracks of some hierarchy depends on the visual contrast of the cracks to the background, and the ratio of the area which the structure covers in the photograph to the area of the photograph. The contrast is determined by the crack width and overriding larger crack patterns. When counts are made on photos at high magnification, features which have scales greater than those of concern are not counted (such as highly magnified section of a crack which looks like a slot crossing the photograph). Therefore, to first order, the density $\rho^{-}$, as a measure, is proportional to the crack length $\underline{\ell}$ and inversely proportional to the square of the mean spacing $\mathrm{ms}^{2}$, of some hierarchy of cracks.

$$
\rho n \ell / m s^{2}
$$


Plate 1: Conway Granite Sample 704.4

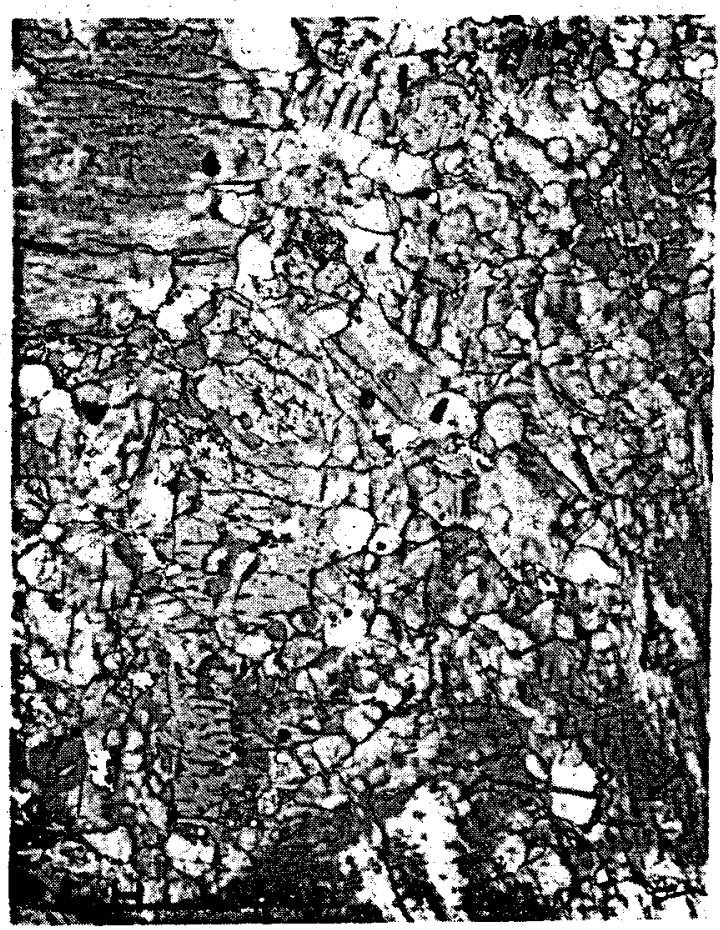

a

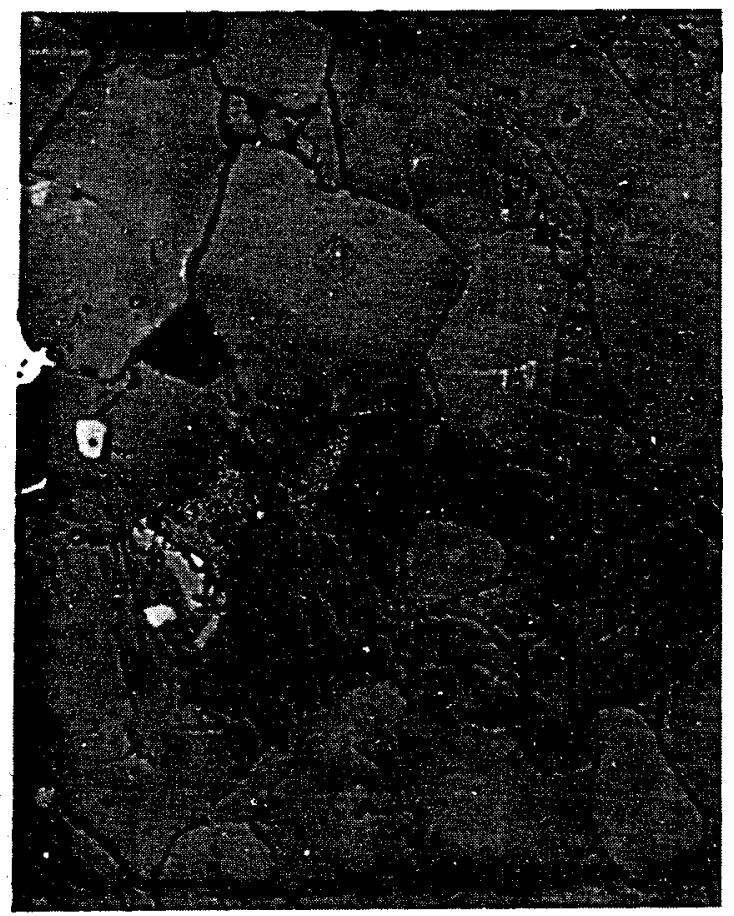

c

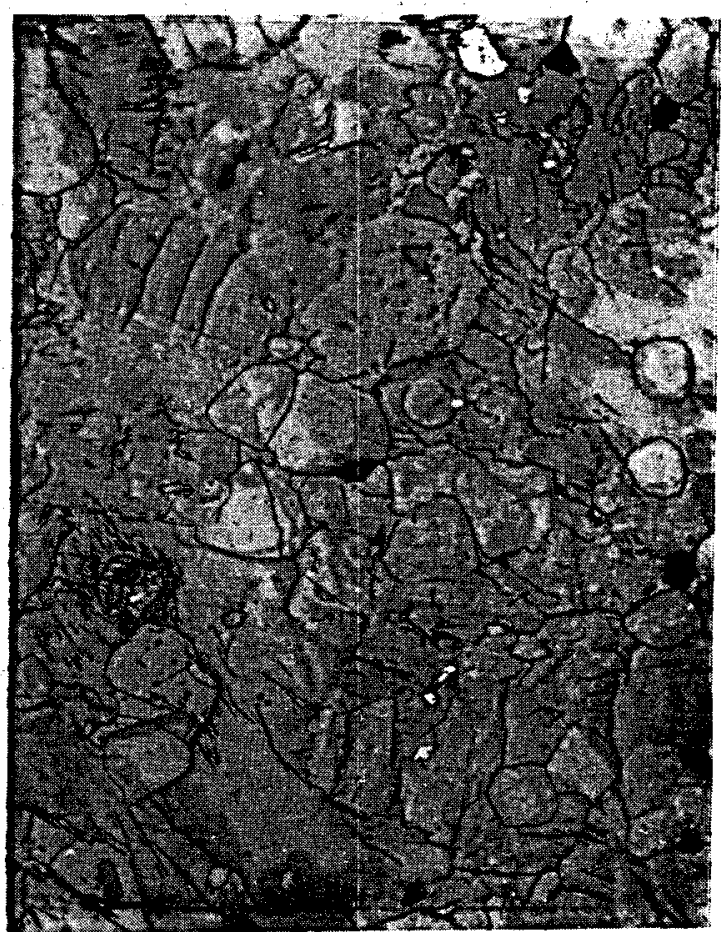

b

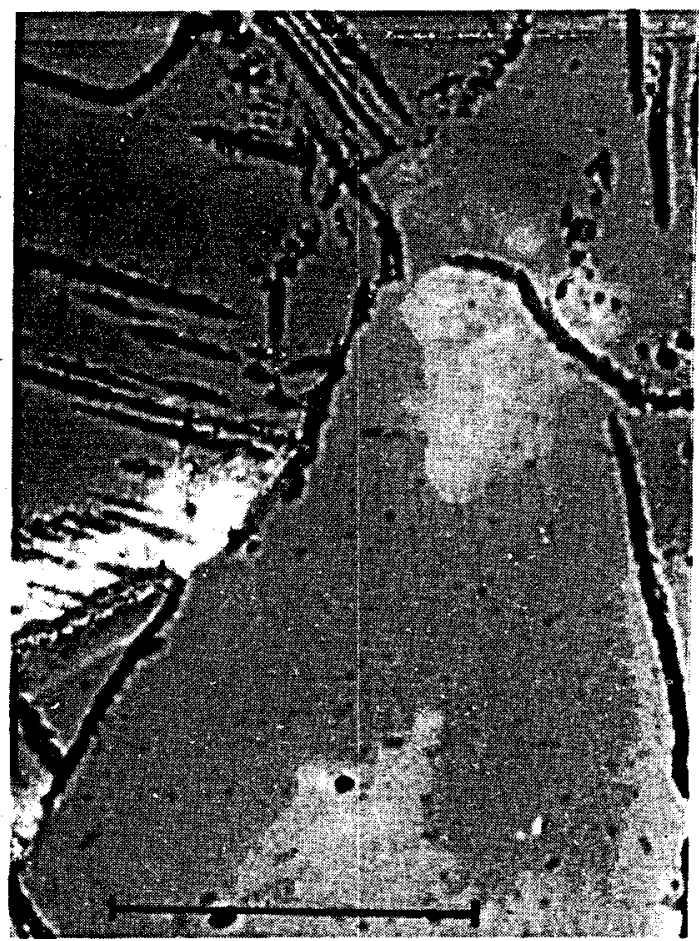

$a$ 
Plate 2: $\quad$ Conway Granite Sample 381.9

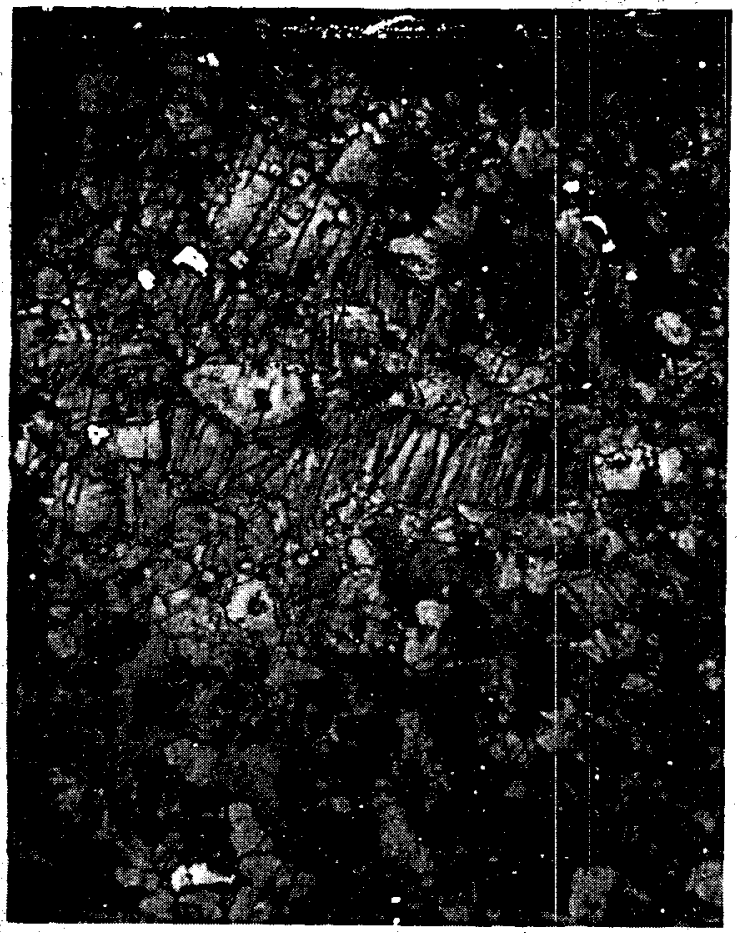

a

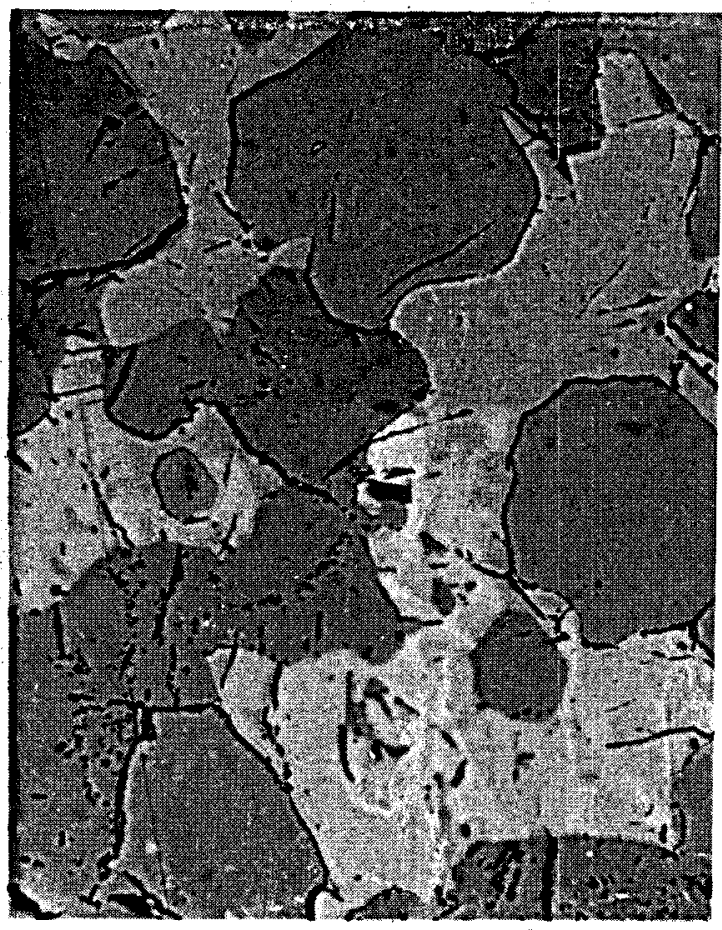

c

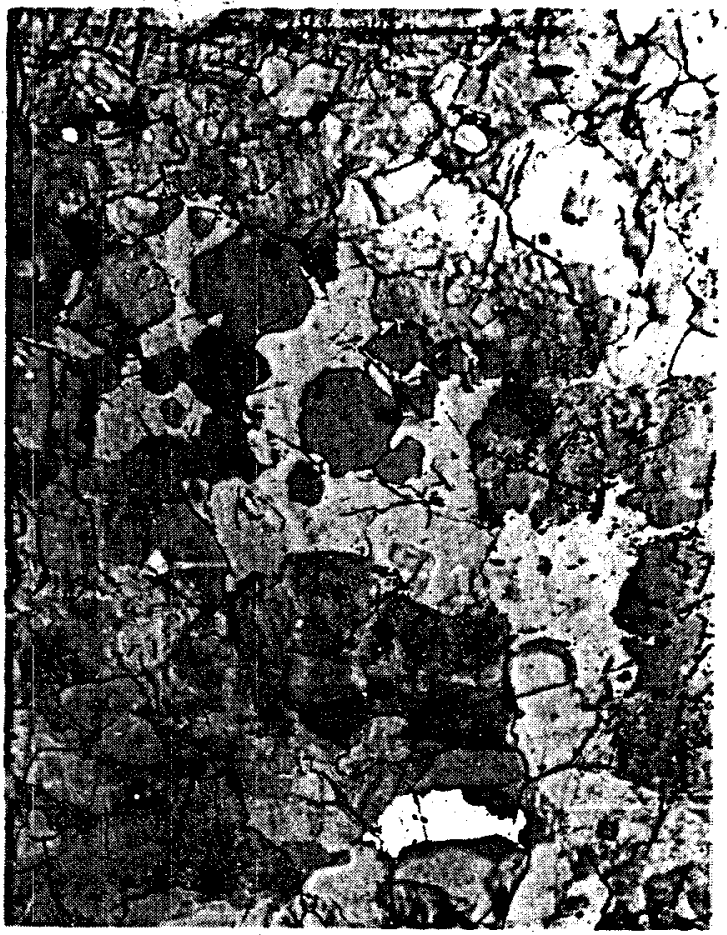

b

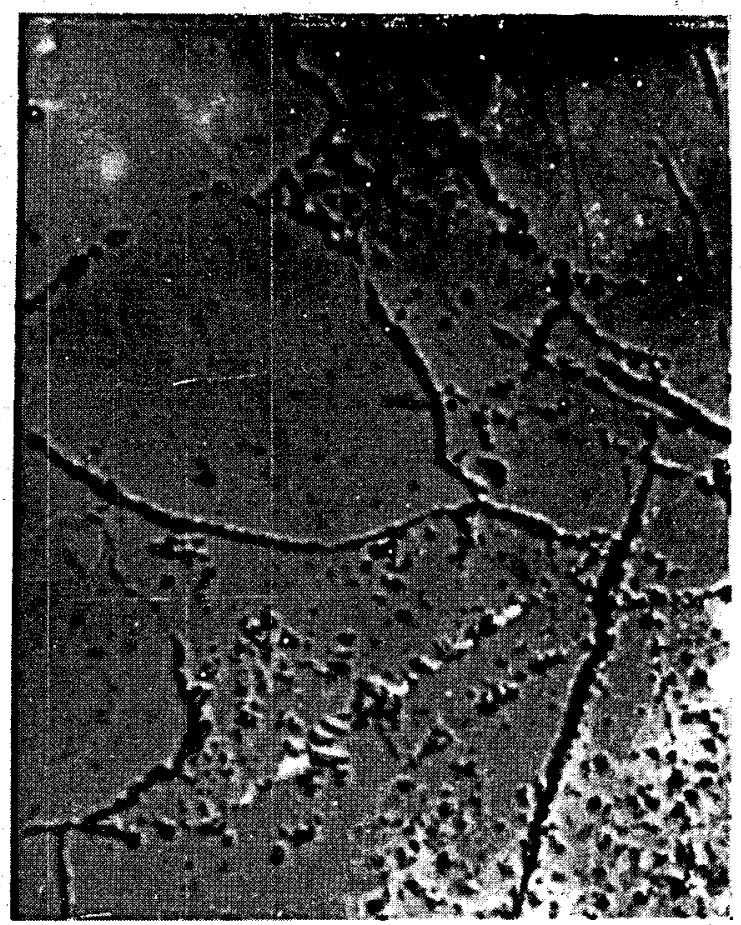

d 
Plate 3: Conway Granite Samples 448.1 and 335.0

Sample 448.1

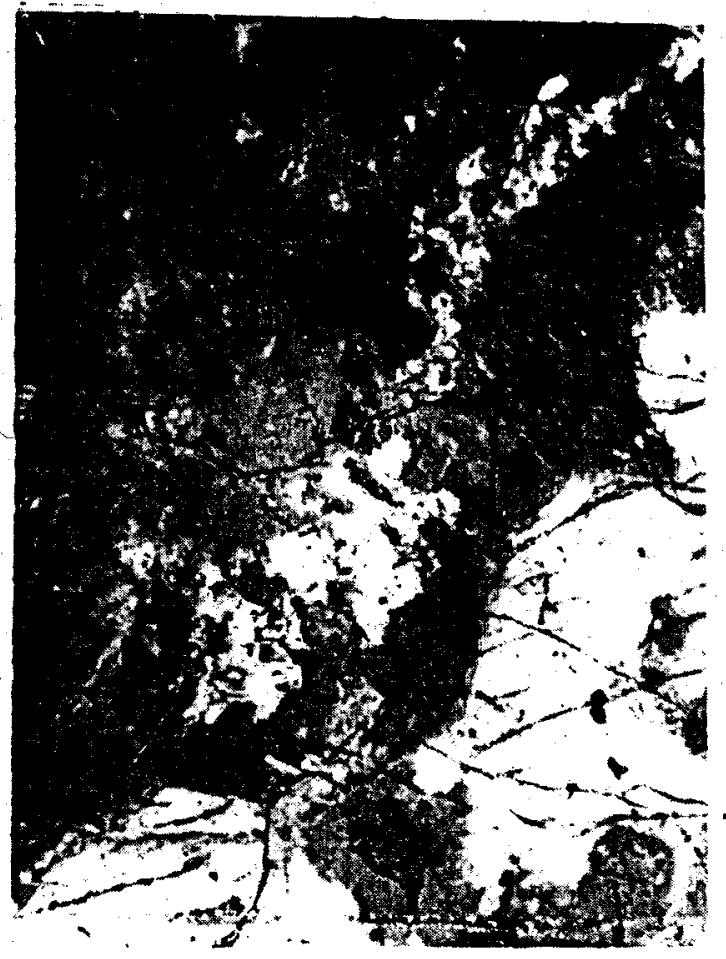

a
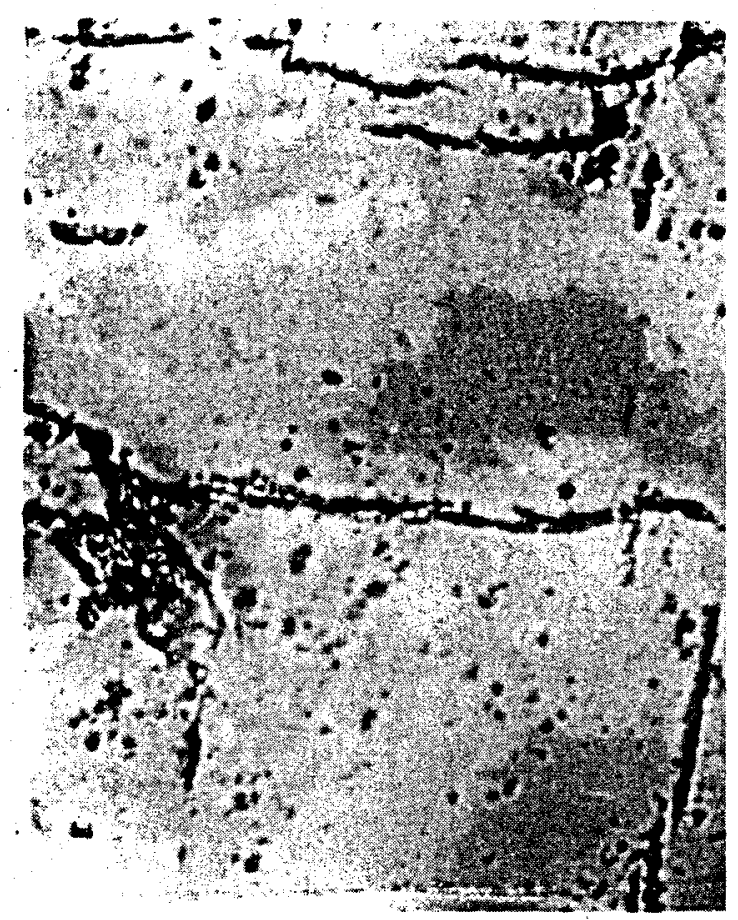

c
Sample 335.0

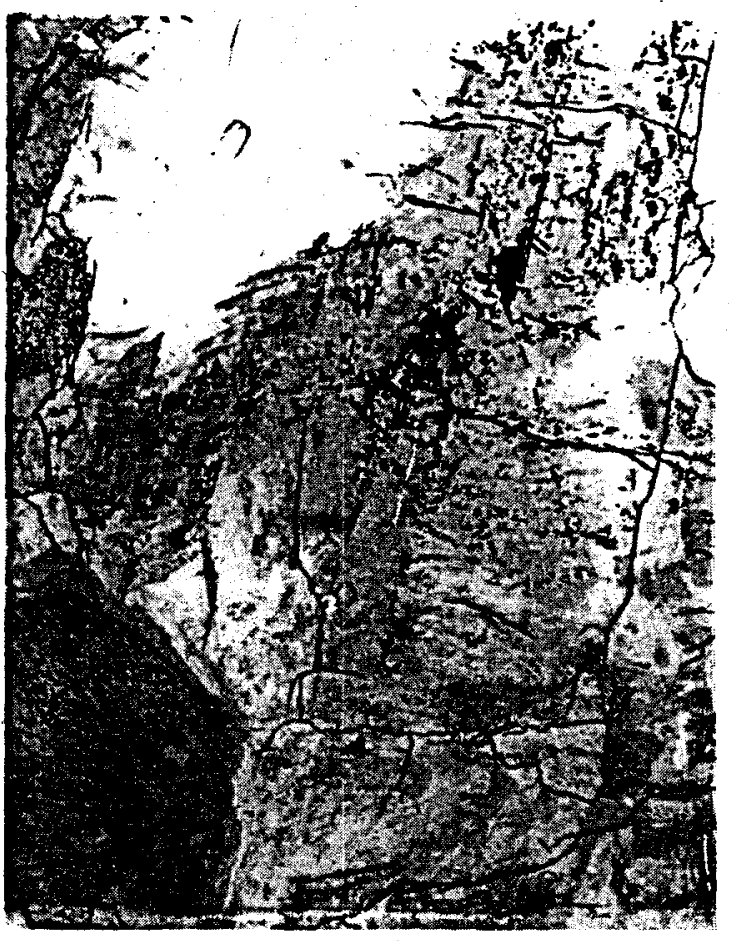

b

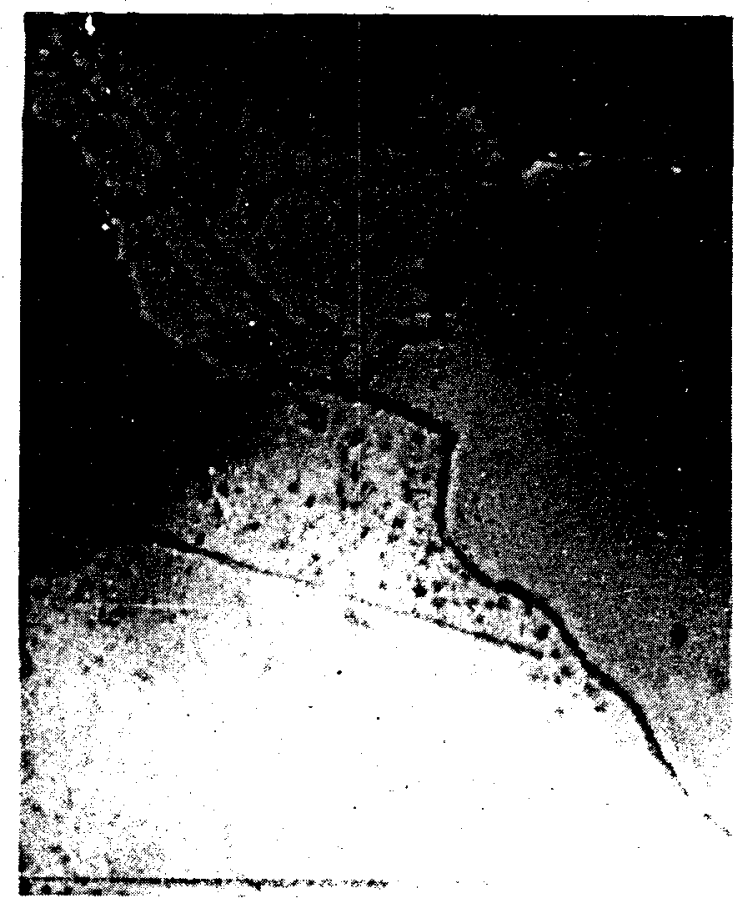

$\mathbf{a}$ 
Plate 4: Lamprophyre rock 610.2 at: a) $32 x$; b) $63 x$; c) $160 x$; d) $400 x$.

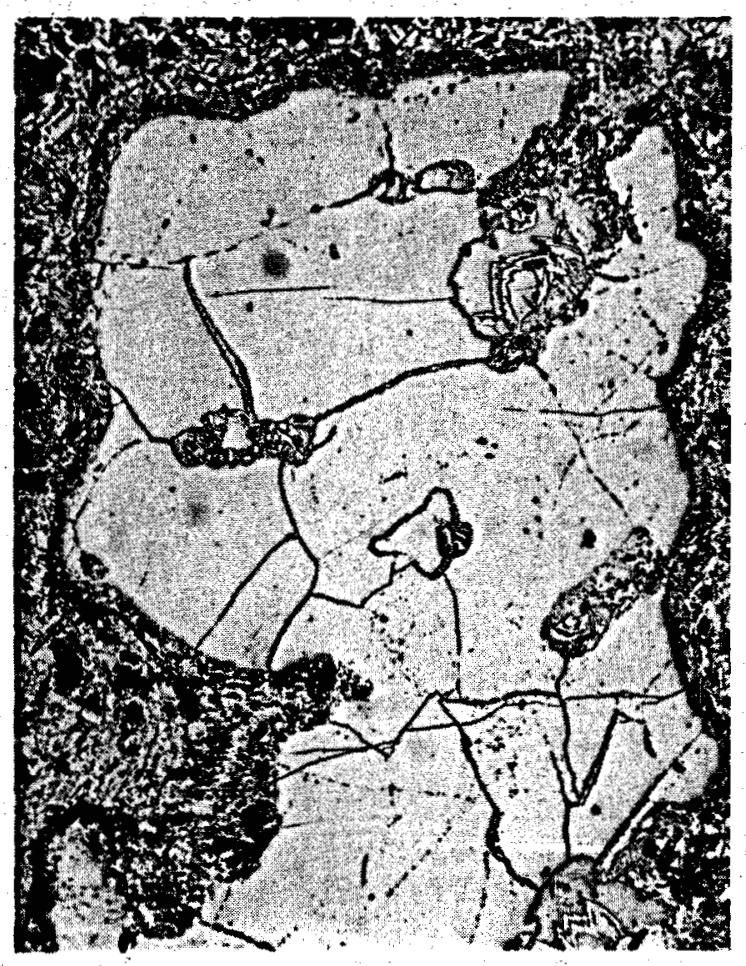

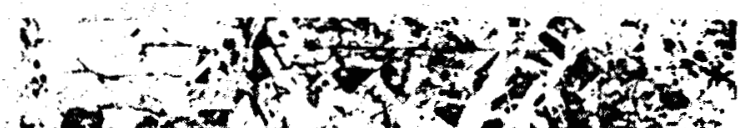

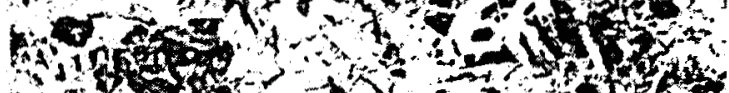

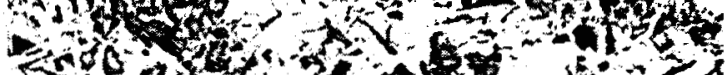

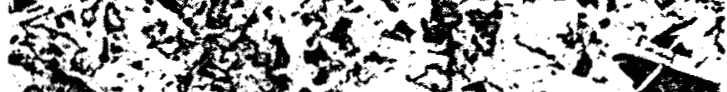

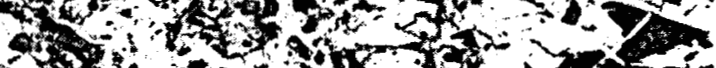

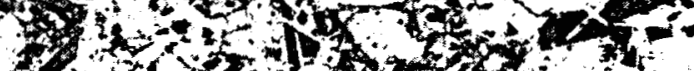

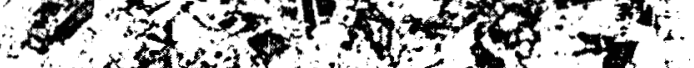

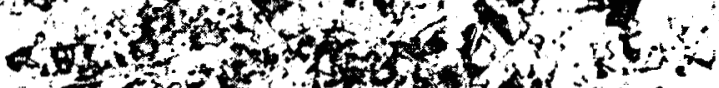

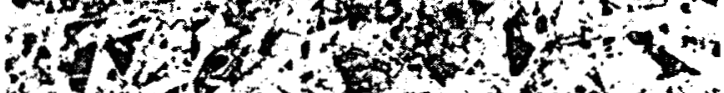

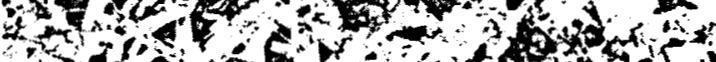

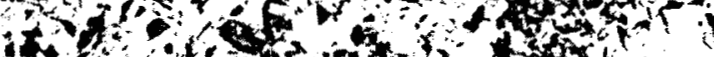
1.

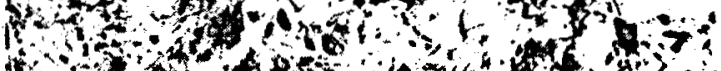

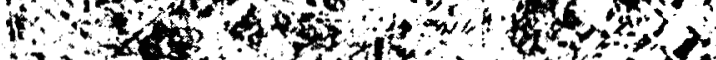

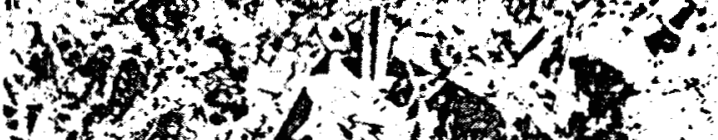

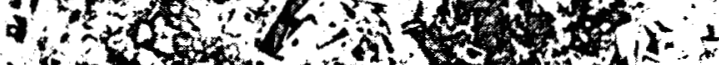

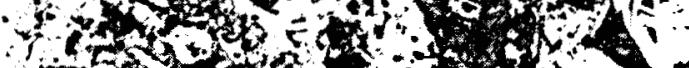

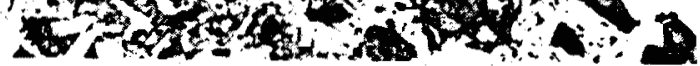

a: phenocryst
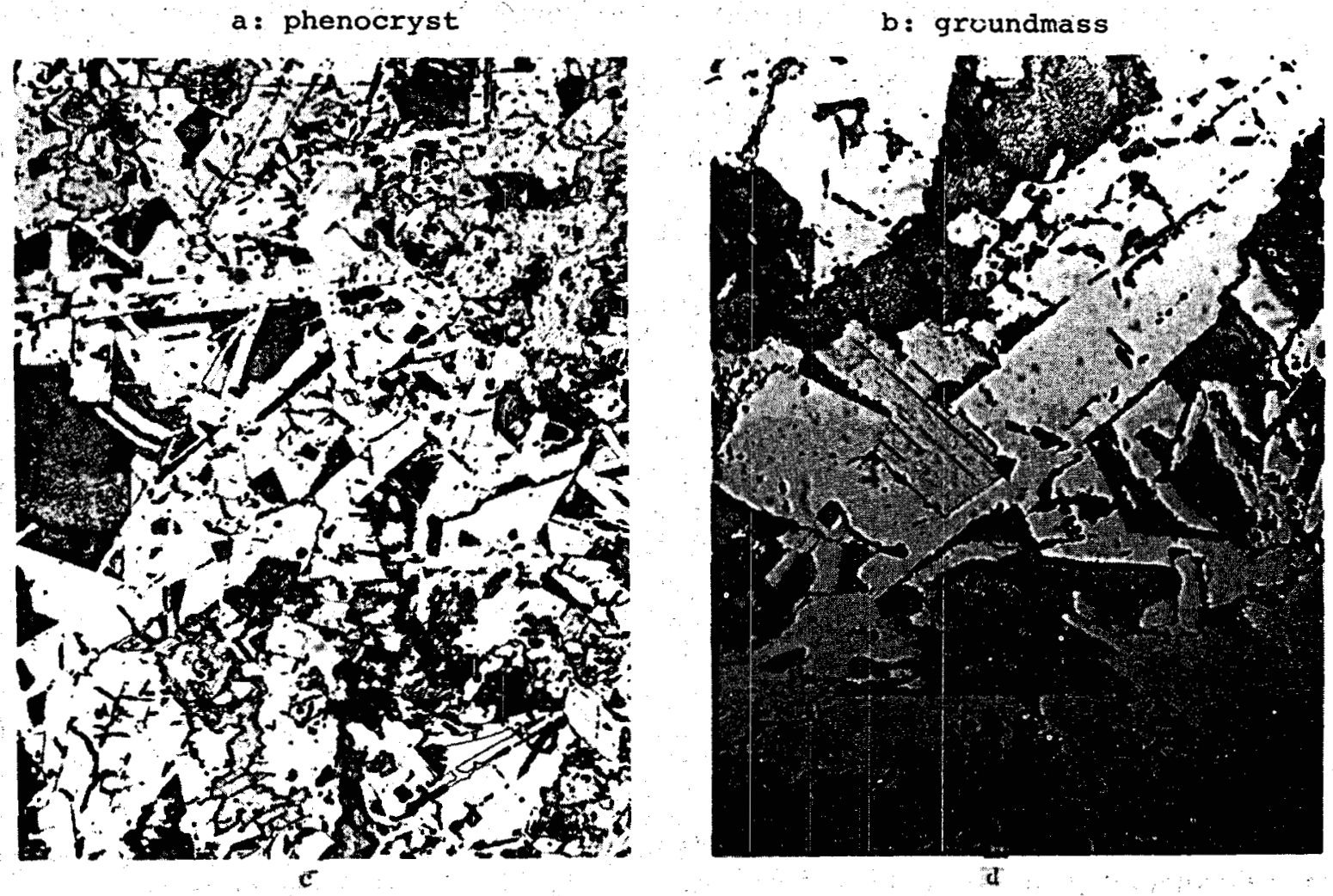
Figures 9-11 show $\rho^{-}$plotted against standard-circle-length corrected for magnification. The vertical height of each box corresponds to the range of spacings that were measured using a number of photographs. Samples 381.9 and 704.4 belong to group II and have already obviously different spectra of cracks than do samples 448.1 and 610.2 .

Figure 9 shows that 448.1 has a hierarchy of visually dominant patterns (see also Plate $3 a$ ). As one looks at higher and higher magnifications (shorter and shorter scale lengths) one resolves finer and finer networks of cracks. At low power, one sees and counts mostly the predominantly dentritic cracks that have the largest spacing.

Figure 10 shows that the crack pattern of 381.9 and 704.4 are dominated by a single hierarchy, which is the only one counted at all magnifications. Plates 1 and 2 show that the crack length spectra are fairly narrow. One does not see increasing finer networks as one goes to higher magnifications.

Sample 610.?. (Fig. 1.7) is somewhat complex. It has a much finer structure than any of the granitic samples, but it also contains a phenocryst and a calcite filled vein which runs the length of the sample.

Comparison of Figs. 9-11 with Figs. 5-8 show a significant correlation. Sample 381.9 has a single hierarchy of cracks and it has the smoothest S-shaped curve (dominated by a single inflection region). Sample 448.1 , which shows a broad distribution of hierarchies of structure, has also the "kinkiest" modulipressure curves, and an intermediate situation holds for 610.2.

These correlations are not exploited in this paper. (In a later paper we will discuss the inversion of the moduli data into microstructure.) Here we simply demonstrate this qualitative correlation and briefly point out one guide to interpreting the result.

The general form of an S-shaped curve of $\log C-\log P$ can be modeled with a set of simple assumptions. Consider a low porosity rock with open microcracks. Let the cracks form a single population. The population is defined by all cracks having the same length a and, at zero pressures, a distribution of widths $b_{j}$ which is uniform from closed $(b=0)$ to some maximum value $b_{m}$. Assume further that all the cracks close linearly with pressure, the crack characterized by $b_{m}$ closing at a pressure $P$

An elastic compliance of the rock is then simply a linear and decreasing function of pressure up to $P_{1}$. At higher pressures, the compliance has its limiting value (assuming the high pressure pins all the closed cracks so they cannot slip). The modulus $\underline{C}$ is then of the form

$$
\begin{array}{ll}
C / C_{0}=\frac{1}{1+A-B P} & P \leq P_{C m} ; A, B \text { constants } \\
C / C_{0}=1 & P>P_{C m}
\end{array}
$$

where $C_{0}$ is the "intrinsic" value of the modulus at high pressures.

$$
\frac{d \log C}{d \log P}=\frac{B P}{1+A-B P}
$$

A plot of $\log C$ versus $\log P$ is essentially flat at low pressures, and becomes increasingly concave upward for pressures near, but less than $P_{\text {cm. Above }}$ $P_{\mathrm{cm}}$ the curve is flat. This curve differs from the S-shaped data curves mostly 


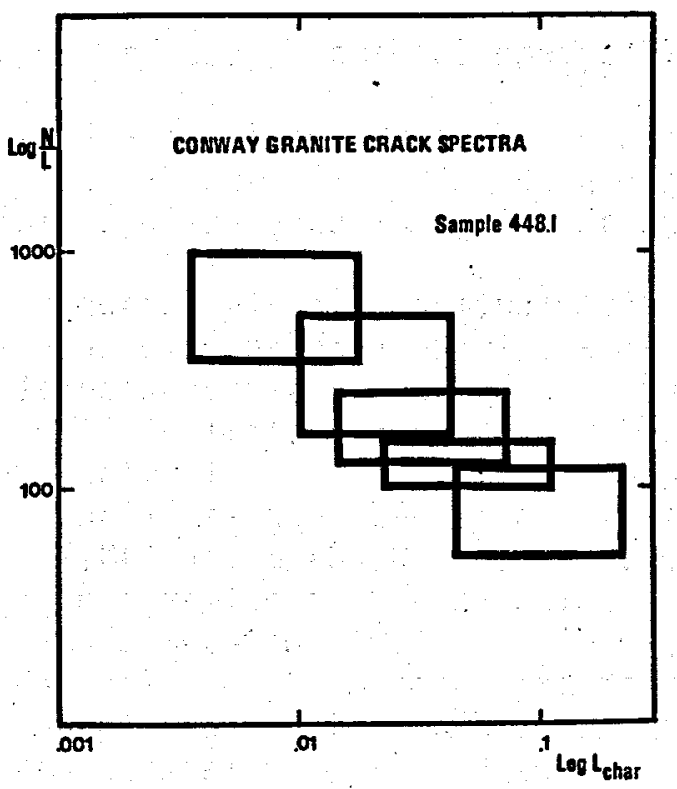

Fig. 9.

Logarithmic plot of cracks intersected by characteristic (standard) circles. The characteristic length $L_{\text {char }}$ is the circle circumference corrected for magnification. The number density $N / L$ is sensitive to crack length and crack spacing.

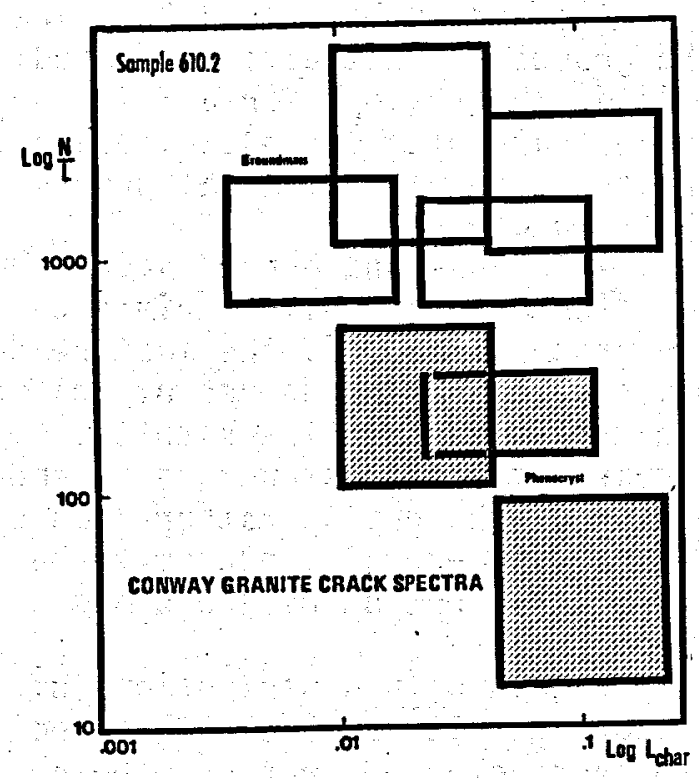

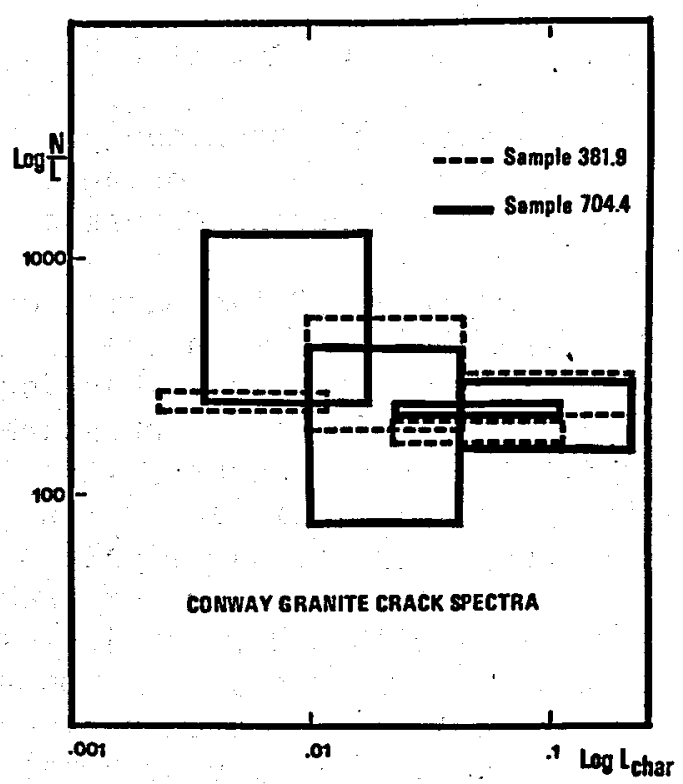

Fig. 10.

Logarithmic plot of cracks intersected by characteristic (standard) circles. The characteristic length $L_{\text {char }}$ is the circle circumference corrected for magnification. The number density $N / L$ is sensitive to crack length and crack spacing.

Fig. 11 .

Logarithmic plot of cracks intersected by characteristic (standard) circles. The characteristic length $L_{\text {char }}$ is the circle circumference corrected for magnification. The number density $N / L$ is sensitive to crack length and crack spacing. 
in having a sharp corner at $P=P_{c m}$, but this difference is minor (see Warren, 1977).

Therefore, but nonuniquely, a single S-shaped inflection region can be interpreted as due to the closing of such a single population of cracks. The top of the inflection region occurs at the pressure at which the population is fully closed.

Now sample 381.9 has narrow crack length distribution. It also shows a simple S-shaped curve with the top inflection at about 500 bars as noted earlier. If the data for this rock, therefore, is interpreted by such a simple population, then the compressibility - pressure curve should approximate a straight line of constant slope for pressures less then 500 bars, and it should be flat for greater pressures. We see in Fig. 12 that this is not a bad approximation.

By comparison, an implication can also be drawn for the data for 448.1 . This sample has a hierarchy of crack structures which extend to patterns of longer cracks with wider spacings than in sample 31.9 . It is not yet clear that it has any appreciable component of finer cracks than in 381.9 . The inflections in the data below -500 bars can be -interpreted as being a consequence of the pressure effects on several hierarchies of cracks. The inflection regions may be associated with piece-wise closure of longer cracks, or with nonlinear strains caused by the complexity of the crack patterns.

\section{RESULTS}

We address two questions. First, in the Conway granite, is microstructure related directly to phase or to depth? On the matter of phase, al though the lamprophyre dike rocks form their own group, the other two groups each contain a member from the 0sceola formation as well as a member from the Conway formation.

On the matter of depth, a coarse indication of the decrement in the compressional and shear velocities and the density is given in Fig. 13. Plotted are the velocity ratios at 50 bars to $3 \mathrm{~Kb}$ and density ratios at 50 bars to $4 \mathrm{~Kb}$. The $v_{p}$ and $V_{s}$ ratios track each other well, but the groups are not differentiated.

There is no systematic relation to phase or depth, (except for a faint suggestion of a correlation of the mean trends of the data with depth). Therefore, these groups do not correspond to formation groups or to mineralogical groups (with the exception of the lamprophyre sample) or to depth.

- A striking correlation is found between the $V_{p}$ groups and a hand specimen observation. Plate 5 contains low-power microphotographs of entire thin sections, grouped according to $V_{p}$ groups. Between groups I and II, the most readily apparent differences are in the average grain size and the degree of uniform$i$ ty of the distributions of the clots of dark minerals through the samples.

This correlation suggests that for these rocks, the microstructure is controlled by grain size and the spatial distribution of the grains rather than by the actual modalities. The samples in group II have a general tendency to be smaller grained as well as to show a more uniform distribution of the clots (which contain opaques + biotite + chlorite?).

The second question which can be asked is: Can in situ distributions of cracks be distinguished from cracks induced by coring? It has been suggested that cracks, inferred from strain data, with apparent closing pressures below in situ pressures, do not correspond to in situ features (the highest in situ Tithostatic pressures on the Conway rocks are Tess than 200 bars; the magnitude and direction of the anistropy of the in situ stress is not known). This 
Plate 5: Conway Sample Thin Sections
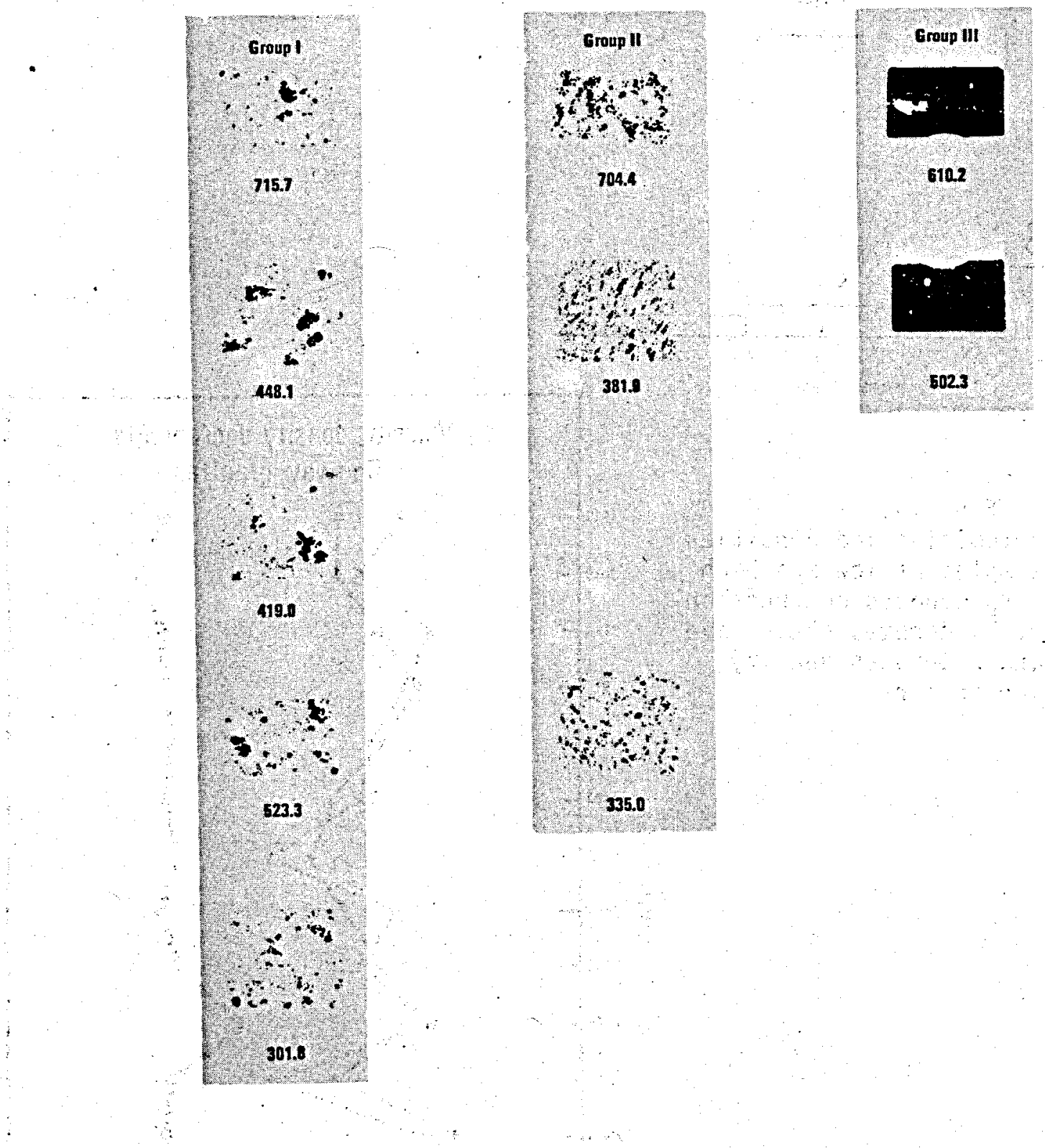


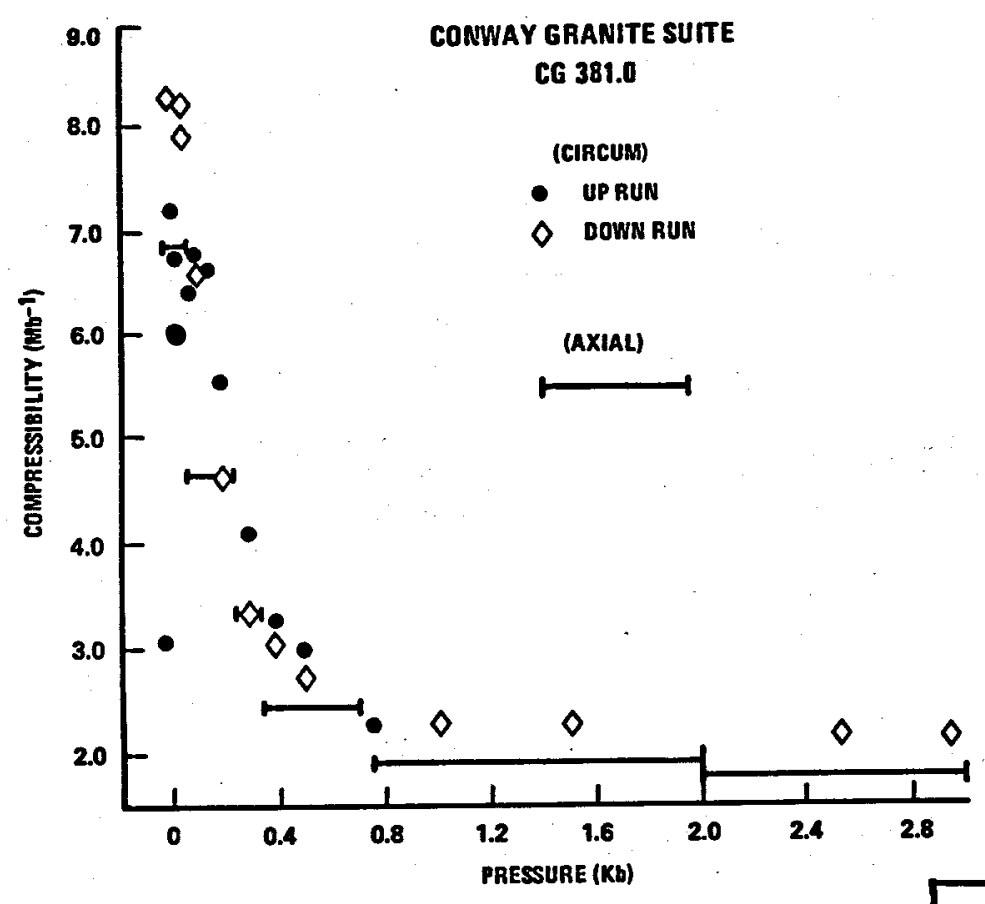

Fig. 12.

Static compressibility ver-

- sus pressure, for sample 381.0 .

Fig. 13.

Ratios of velocities and densities of Conway samples at low and high pressures. $V_{p}$ denotes compressional velocity, $V_{s}$ denotes shear wave velocity, and $\rho$ denotes density. Pressures are in bars.

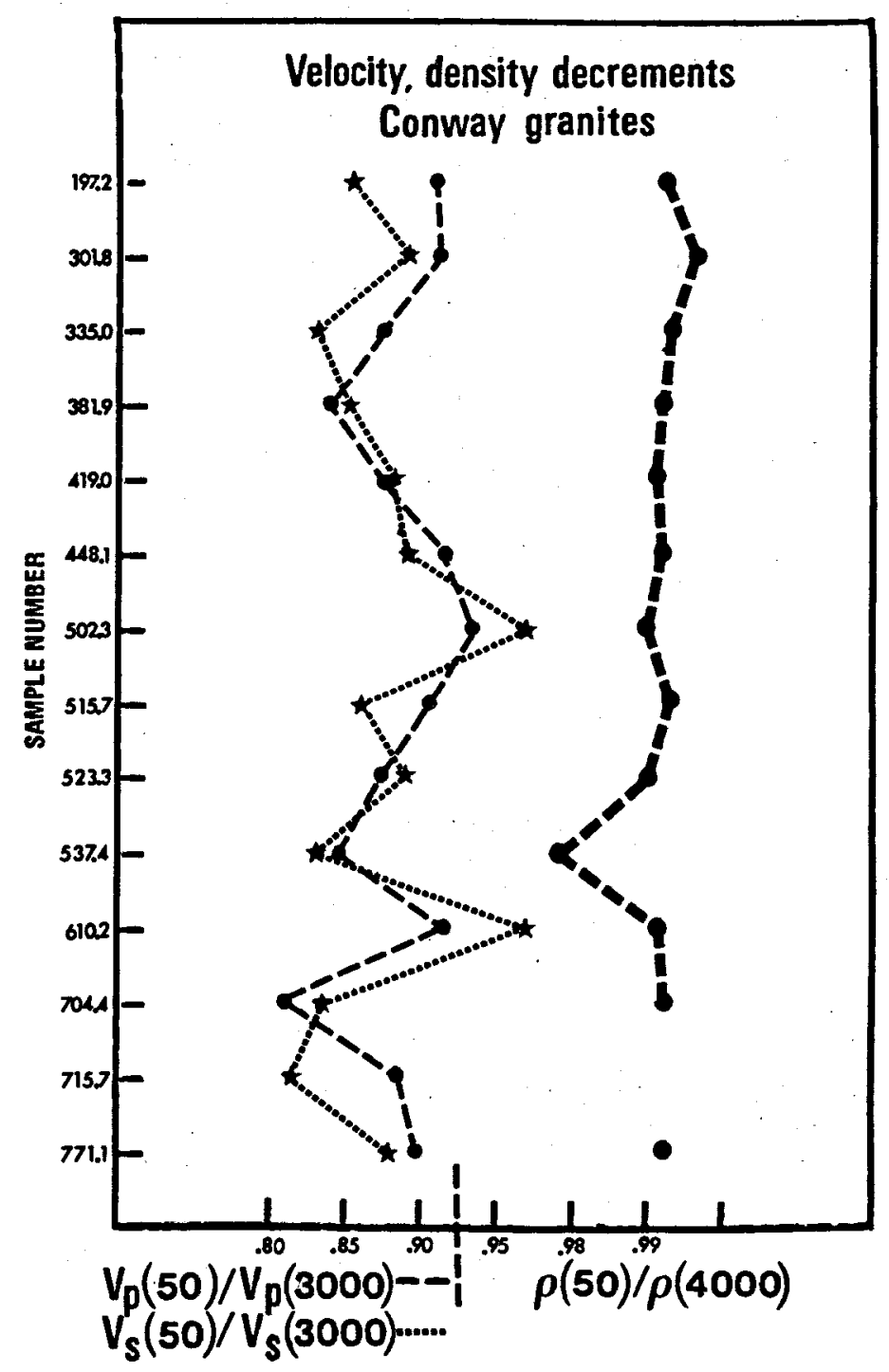


interpretation does not yet seem to be proven, and may not be warranted. In the data here, the "rough" moduli curves correspond to samples with hierarchies of microstructures. The comparison indicates that strains at the lowest pressures may be assocjated with piece-wise closure and nonlinear effects which are inherent in the complexities of the crack patterns. If so, such low pressure strains need not indicate that the features they correspond to do not exist in situ.

The microstructures controlling the velocities are related to the spatial distribution of the minerals. If cracks have been introduced by stress relaxation due to coring, their distribution is apparently also being controlled by the mineral distribution and hence is reflective of the type of microfracturing the rock would have in situ.

The results suggest that for these rocks, coring here may intensify the amount of cracking but not the type of cracking that the rock may have in situ. A distinct population of very thin cracks introduced by coring is not needed to explain the low pressure and strain and velocity data of these rocks.

\section{ACKNOWLEDGEMENTS}

The Conway samples are part of the collection curated by William Laughi in of LASL. Mineralogy and modal analysis are courtesy of Andrea Eddy of LASL. Velocity, strain, and petrographic measurements of cracks were made by Rod Trice, Mike Tiernan, and Tanya Preiser. The computer work, curve fitting and statistical grouping techniques were developed by Mike Tiernan. I wish to especially thank John Christie and Mary Wegner for the use of the reflection microscope, instructions on photographic techniques, and discussions on the petrographic study. This work was supported by ERDA Grant EY-76-S-03-0034 P.A. 224.

\section{REFERENCES}

1. F. Birch, R. F. Roy, and E. R. Decker, Heat Flow and Thermal History in New England and New York," Studies of Appalachian Geology; Northern and Maritime, E. A. Zen, W. S. White, J. B. Hadley, and J. B. Thompson (Eds.), Wiley and Sons, New York, pp. 437-451 (1968).

2. J. B. Lyons, H. Faul, "Isotope Geochronology of the Northern Appalachians," Studies of Appalachian Geology: Northern and Maritime, E. A. Zen, W. S. White, J. B. Hadley, and J. B. Thompson (Eds.), Wiley and Sons, New York, pp. 305-318 (1968).

3. G. W. Stewart, "Deep Heat Flow and Fracturing Tests in Conway Granite," Progress Report \#1, ERDA E(11-1), 2720 (1976).

4. M. Tiernan and N. Warren, "Statistical Tests for the Characterization of Systematics of Rock Elastic Properties Data," (in preparation, 1979).

5. N. Warren, "Characterization of Modulus-Pressure Systematics of Rocks: Dependence on Microstructure," The Earth's Crust, Geophys. Mono. 20, AGU, Washington, D. C., pp. 119-148 (1977).

6. N. Warren and T. Preiser, "Characterizing Systematics of Patterns in Microstructure in Rock," (in preparation, 1979). 
7. N. Warren and R. Trice, "Correlation of Elastic Moduli Systematics with Texture in Lunar Materials," Proceedings of the 6 th Lunar Science Conference, Supplement 6, V. 3, pp. 55-3268 (1975).

\section{APPENDIX 1}

Table A-1

VELOCITY DATA QUALITY

\begin{tabular}{|c|c|c|c|c|}
\hline Sample & $\nabla_{p}$ & max. hyst. & $\nabla_{8}$ & max. hyst. \\
\hline 197.2 & $\mathbf{f}$ & 1.57 & G & \\
\hline 301.8 & G & & G & \\
\hline 335.0 & G & & $\mathbf{G}$ & \\
\hline 381.9 & $\mathbf{G}$ & & $\mathbf{G}$ & \\
\hline 419.0 & G & & $\mathbf{p}$ & $4.0 \%$ \\
\hline 448.1 & G & & $\mathbf{E}$ & $2.5 \%$ \\
\hline 502.3 & $\mathbf{G}$ & & $\mathbf{G}$ & \\
\hline 515.7 & $\begin{array}{l}\text { anomalous large } \\
\text { change in velocity } \\
P: 3 \mathrm{~Kb}\end{array}$ & & G & \\
\hline 523.3 & $\mathbf{f}$ & $2.0 \%$ & f & $2.0 \%$ \\
\hline 537.4 & crossover at $2 \mathrm{~Kb}^{*}$ & $4.5 \%$ & $\mathbf{G}$ & $\therefore$ \\
\hline 610.2 & anomalous up-run & $3.5 \%$ & G & \\
\hline 704.4 & G & & $\mathbf{f}$ & $(\geq 1.0 \%)$ \\
\hline 715.7 & $\mathbf{f}$ & $3.0 \%$ & & \\
\hline 771.1 & $(G, \underset{f}{f}$ second run $)$ & $3.0 \%$ & & \\
\hline $\begin{array}{l}=\text { good } \\
=\text { falr } \\
=\text { poor }\end{array}$ & . & & & \\
\hline
\end{tabular}


Conway Granite Suite

Sample CG 197.2

$\rho=2.614 \mathrm{gm} / \mathrm{cm}^{3}$

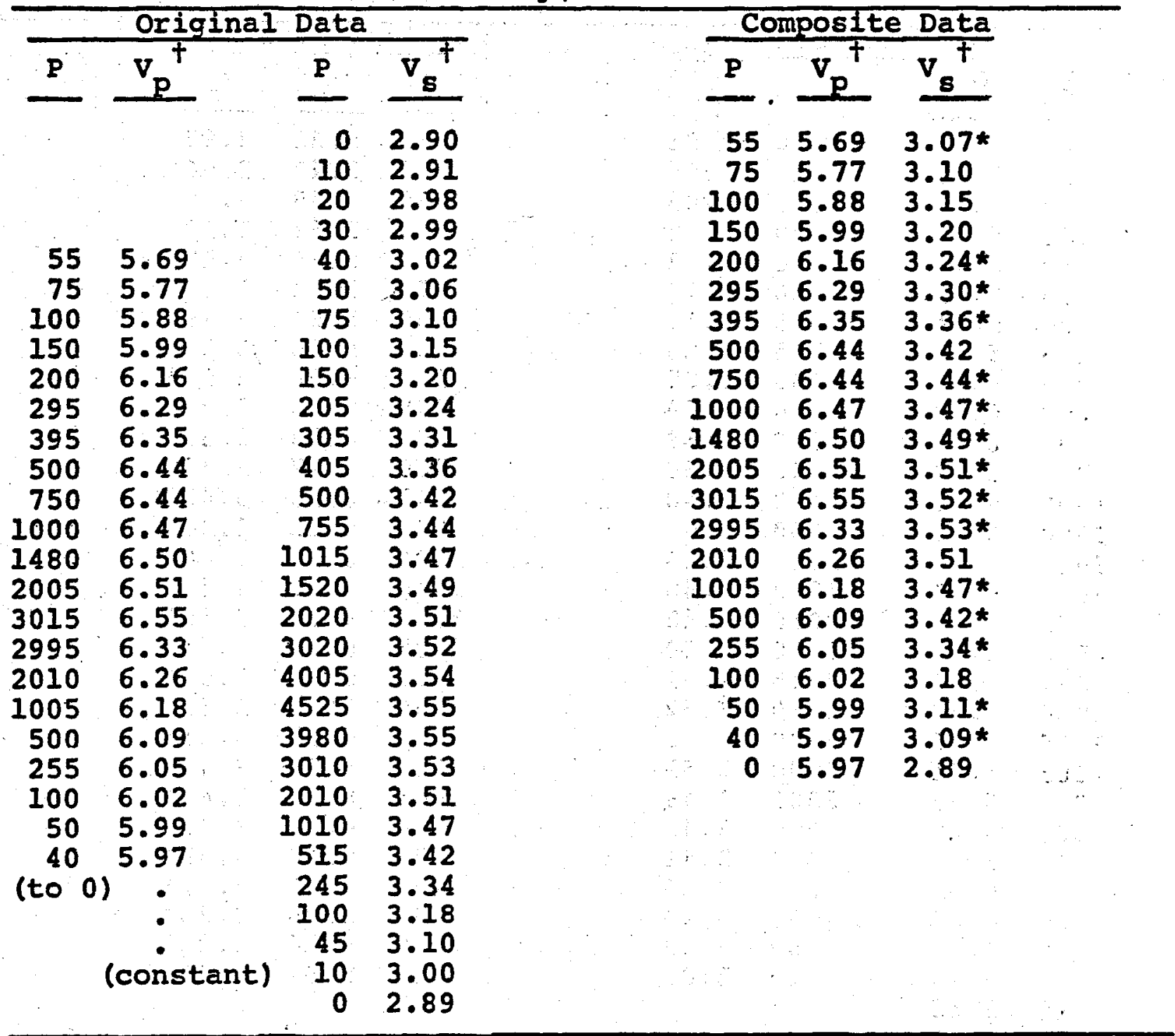

* interpolated values

tnot corrected for strain 
Conway Granite Suite

Sample CG 301.8

$p=2.612 \mathrm{gm} / \mathrm{cm}^{3}$

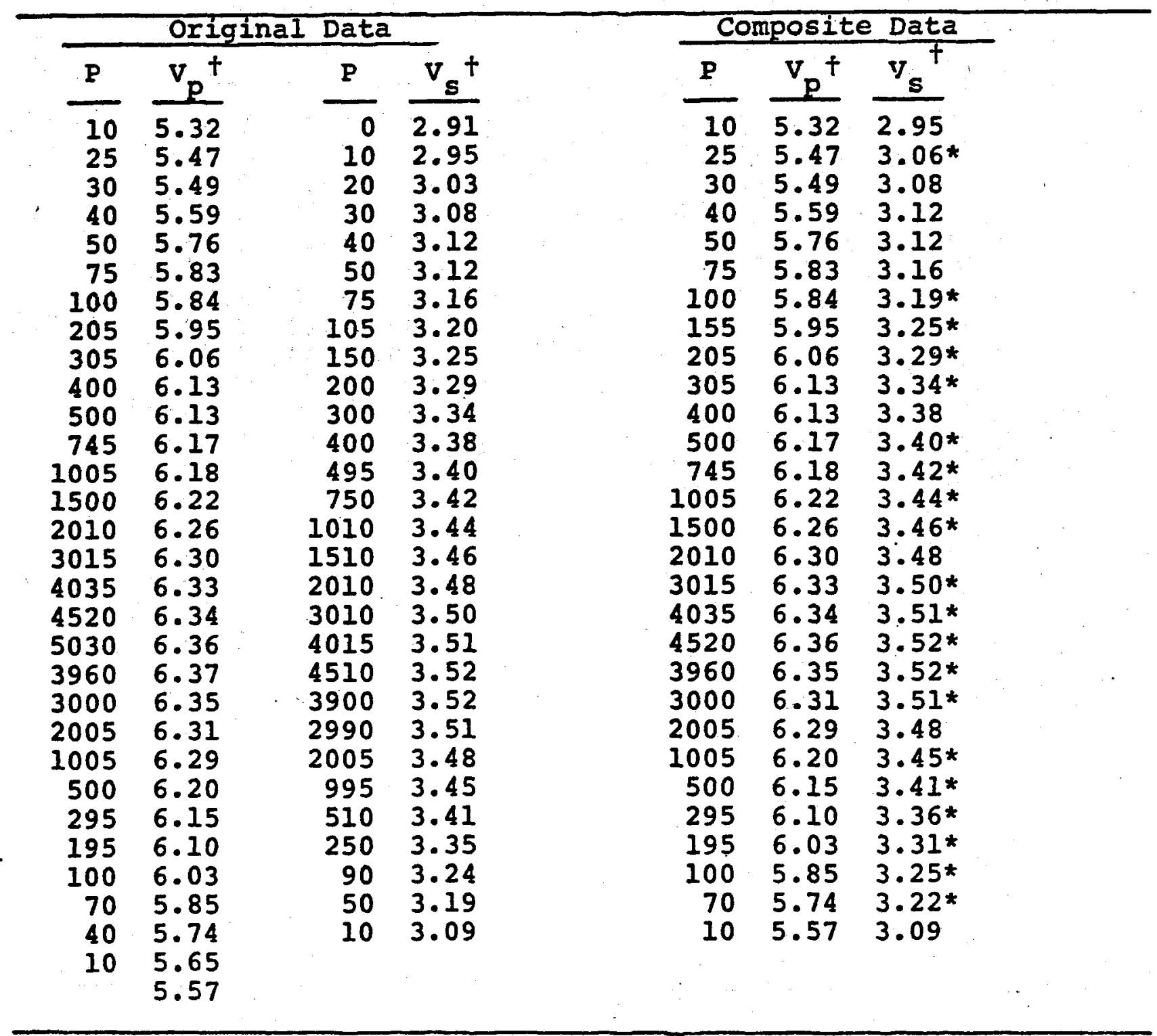

* interpolated values

tnot corrected for strain 
Conway Granite suite

Sample CG 335.0

$p=2.624 \mathrm{gm} / \mathrm{cm}^{3}$

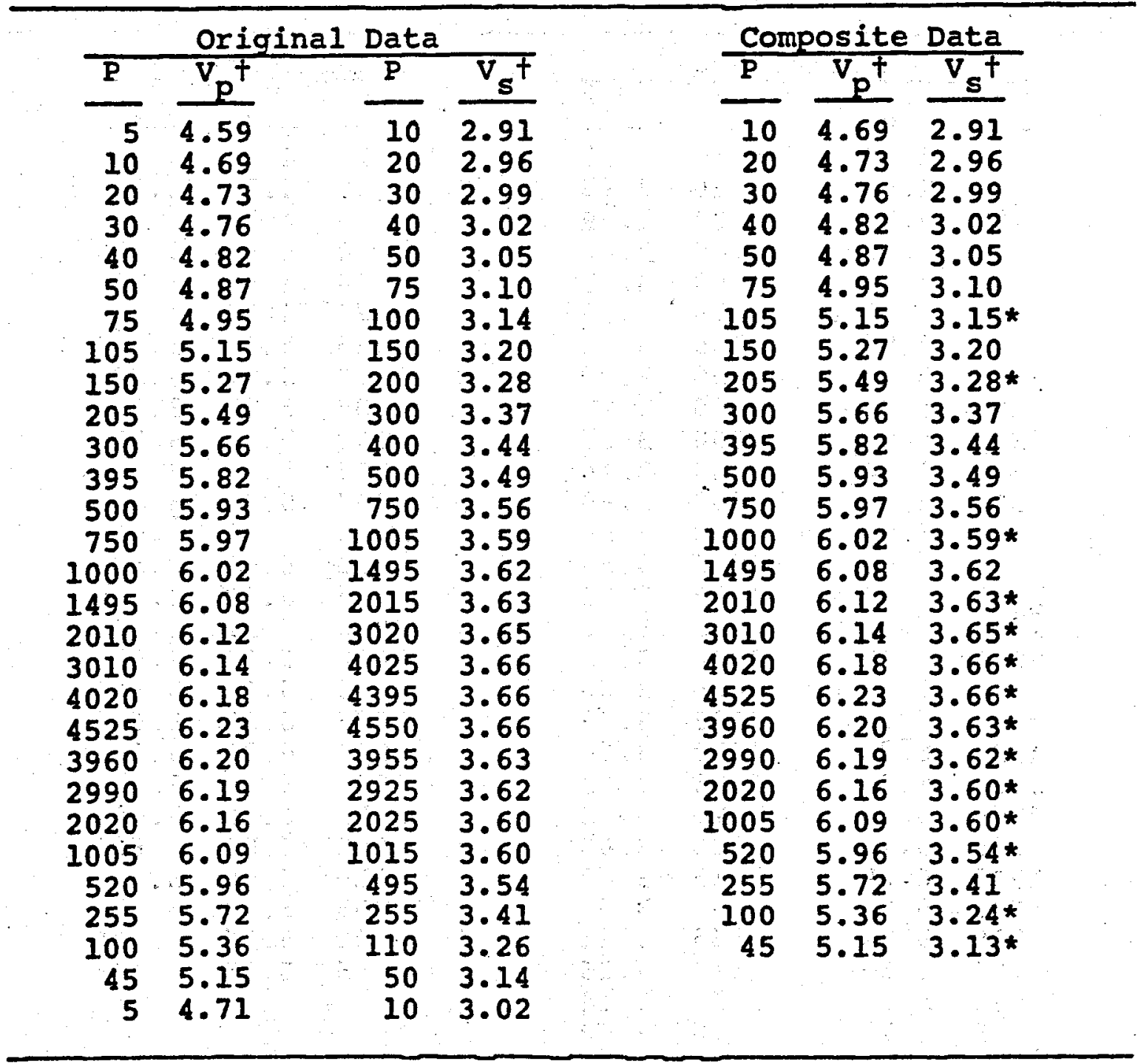

* interpolated values

tnot corrected for strain 
Conway Granite Suite

Sample CG 335.0

$p=2.624 \mathrm{gm} / \mathrm{cm}^{3}$

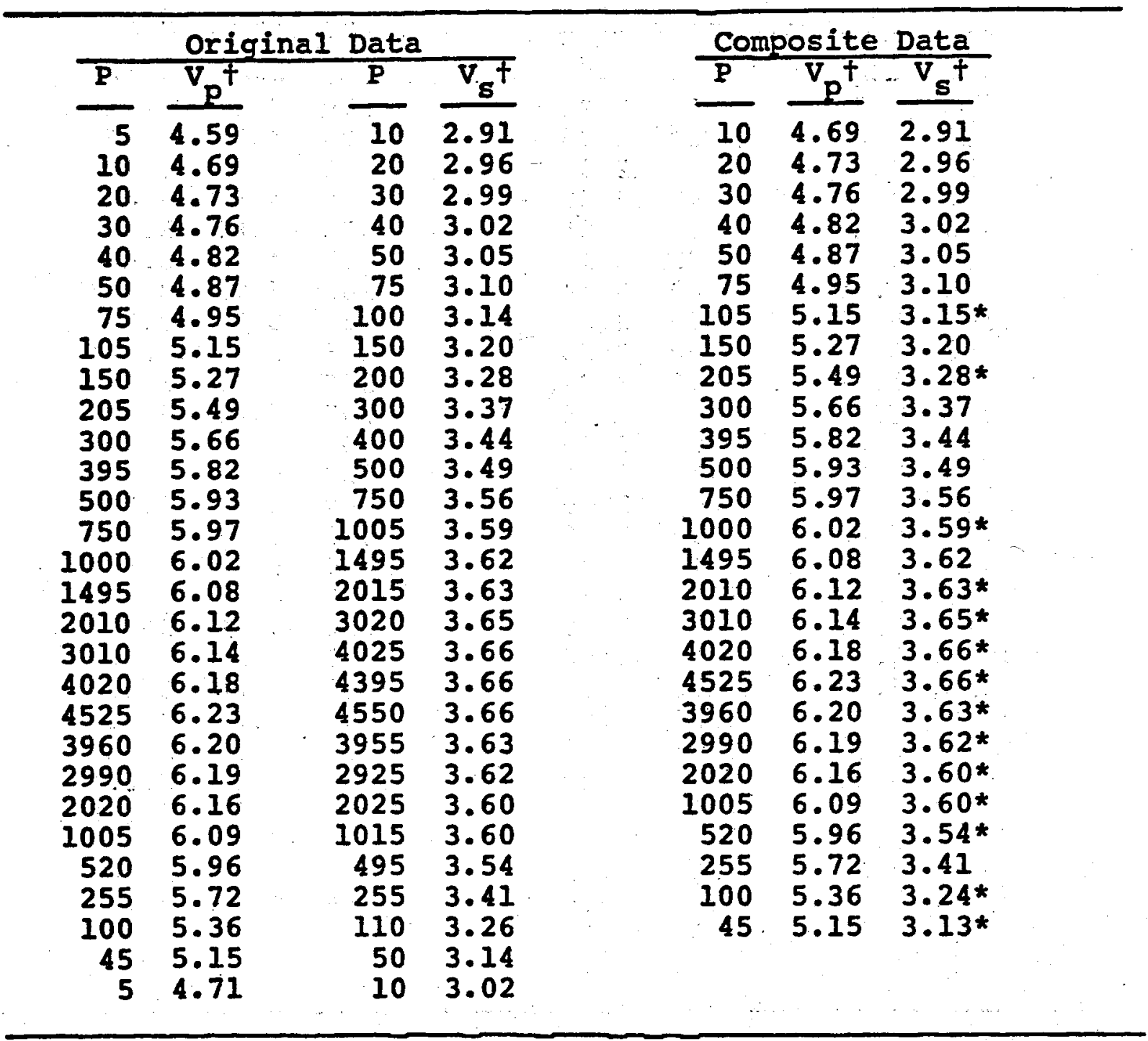

* interpolated values

tnot corrected for strain 
Conway Granite Suite

Sample 381.9

$p=2.639 \mathrm{gm} / \mathrm{cm}^{3}$

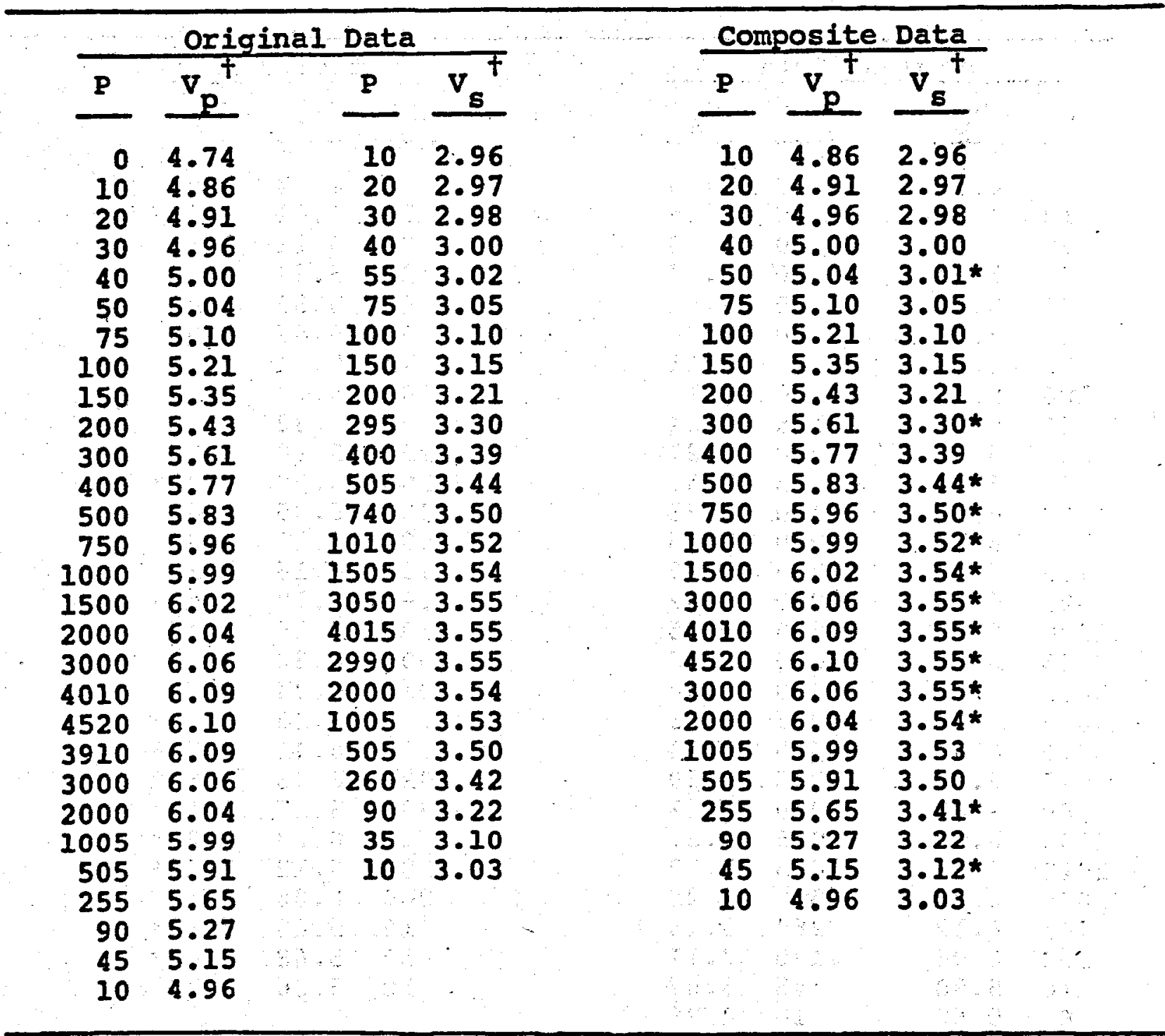

*interpolated

tnot corrected for strain 
Conway Granite Suite

Sample CG 419.0

$$
p=2.527 \mathrm{gm} / \mathrm{cm}^{3}
$$

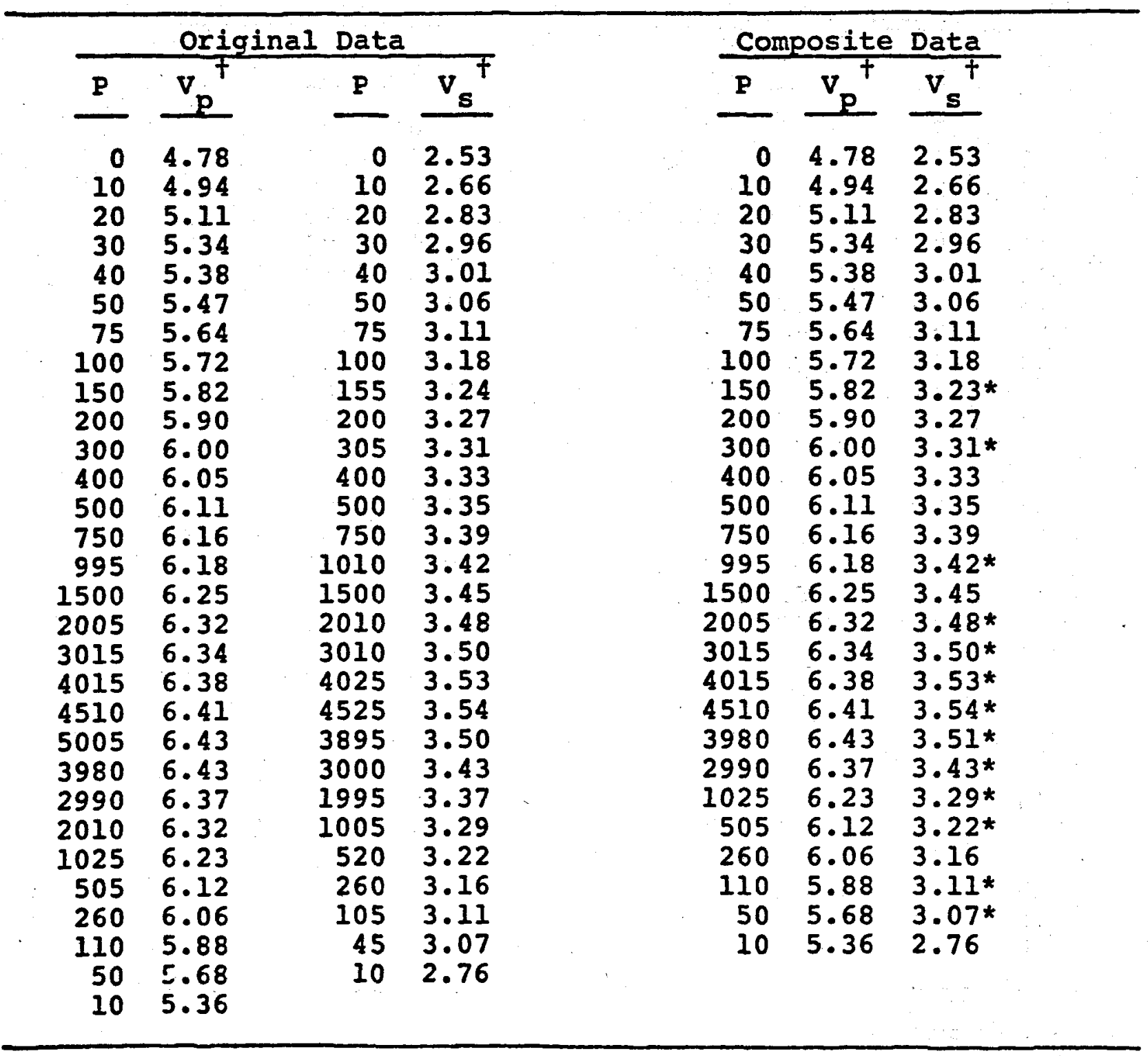

tnot corrected for strain

*interpolated values 
Conway Granite Suite

Sample CG 448.1 $p=2.603 \mathrm{gm} / \mathrm{cm}^{3}$

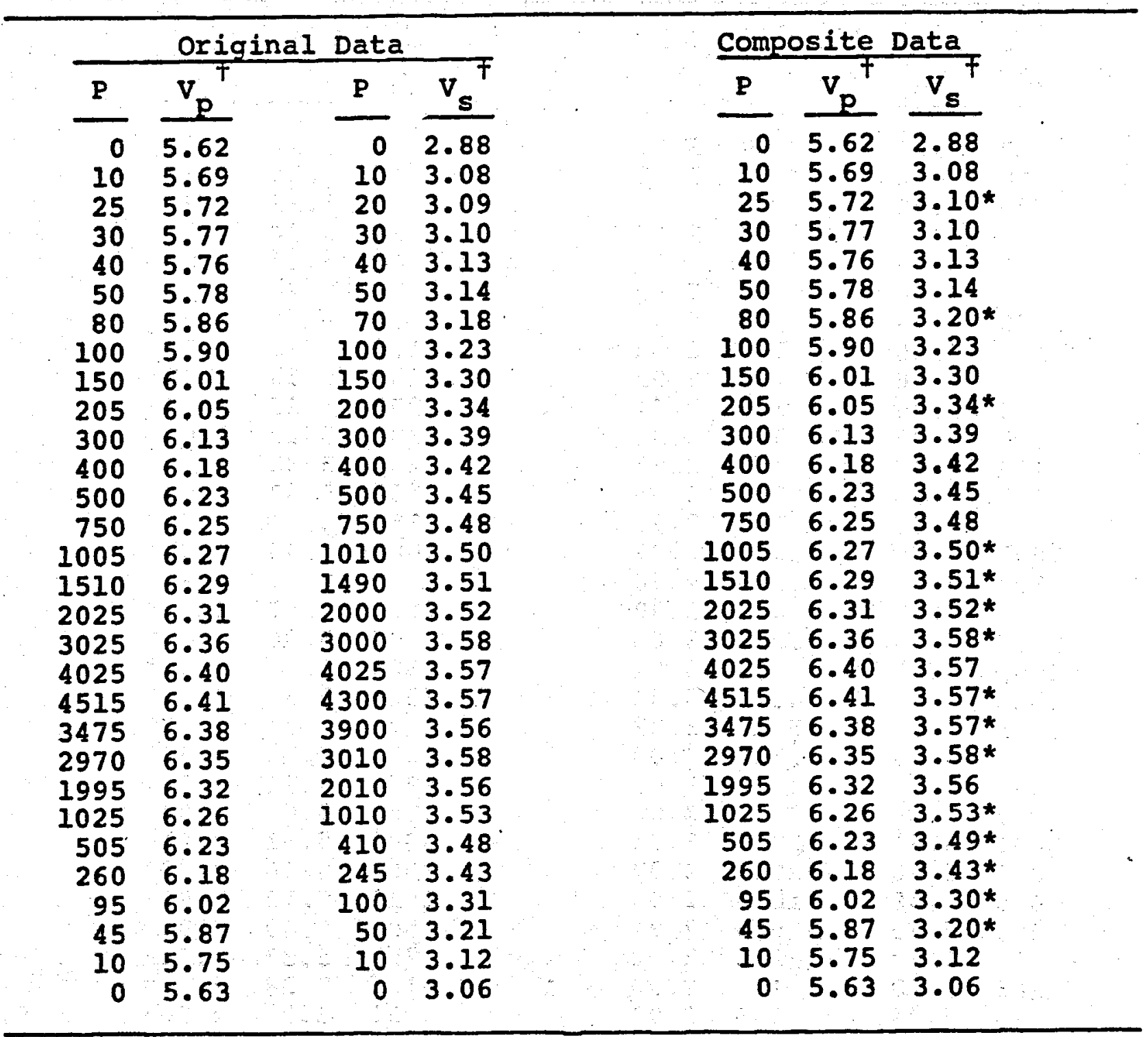

*interpolated values

tnot corrected for strain 
Conway Granite Suite

Sample CG 502.3

$$
p=2.810 \mathrm{gm} / \mathrm{cm}^{3}
$$

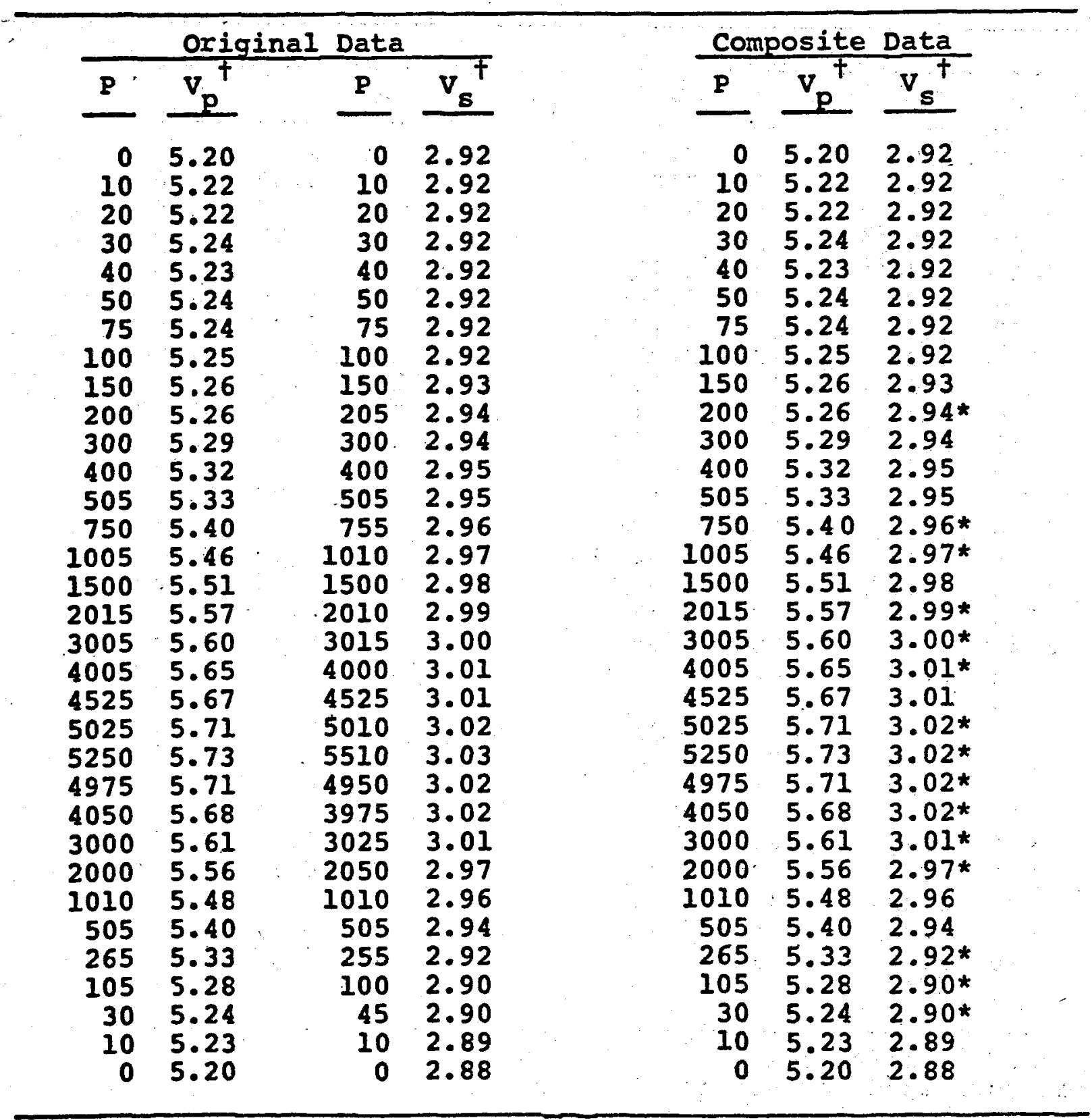

*interpolated values

tnot corrected for strain 
Conway Granite Suite

Sample CG 515.7 $p=2.585 \mathrm{gm} / \mathrm{cm}^{3}$

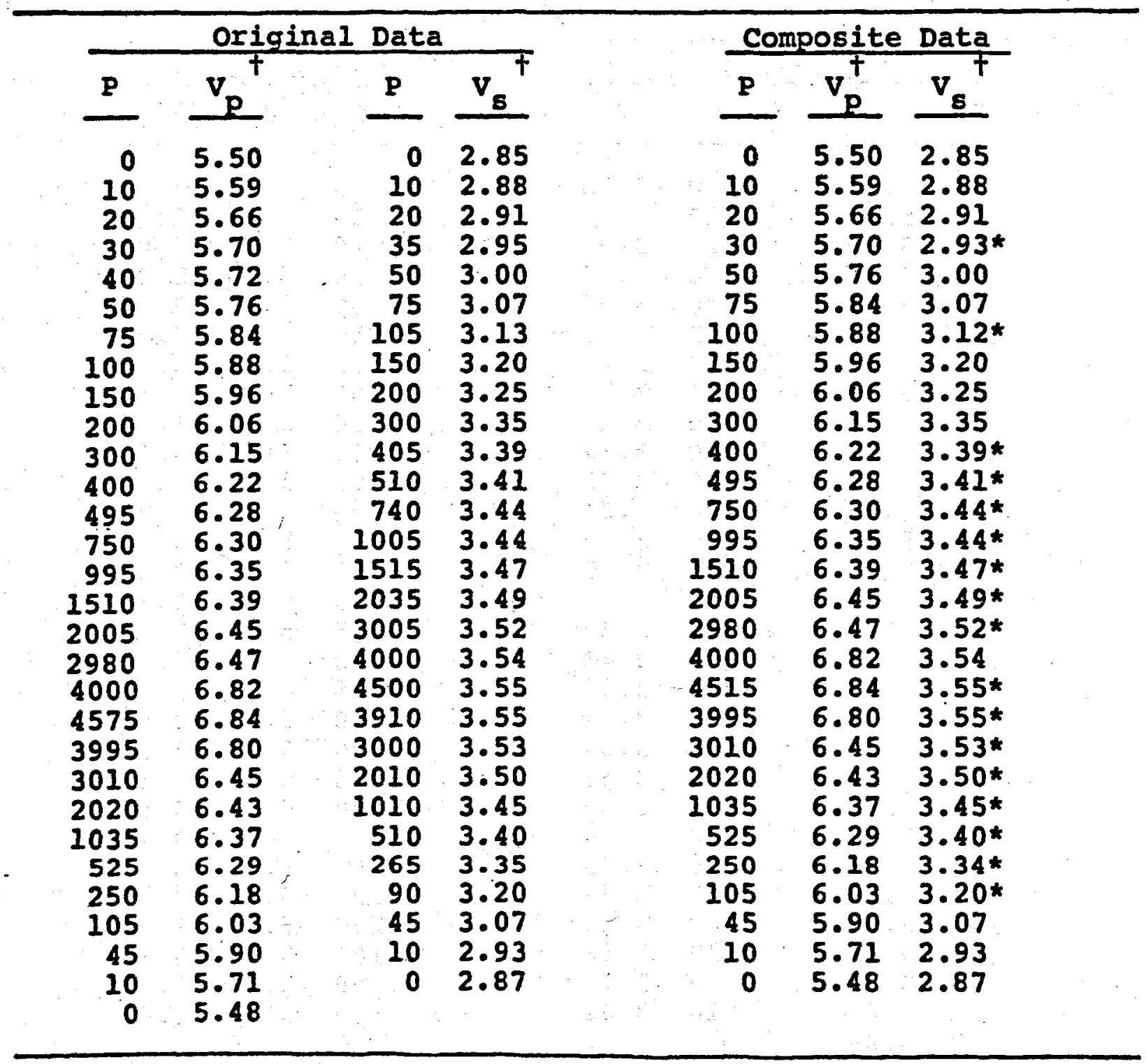

*interpolated values

tnot corrected for strain 
Conway Granite Suite

Sample CG 523.3

$$
p=2.574 \mathrm{gm} / \mathrm{cm}^{3}
$$

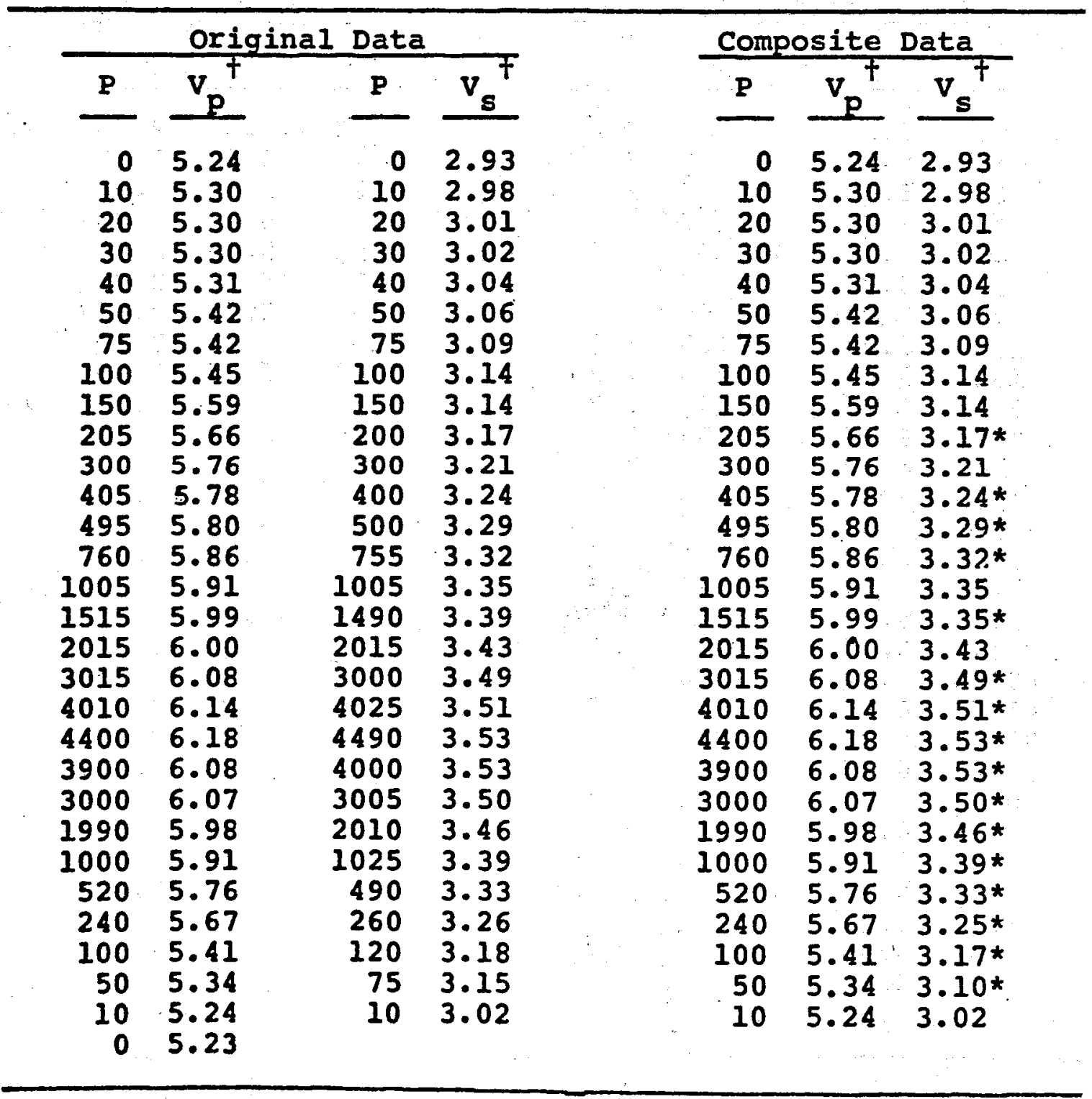

*interpolated values

tnot corrected for strain 
Conway Granite Suite

Sample CG 537.4

$$
p=2.420 \mathrm{~g} / \mathrm{cm}^{3}
$$

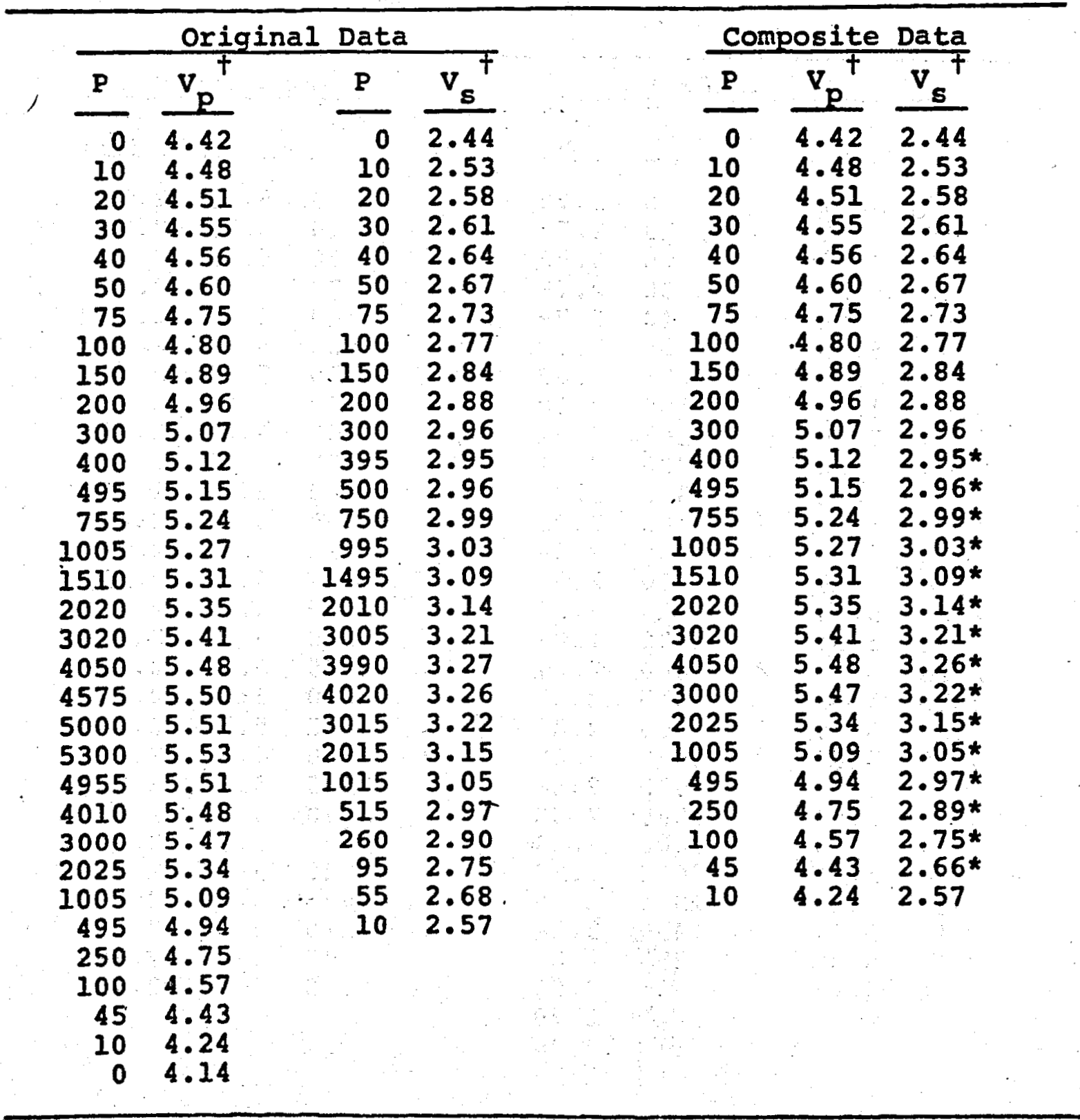

tnot corrected for strain

*interpolated values 
Conway Granite Suite

Sample CG 610.2

$p=2.786 \mathrm{gm} / \mathrm{cm}^{3}$

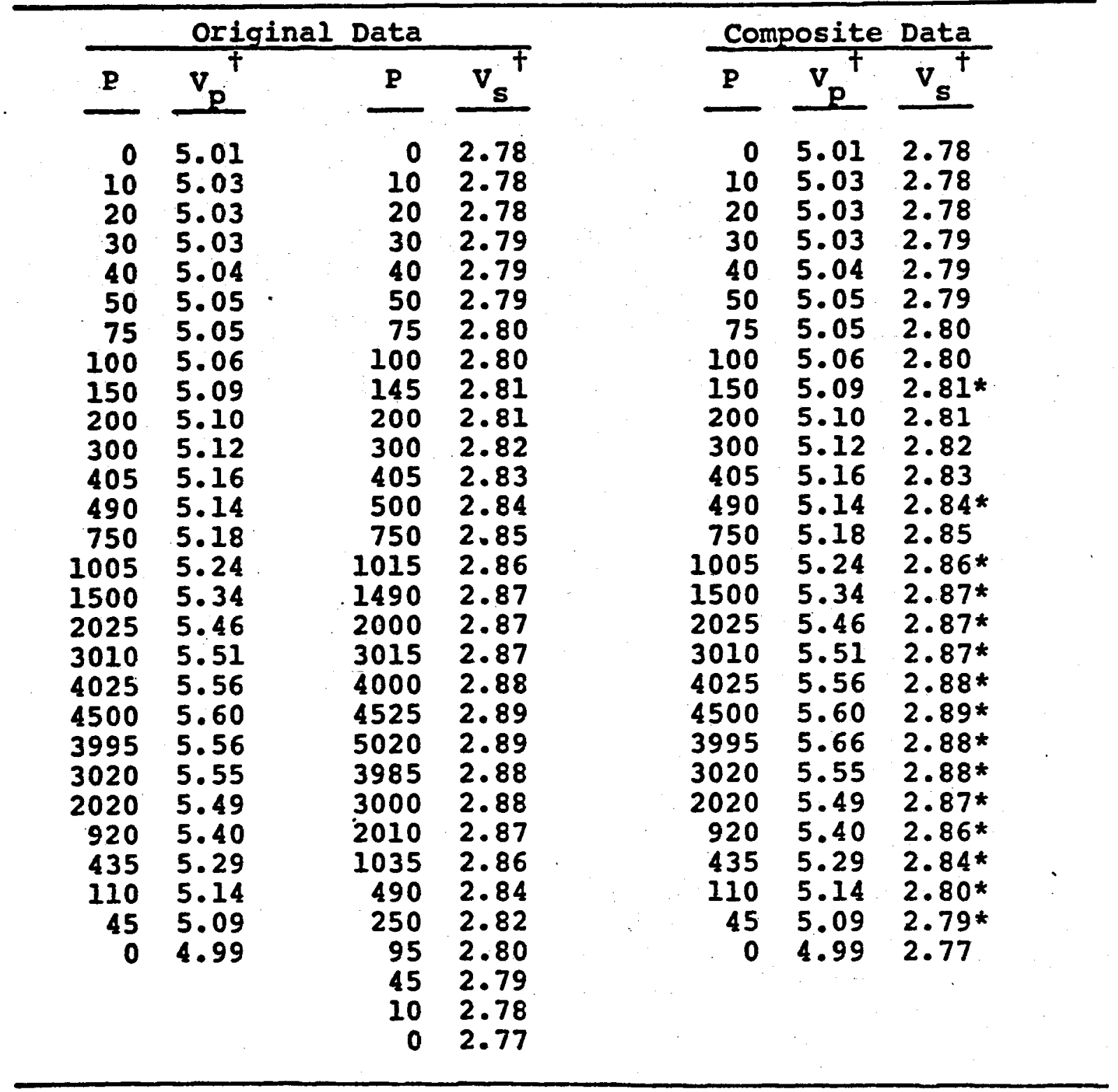

*interpolated values

tnot corrected for strain 
Conway Granite Suite.

Sample CG 704.4

$$
\rho=2.656 \mathrm{~g} / \mathrm{cm}^{3}
$$

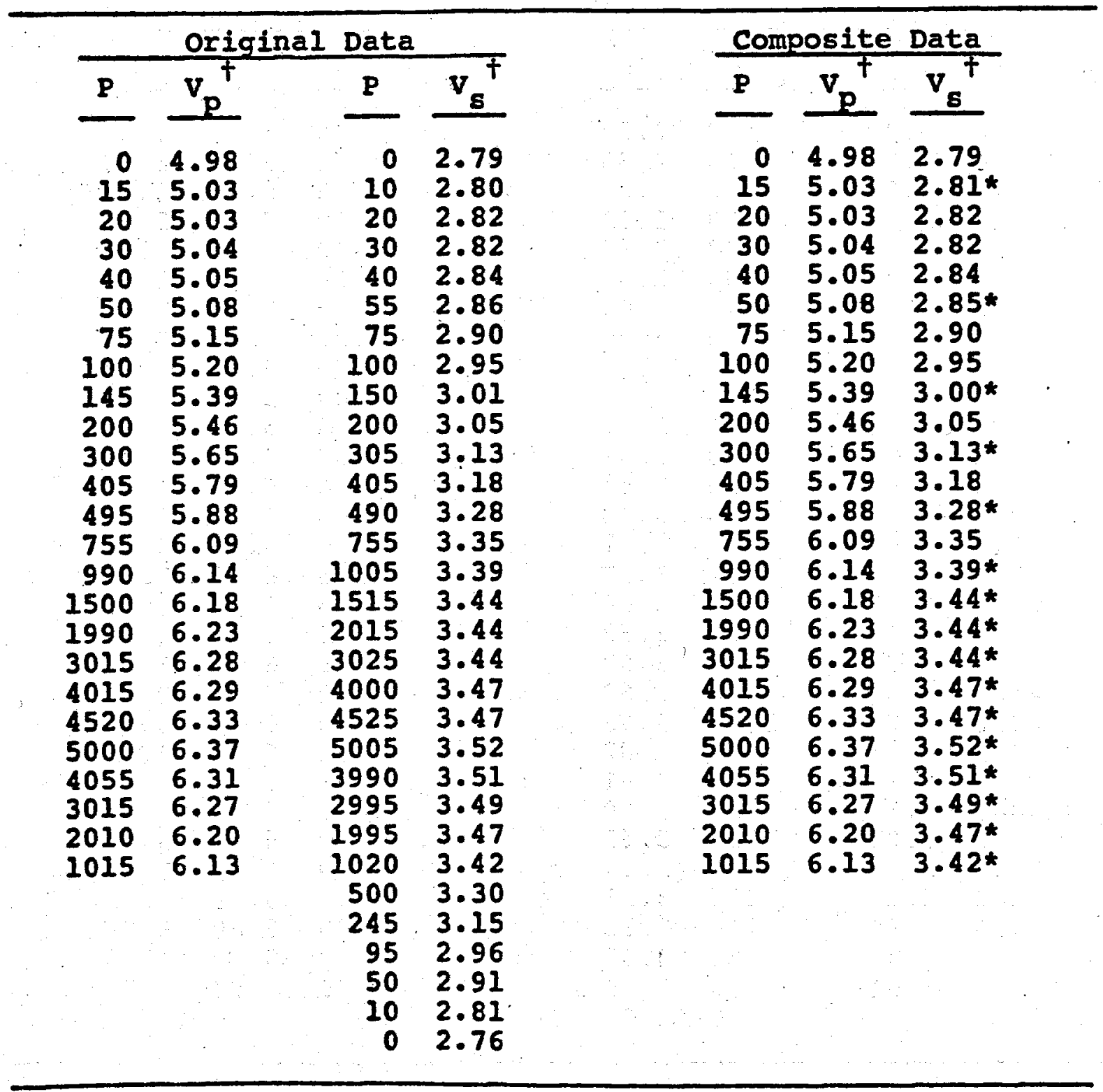

tnot corrected for strain

* interpolated values 
Conway Granite Suite

Sample CG 715.73

$p=2.619 \mathrm{~g} / \mathrm{cm}^{3}$

\begin{tabular}{|c|c|c|c|c|c|c|}
\hline \multicolumn{4}{|c|}{ Original Data } & \multicolumn{3}{|c|}{ Composite Data } \\
\hline $\bar{P}$ & $v_{p}^{t}$ & $\mathbf{P}$ & $v_{s}^{\top}$ & $P$ & $v_{p}^{t}$ & $\mathrm{v}_{s}^{+}$ \\
\hline $\begin{array}{r}0 \\
10 \\
25 \\
30 \\
40 \\
50 \\
75 \\
100 \\
150 \\
200 \\
305 \\
400 \\
500 \\
760 \\
1010 \\
1515 \\
2005 \\
3010 \\
4015 \\
4400 \\
3980 \\
2995 \\
2005 \\
1000 \\
510 \\
250 \\
105 \\
50 \\
10 \\
0\end{array}$ & $\begin{array}{l}5.20 \\
5.27 \\
5.35 \\
5.36 \\
5.37 \\
5.38 \\
5.43 \\
5.49 \\
5.61 \\
5.65 \\
5.76 \\
5.81 \\
5.90 \\
5.94 \\
5.97 \\
6.02 \\
6.21 \\
6.23 \\
6.29 \\
6.31 \\
6.26 \\
6.21 \\
6.17 \\
6.14 \\
6.03 \\
5.91 \\
5.73 \\
5.60 \\
5.27 \\
5.04\end{array}$ & $\begin{array}{r}0 \\
10 \\
20 \\
30 \\
40 \\
50 \\
75 \\
100 \\
150 \\
205 \\
300 \\
400 \\
490 \\
765 \\
1010 \\
1510 \\
1995 \\
3025 \\
4020 \\
4520 \\
5000 \\
3985 \\
2975 \\
1995 \\
1025 \\
500 \\
255 \\
110 \\
50 \\
10 \\
0\end{array}$ & $\begin{array}{l}2.83 \\
2.85 \\
2.88 \\
2.90 \\
2.93 \\
2.94 \\
3.00 \\
3.05 \\
3.13 \\
3.21 \\
3.31 \\
3.37 \\
3.41 \\
3.48 \\
3.51 \\
3.55 \\
3.60 \\
3.62 \\
3.62 \\
3.62 \\
3.63 \\
3.62 \\
3.61 \\
3.60 \\
3.53 \\
3.44 \\
3.31 \\
3.12 \\
3.01 \\
2.89 \\
2.80\end{array}$ & $\begin{array}{r}0 \\
10 \\
25 \\
30 \\
40 \\
50 \\
75 \\
100 \\
150 \\
200 \\
305 \\
400 \\
500 \\
760 \\
1010 \\
1515 \\
2005 \\
3010 \\
4015 \\
4400 \\
3980 \\
2995 \\
2005 \\
1000 \\
510 \\
250 \\
105 \\
50 \\
10 \\
0\end{array}$ & $\begin{array}{l}5.20 \\
5.27 \\
5.35 \\
5.36 \\
5.37 \\
5.38 \\
5.43 \\
5.49 \\
5.61 \\
5.65 \\
5.76 \\
5.81 \\
5.90 \\
5.9 .4 \\
5.97 \\
6.02 \\
6.21 \\
6.23 \\
6.29 \\
6.31 \\
6.26 \\
6.21 \\
6.17 \\
6.14 \\
6.03 \\
5.91 \\
5.73 \\
5.60 \\
5.27 \\
5.04\end{array}$ & $\begin{array}{l}2.83 \\
2.85 \\
2.89 \\
2.90 \\
2.93 \\
2.94 \\
3.00 \\
3.05 \\
3.13 \\
3.21^{\star} \\
3.31 \\
3.37 \\
3.41^{\star} \\
3.48^{\star} \\
3.51 \\
3.55^{\star} \\
3.60^{\star} \\
3.62 \star \\
3.62 \star \\
3.62 \star \\
3.62 \star \\
3.61 \star \\
3.60^{\star} \\
3.53^{\star} \\
3.44^{\star} \\
3.30^{\star} \\
3.11^{\star} \\
3.01 \\
2.89 \\
2.80^{\star}\end{array}$ \\
\hline
\end{tabular}

* interpolated values

t not corrected for strain 
Conway Granite Suite

Sample CG 771.1

$$
\rho=2.632 \mathrm{~g} / \mathrm{cm}^{3}
$$

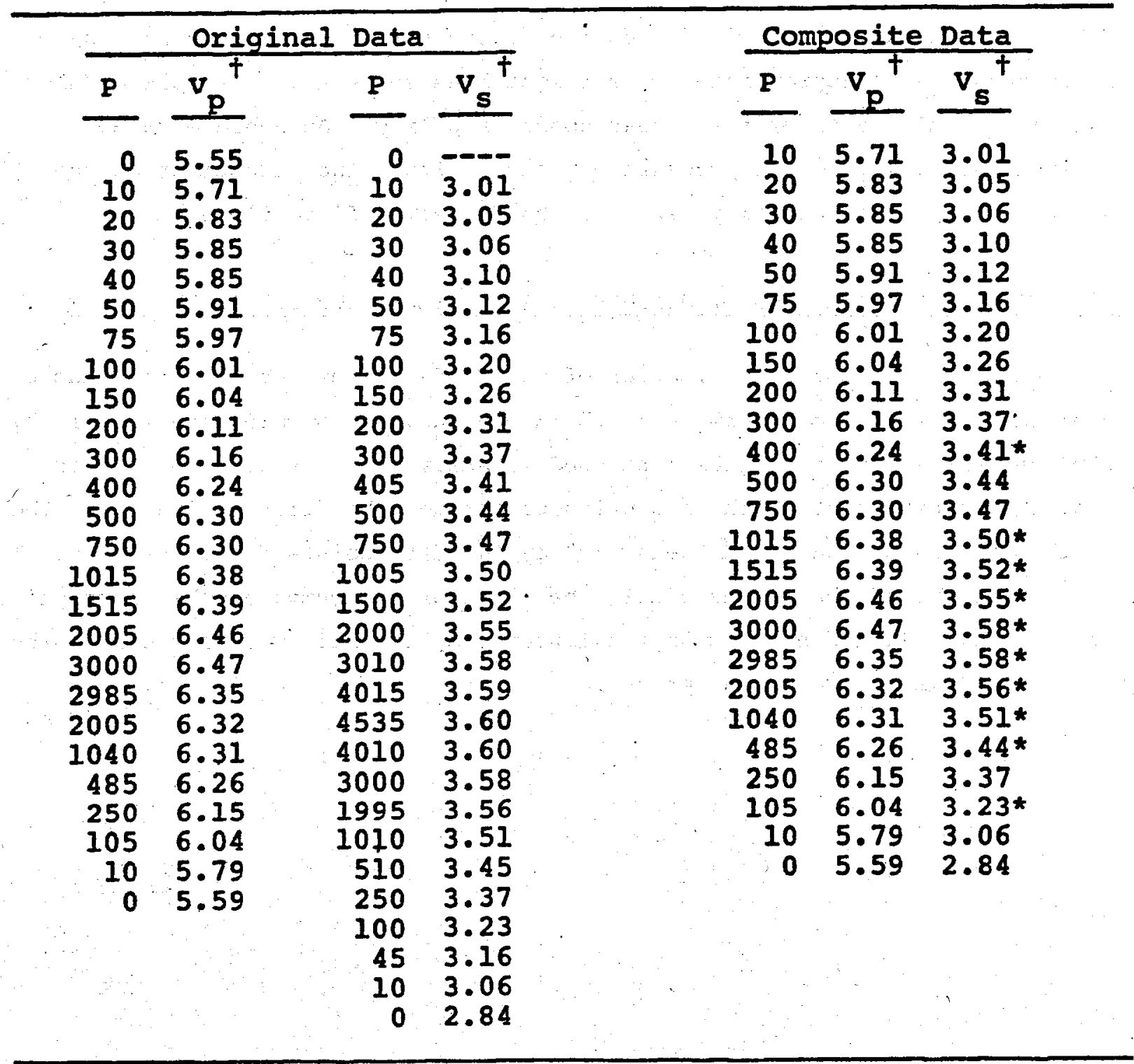

tnot corrected for strain

*interpolated values 
APPENDIX 2

STATIC BULK MODULUS VS PRESSURE

\section{SET 1: AXIAL GAUGES AND BALANCE BRIDGE MEASUREMENT}

Bulk moduli, $\mathrm{K}$, were derived from the static strain data. The strainpressure curves were approximated by straight line segments. The bulk modulus was simply calculated as $3 x$ the linear compressibility. An average value for $K$ is given over any range in pressure in which, within the resolution of the data, the strain is essentially linear or has a well-defined slope.

SET 2: CIRCUMFERENTIAL GAUGES, MEASURED USING A BLH 1200B STRAIN INDICATOR

Strains were measured to an order of magnitude higher accuracy than those determined in set 1 . To determine the bulk modulus, the strain data was fit by the spline-curve-fitting program mentioned in Analysis. The program we used generates a smooth curve which is continuous through the first derivative. The curve through any one datum is "weighted" by two data points on either side. The first coefficient of the spline-fit is the slope of the curve at the datum point. The bulk modulus listed here is $3 \mathrm{x}$ the linear compressibility obtained from the local slope of the curve at any pressure. 
SET 1

Conway Granite

STATIC MODULI

Sample number Preasure Range (Bb) Compressibility $\left(\mathrm{mb}^{-1}\right)$ Bulk Modulus (mb)

197.2

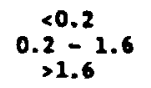

2.8

.28
.35

301.8

data oot rellable

335.0

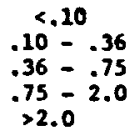

5.60

4.23

2.33

1.63
1.40

381.9

$<.08$

$.08-.25$

$.25=.35$

$.35-.75$

$>2.0$

419.0

$<.05$

$.05-.12$

$50-2.6$

$>2.6$

6.67

4.50

3.23

2.34

1.82

8.0

8.0
4.0

4.0
2.67

2.39

2.18

6.66

448.1

$<508$

$.08-.18$

$.40-1.5$

$>1.5$

4.00

2.58

2.22

2.00

.55

502.3

$<.60$

$.60-2: 5$

3.10

2.82
1.88

.17
.23
.42
.61
.71

515.7

$<0.10$

$$
\begin{aligned}
& .10-.25 \\
& >.25
\end{aligned}
$$

4.75

2.62

1.70

523.3

$<.10$

$.10-.40$

$.60=1.8$

$1.8-2.5$

$>2.5$

\subsection{0}

2.78

2.58

2.16

2.10

337.4

$<0.12$

$.12-.25$

$.25-.50$

$.30-2.0$

610.2

$$
4.40
$$

$.40-.80$

$>2.0=2.0$

19.70

12.40

8.85

6.70
4.81

3.68

2.98

2.20

1.82

704.4

$$
\begin{aligned}
& <2.0 \\
& .20=.30 \\
& .30=.60 \\
& .60=.75 \\
& .75=3.0 \\
& >3.0
\end{aligned}
$$

5.26

4.86

2.72

2.36

1.67

215,7

data not rellable

771,1

$$
\begin{aligned}
& <0.1 \\
& .10-.25 \\
& .25=.50
\end{aligned}
$$

5.35 
SET 2

Conway Granite

CIRCUMFERENTIAL STATIC MODULI

Sample CG 335.0

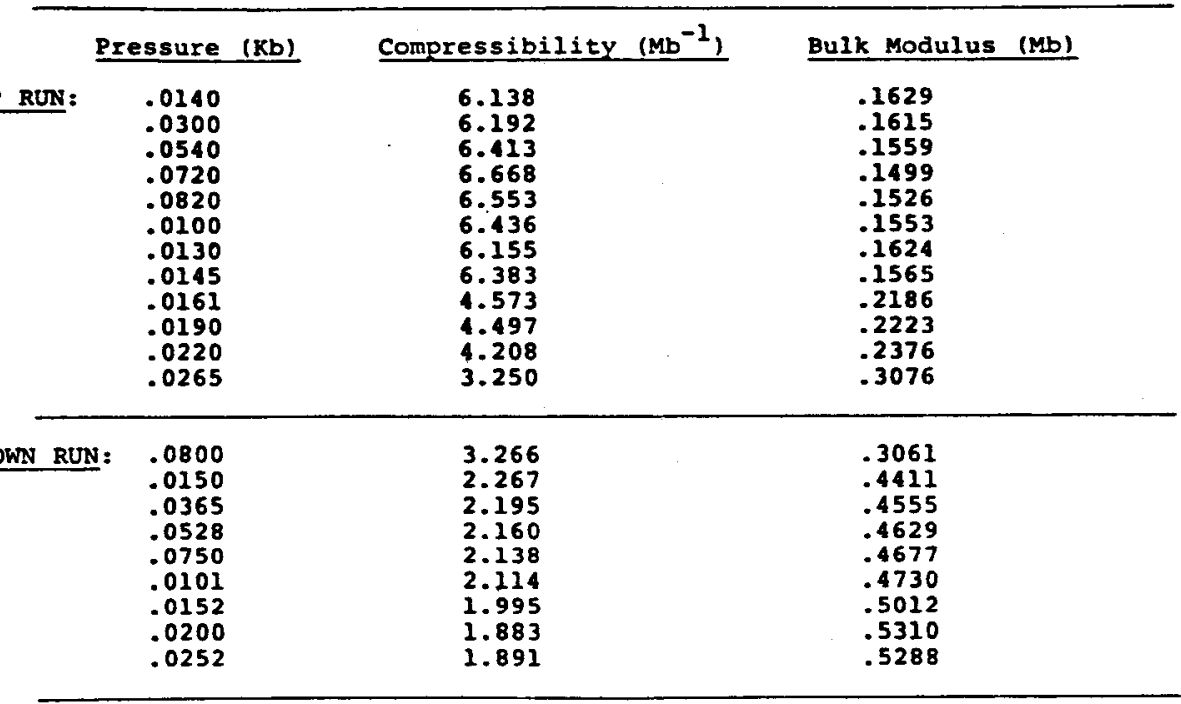

Sample CG 381.0

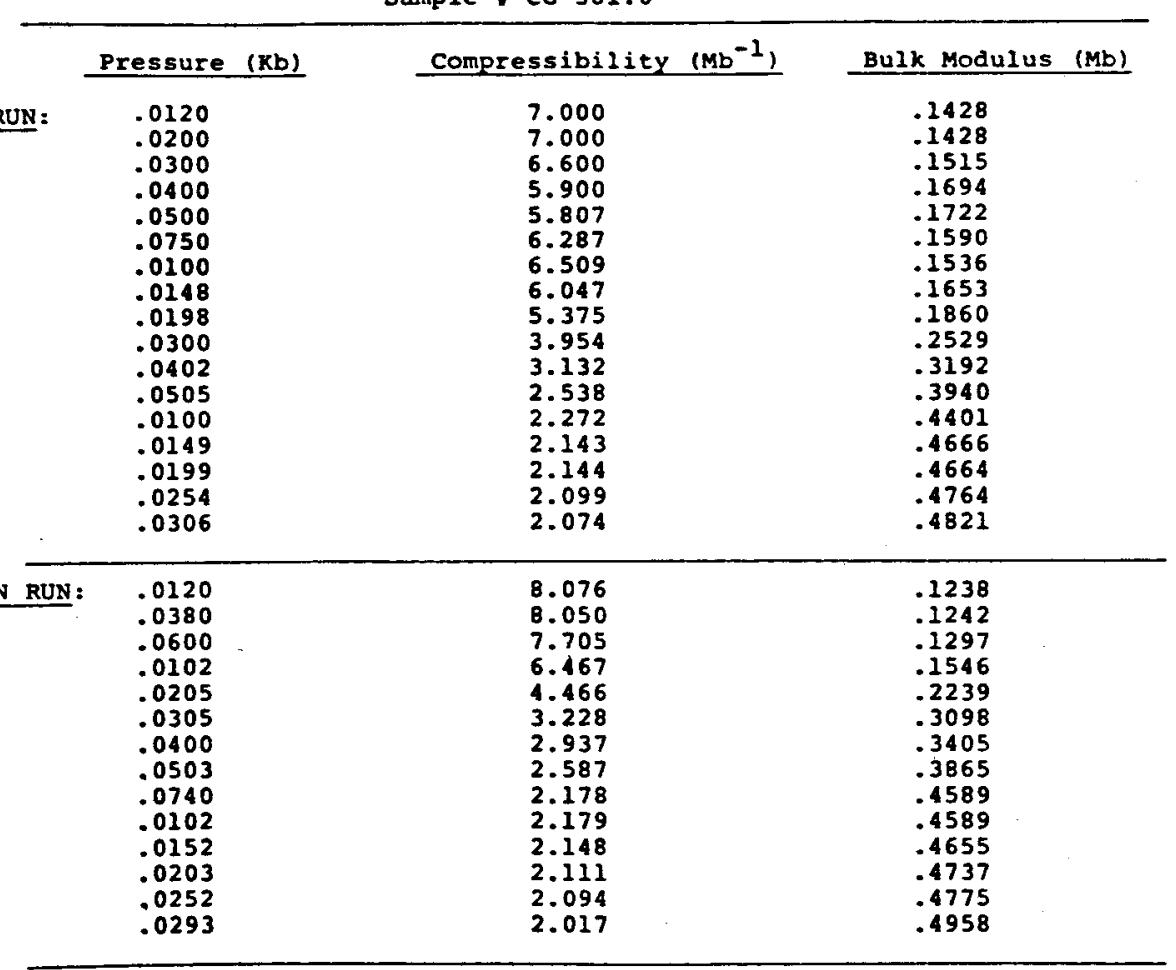


Sample CG 448.1

\begin{tabular}{|c|c|c|c|}
\hline & Pressure (Xb) & Compressibility $\left(\mathrm{Mb}^{-1}\right)$ & Bulk Modulus (Mb) \\
\hline UP RUN: & $\begin{array}{l}.0100 \\
.0200 \\
.0300 \\
.0400 \\
.0500 \\
.0750 \\
.0100 \\
.0145 \\
.0200 \\
.0298 \\
.1020 \\
.0500 \\
.0750 \\
.0100 \\
.0111 \\
.0130 \\
.0150 \\
.0160 \\
.0175\end{array}$ & $\begin{array}{l}3.380 \\
4.387 \\
4.200 \\
4.383 \\
4.500 \\
3.927 \\
3.921 \\
3.185 \\
3.096 \\
2.126 \\
2.183 \\
1.886 \\
1.883 \\
1.757 \\
1.752 \\
1.752 \\
1.712 \\
1.721 \\
1.722\end{array}$ & $\begin{array}{l}.2958 \\
.2279 \\
.2381 \\
.2281 \\
.2222 \\
.2546 \\
.3106 \\
.3140 \\
.3230 \\
.4122 \\
.1581 \\
.5302 \\
.5311 \\
.5691 \\
.5701 \\
.5707 \\
.5814 \\
.5811 \\
.5807\end{array}$ \\
\hline
\end{tabular}

Sample CG 610.2

\begin{tabular}{|c|c|c|c|c|}
\hline \multicolumn{2}{|r|}{ Pressure (RD) } & \multicolumn{2}{|c|}{ Compressibility $\left(\mathrm{mb}^{-1}\right)$} & Bulk Modulus (Mb) \\
\hline UP RUN: & $\begin{array}{l}.0100 \\
.0200 \\
.0300 \\
.0400 \\
.0500 \\
.0750 \\
.0100 \\
.0145 \\
.0200 \\
.0295 \\
.0398 \\
.0500 \\
.0735 \\
.0100 \\
.0148 \\
.0199 \\
.0298\end{array}$ & $\begin{array}{l}3.171 \\
3.000 \\
3.000 \\
3.000 \\
3.000 \\
2.954 \\
2.904 \\
3.019 \\
3.149 \\
3.273 \\
3.348 \\
3.370 \\
3.118 \\
3.138 \\
3.352 \\
2.911 \\
2.911\end{array}$ & 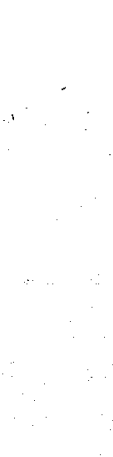 & $\begin{array}{l}.3153 \\
.3333 \\
.3333 \\
.3333 \\
.3333 \\
.3385 \\
.3443 \\
.3312 \\
.3175 \\
.3055 \\
.2986 \\
.2967 \\
.2925 \\
.2908 \\
.2983 \\
.3435 \\
.3435\end{array}$ \\
\hline 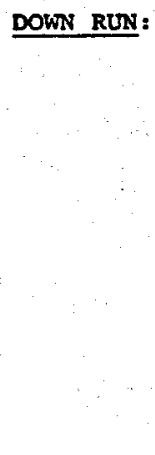 & $\begin{array}{l}.0100 \\
.0200 \\
.0300 \\
.0400 \\
.0500 \\
.0750 \\
.0100 \\
.0145 \\
.0200 \\
.0295 \\
.0398 \\
.0500 \\
.0735 \\
.0100 \\
.0148 \\
.0199 \\
.0298\end{array}$ & $\begin{array}{l}3.171 \\
3.000 \\
3.000 \\
3.000 \\
3.000 \\
2.954 \\
2.904 \\
3.019 \\
3.149 \\
3.273 \\
3.348 \\
3.370 \\
3.418 \\
3.438 \\
3.352 \\
2.911 \\
2.911\end{array}$ & & $\begin{array}{l}.3153 \\
.3333 \\
.3333 \\
.3333 \\
.3333 \\
.3385 \\
.3443 \\
.3312 \\
.3175 \\
.3055 \\
.2986 \\
.2967 \\
.2925 \\
.2908 \\
.2983 \\
.3435 \\
.3435\end{array}$ \\
\hline
\end{tabular}




\section{APPENDIX 3}

UYNAMIC MODULI VS PRESSURE

$V_{p}=$ compressional wave velocity $(k i \pi / \mathrm{sec})$

$v_{s}=$ sheär wave velucily $(\mathrm{km} / \mathrm{sec})$

R/10 $=$ density $\left(\mathrm{gm} / \mathrm{cm}^{\hat{3}}\right)=\rho$

Modulus (units in kilobar) $=10 \times$ R'io $\times$ velocily squared

$G=$ shear modulus $=V_{s}^{2} \rho$

$K=$ Bulk modulus $=v_{s}^{2} \rho-\frac{4}{3} v_{s}^{2} \rho$

Poissón rātio $=\frac{1}{2} \frac{\left(v_{p} / v_{s}\right)^{2}-2}{\left(v_{p} / v_{s}\right)^{2}-1}=v$

$E=$ Young's müduius $=3(1-2 v) K$

$B=$ compressibility $=(\text { Bu } k \text { modulus })^{-1}$

sigma $(B)=$ estimated uncertainties in $B$ 


\section{CONWAY GRANITE $\quad$ CG -197.2}

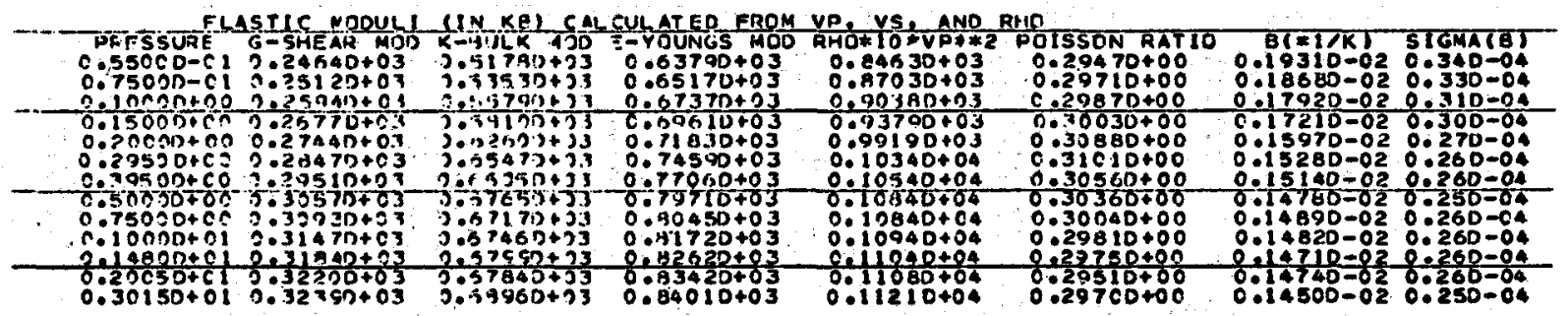

CONWAY GRANITE $\quad$ CG -301.8

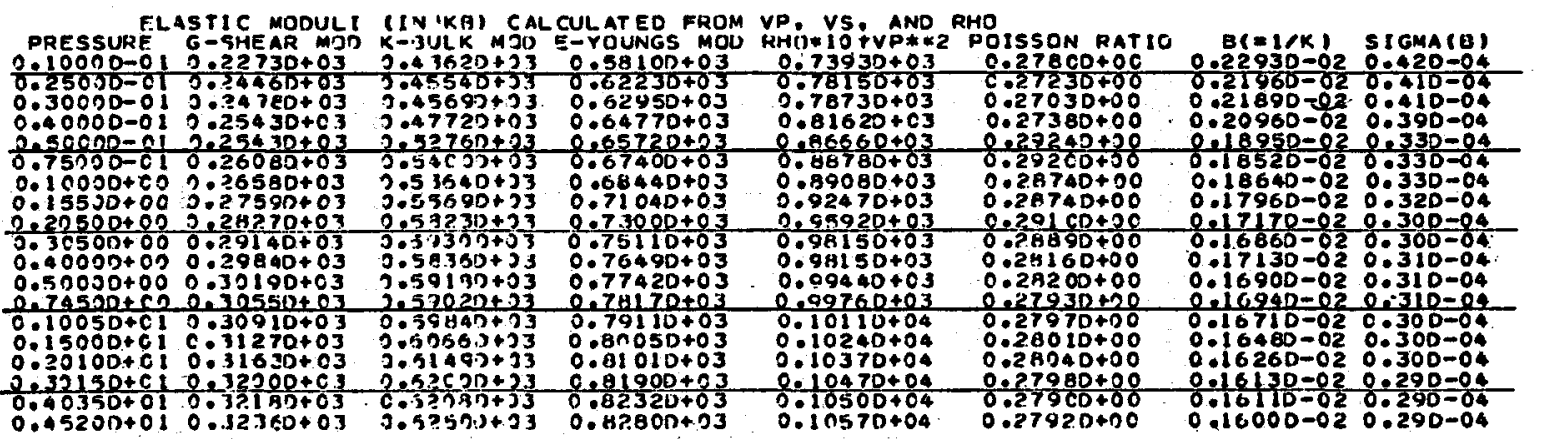

CONWAY GRANITE $\quad C G=335.0$

ELASTIC MOOULI (IN KB) CALCULATEO FROM VP, VS, AND RHO

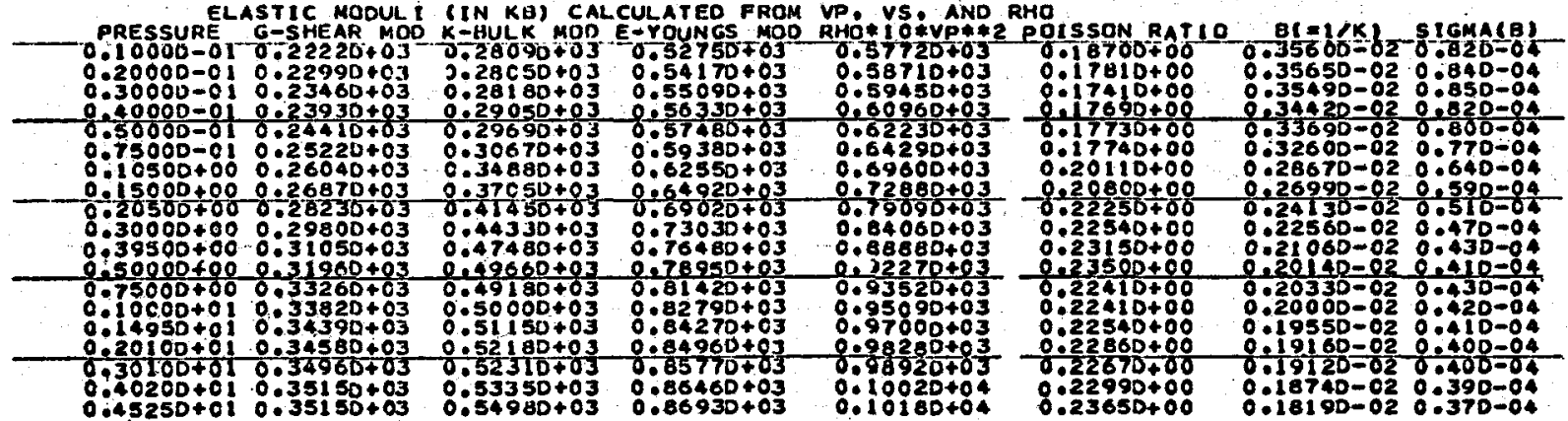


CONWAY GRANITE CG -381.9

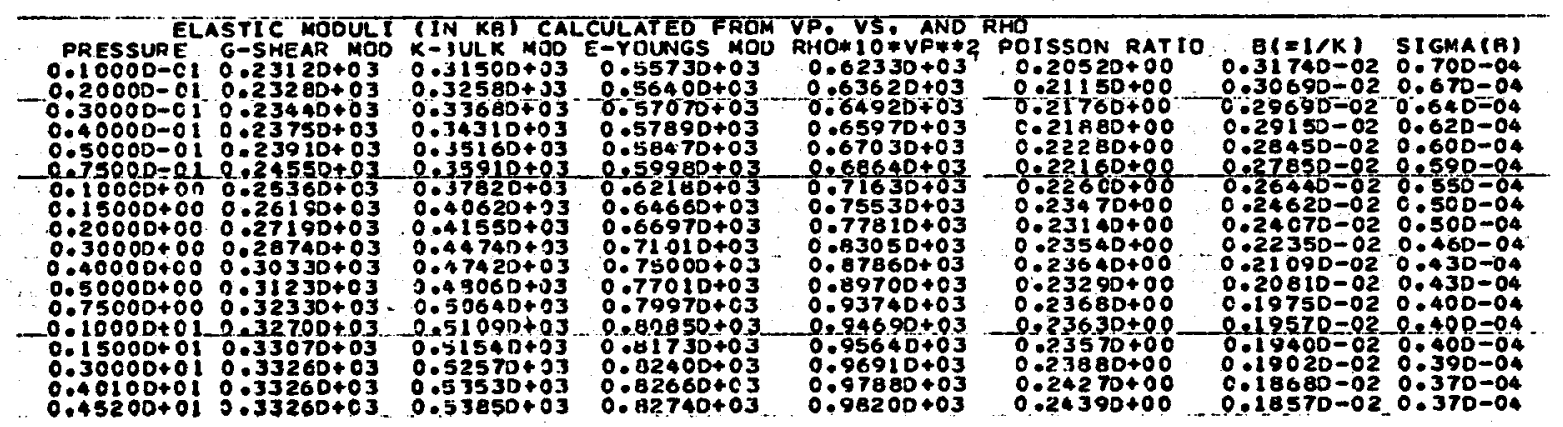

CUNWAY GRANITE C C -419.0

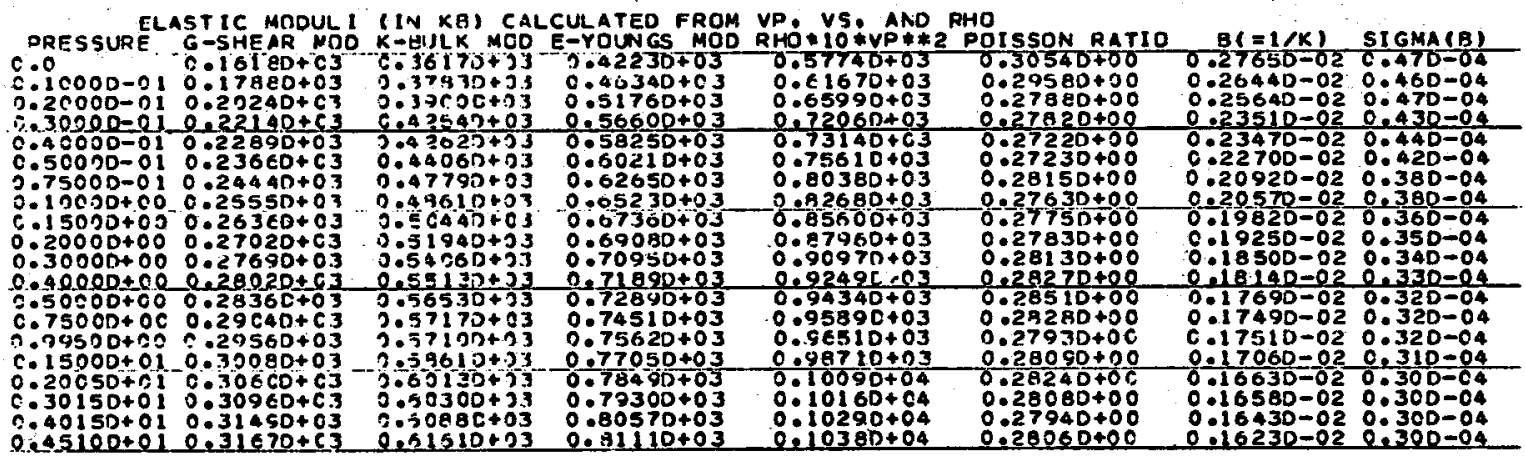

CONWAY GRANITE CG -448.1

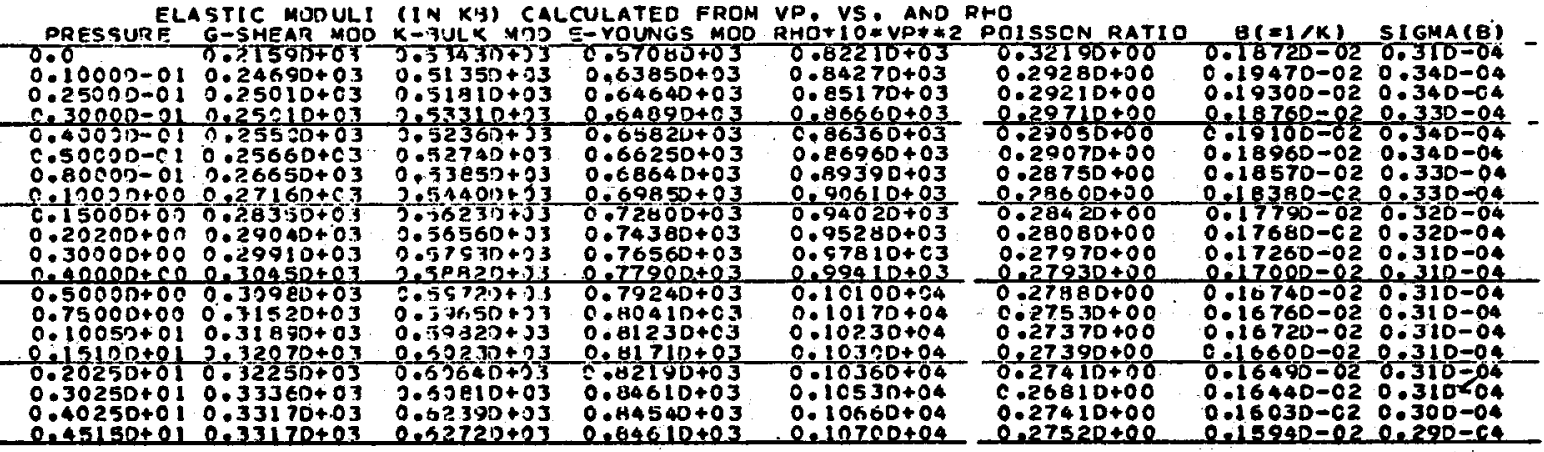


CONHAY GRANITE CG -502.3

\begin{tabular}{|c|c|c|c|}
\hline 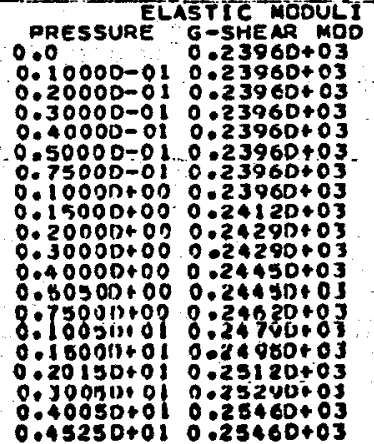 & 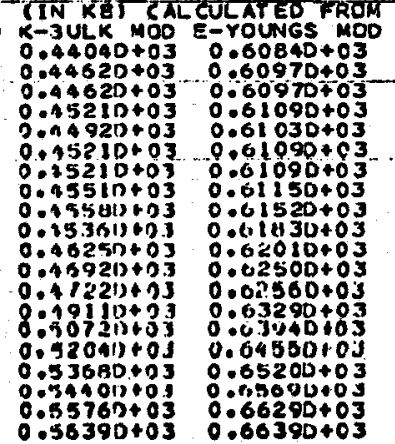 & 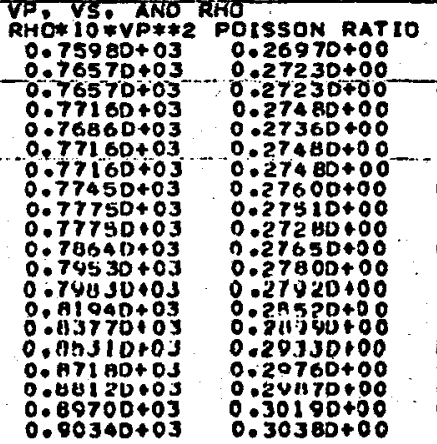 & 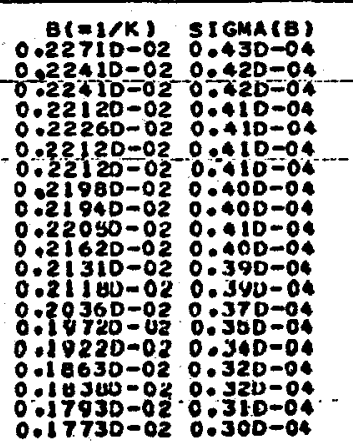 \\
\hline
\end{tabular}

CONHAY GRANITE $\quad C G-515.7$

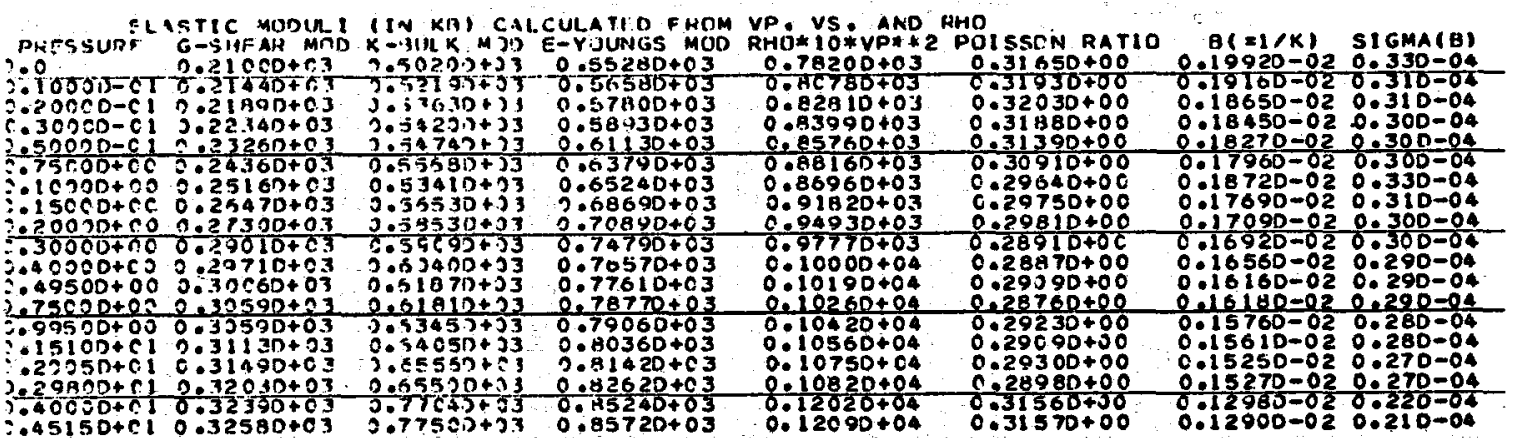

CONWAY GRANITE CG -523.3

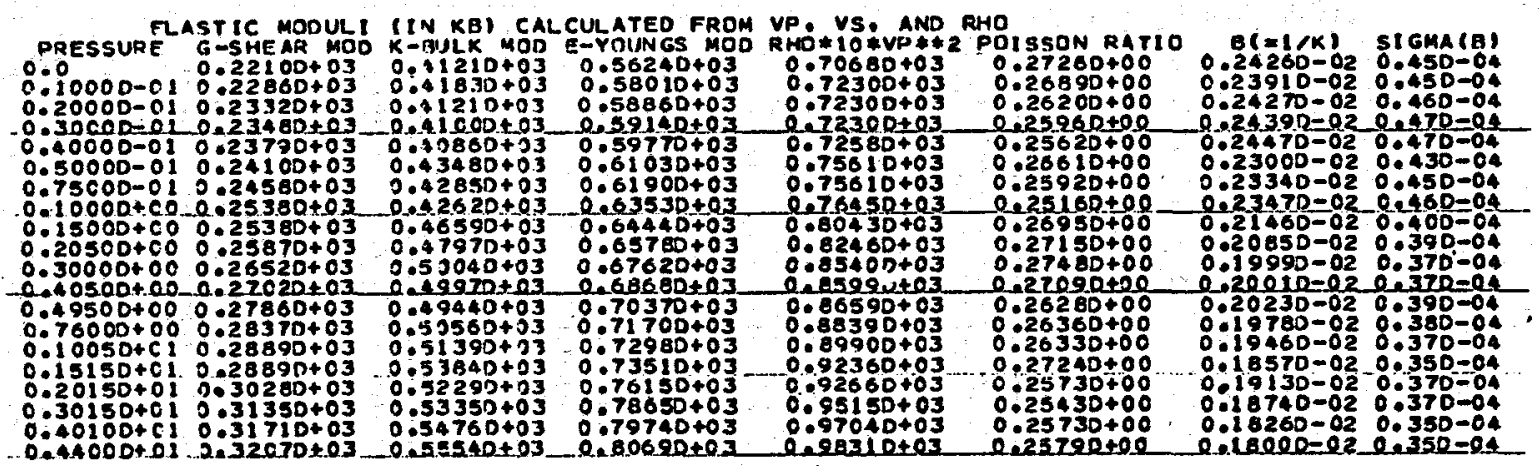


CONWAY GRANITE $\quad$ CG -537.4

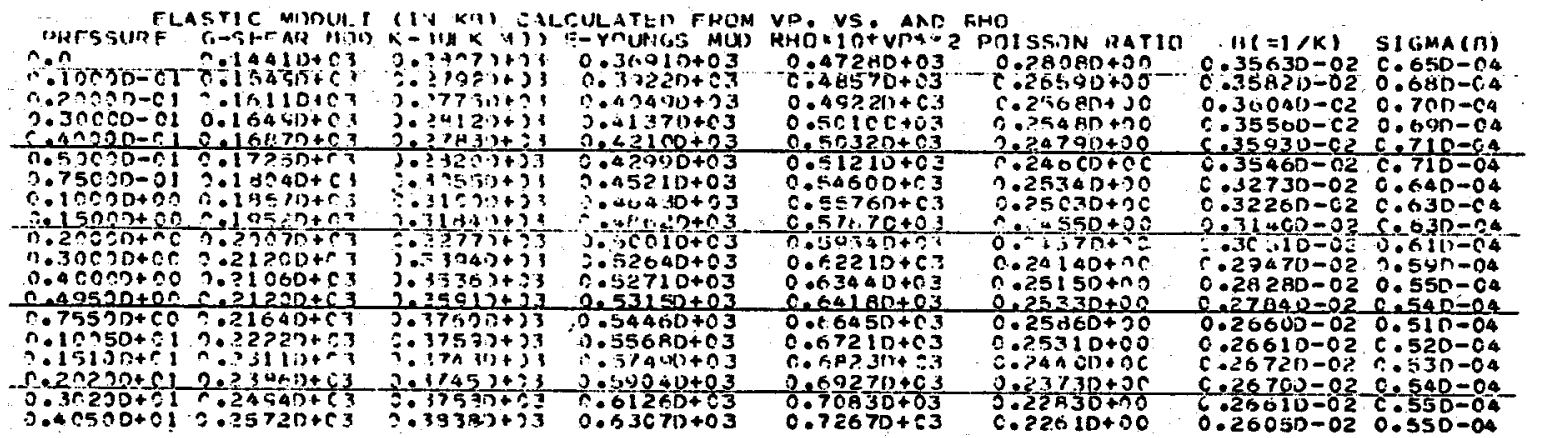

CONWAY GRANITE CG -610.2

ELASTIC MODULI (IN KB) CALCULATED FROM VP, VS, AND RHO

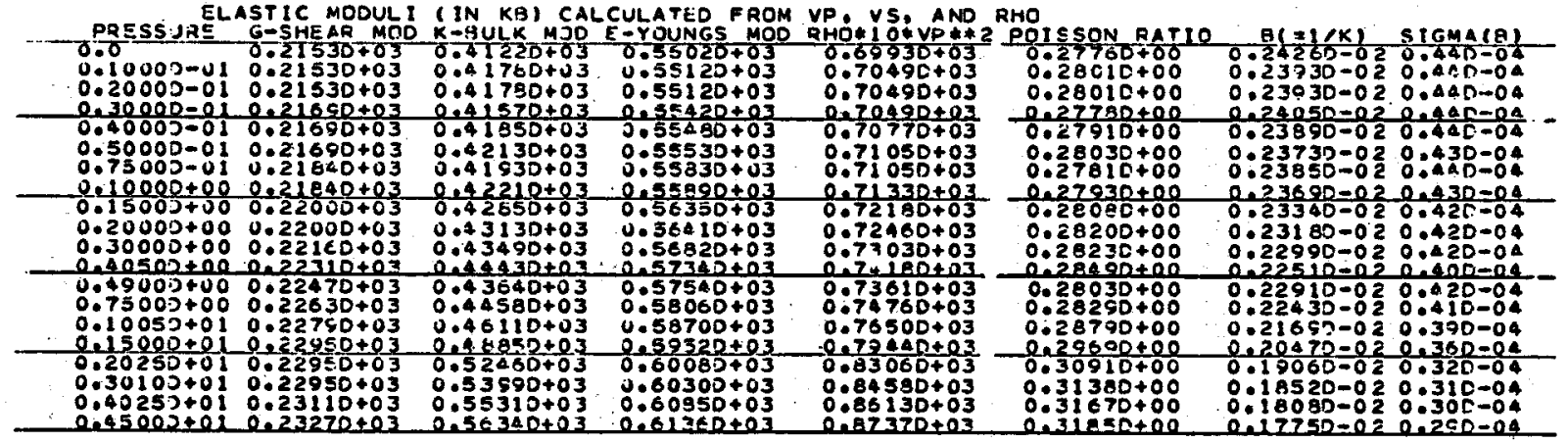

CONWAY GRANITE $\quad$ CG -704.4

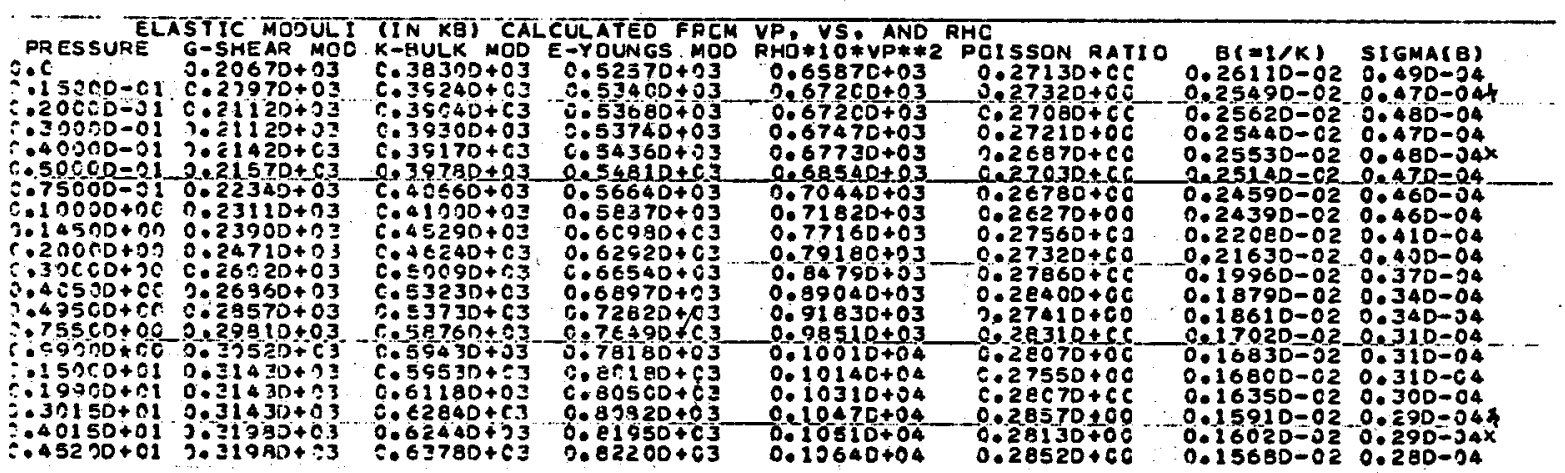

50 . 
CONWAY GRANITE $\quad$ CG -715.7

\begin{tabular}{|c|c|c|c|c|c|c|}
\hline 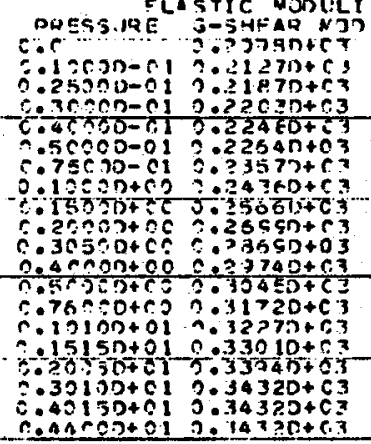 & 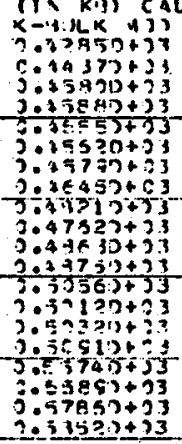 & 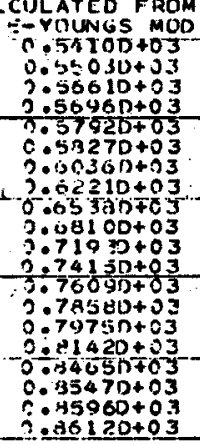 & 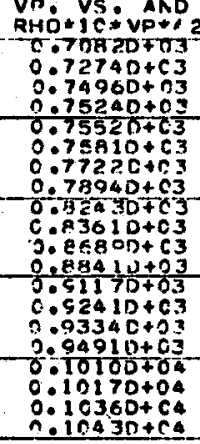 & 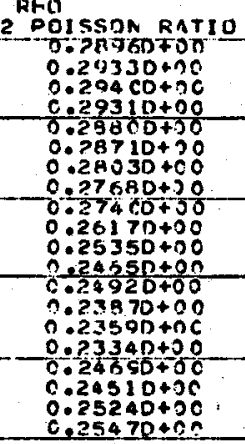 & 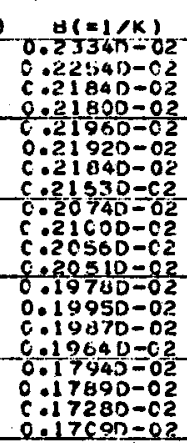 & $\begin{array}{l}83 \\
04 \\
04 \\
04\end{array}$ \\
\hline
\end{tabular}

\section{CONWAY GRANITE $\quad$ CG -771.1}

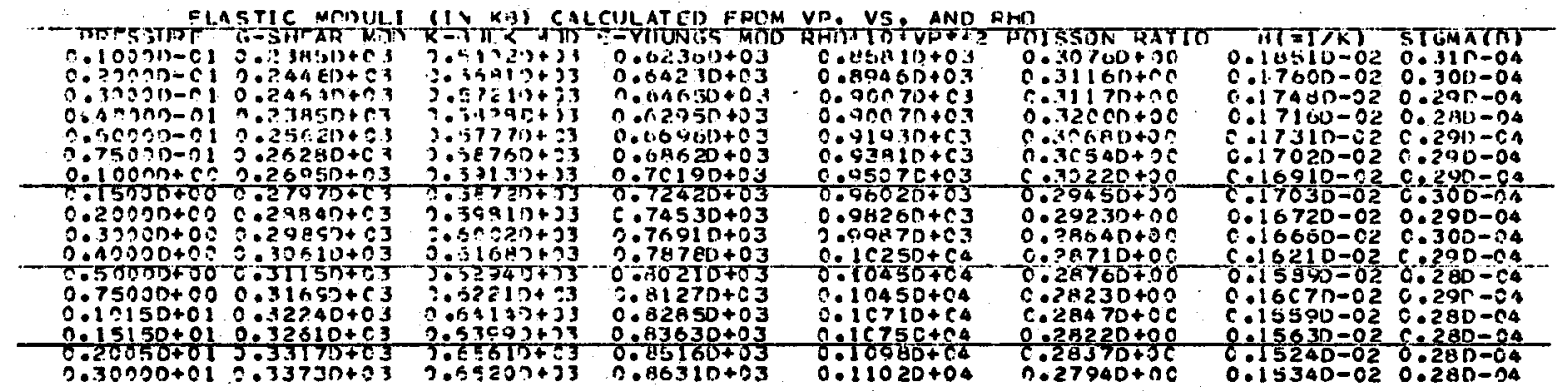

